\title{
QUANTIFICATION OF TRACE METALS IN DECIDUOUS TOOTH ENAMEL USING ENERGY DISPERSIVE X-RAY FLUORESCENCE SPECTROMETRY
}

by

\section{BRIAN KIRKHAM}

A thesis presented to Ryerson University

in partial fulfillment of

the requirements for the degree

\section{MASTER OF SCIENCE}

in the program of

Biomedical Physics

Toronto, Ontario, Canada, 2013

(C) Brian Kirkham 



\section{Author's Declaration}

I hereby declare that 1 am the sole author of this thesis. This is a true copy of the thesis, including any required final revisions, as accepted by my examiners.

I authorize Ryerson University to lend this thesis to other institutions or individuals for the purpose of scholarly research.

I further authorize Ryerson University to reproduce this thesis by photocopying or by other means, in total or in part, at the request of other institutions or individuals for the purpose of scholarly research.

I understand that my thesis may be made electronically available to the public. 



\title{
QUANTIFICATION OF TRACE METALS IN DECIDUOUS TOOTH ENAMEL USING ENERGY DISPERSIVE X-RAY FLUORESCENCE SPECTROMETRY
}

\author{
Brian Kirkham \\ Master of Science \\ Biomedical Physics
}

2013

\begin{abstract}
A non-destructive, multi-elemental analytical method using energy dispersive x-ray fluorescence (EDXRF) spectrometry was developed for the quantification of enamel-manganese (MnE) for comparison to dietary and tap water intakes of Mn, as well as children's height, Weschler Abbreviated Scale of Intelligence Quotient (IQ) test scores and Santa Ana (SA) dexterity test scores. Using the novel analytical method, enamel-iron $(\mathrm{FeE})$, copper $(\mathrm{CuE})$, zinc $(\mathrm{ZnE})$ and lead $(\mathrm{PbE})$ were also quantified and correlated to one another and to children's height, IQ test scores and SA dexterity test scores.

Significant positive correlations were observed between all essential trace elements in surface enamel (Mn, $\mathrm{Fe}, \mathrm{Cu}, \mathrm{Zn}) . \mathrm{MnE}$ was found to have a weak correlation with estimated dietary intake of $\mathrm{Mn}(\mathrm{p}<$ 0.01). No significant correlations were found between oral ingestion of Fe and FeE. Metals concentrations were observed to be highest in incisor enamel for all elements except zinc.
\end{abstract}





\section{Acknowledgements}

I am indebted to Dr. Ana Pejović-Milić for many things. First and foremost, thank you for accepting me first as a research assistant and later as a student. My academic transcript was rather unbecoming of an aspiring graduate student (or any student) but you trusted me and I have benefited tremendously from that. I am also grateful for the funding that enabled me to travel to Madison and Vienna. Both experiences opened my eyes to industrial and academic applications of our field and gave me confidence in the validity and usefulness of my work. I have been happiest as a student for being given the freedom to study and research those areas that I have found most interesting without strict deadlines or undue pressure to publish. I admire your belief in academic freedom despite the strong external pressure against it. Finally, thank you for teaching me about physics, both as a professor and as a thesis supervisor.

Dr. Maryse Bouchard, thank you for being a member of my graduate committee. This work would not have been possible without your valuable contribution of children's teeth and exceptional work on lowlevel manganese exposure. This experience has been unique for me and I am fortunate to have worked in such an interesting field.

Dr. Emily Heath, thank you for being a member of my graduate committee. I admire your work very much and I have valued your input and advice on all matters related to my research and course work. I am also grateful to have taken your Radiation Physics and Radiation Therapy courses.

Dr. Marcus Escobar, thank you for being a member of my graduate committee. I learned a lot from our many meetings, emails, conversations, and above all from your lectures. Knowledge of statistics may be the most useful and broadly applicable knowledge that I have gained over the last two years and I appreciate your patience in teaching me about it.

Eric Da Silva, thank you for your guidance, humor, knowledge, patience and friendship. It has been abundantly helpful to have someone to talk to about the technical points of my research while enjoying an ice cold beer. I am hopeful that there will be plenty more of both in the future.

Raphael Jakubovic, thank you for your help with courses and your good humor.

To my examination committee, thank you for taking time during the busy weeks of late August/early September to review this work.

To my family and friends, thank you for everything. 



\section{Table of Contents}

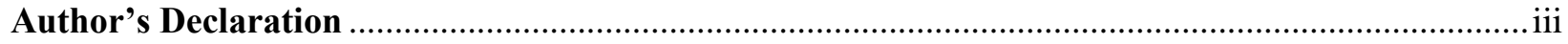

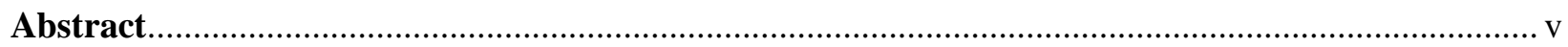

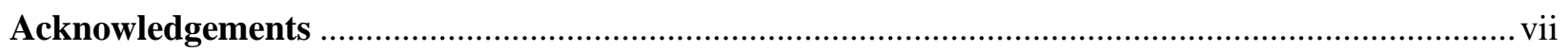

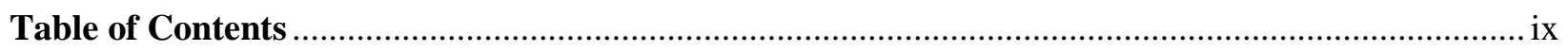

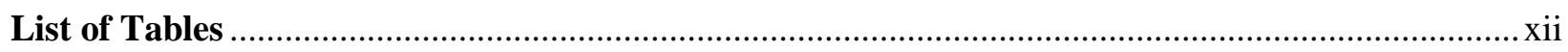

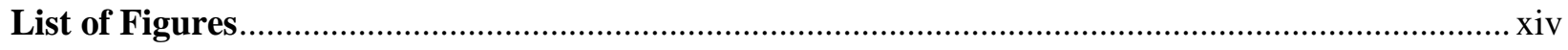

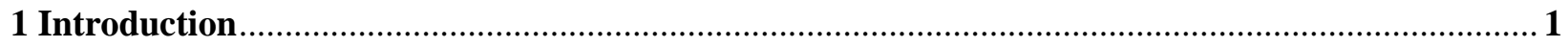

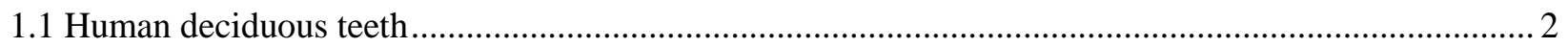

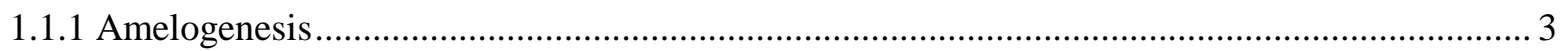

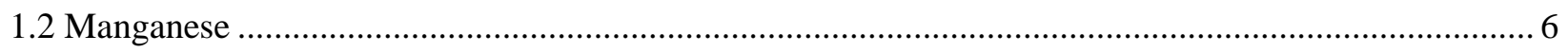

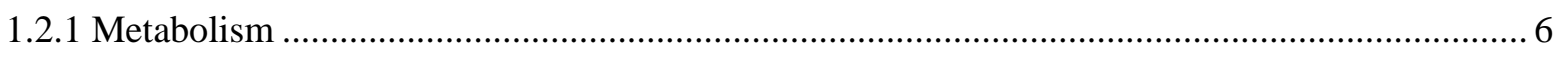

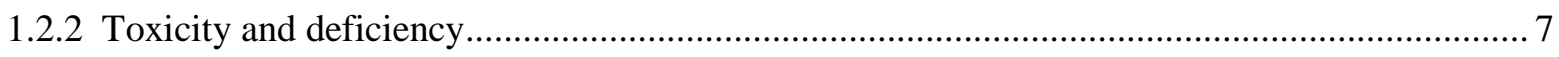

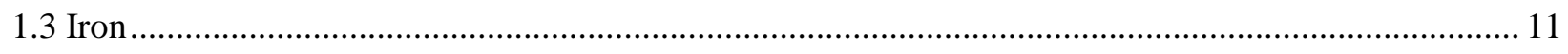

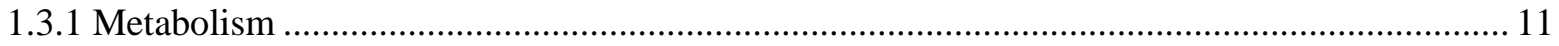

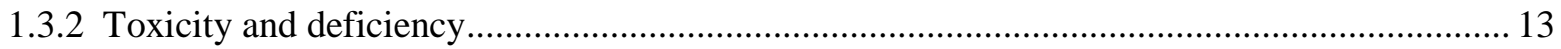

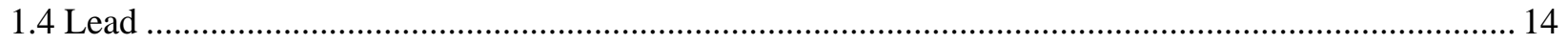

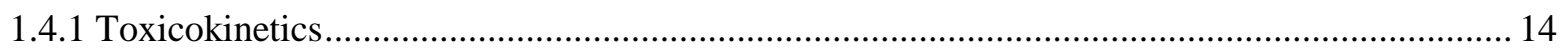

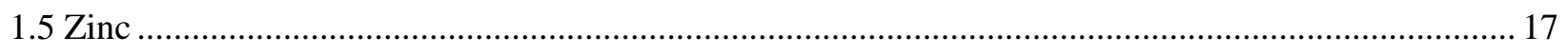

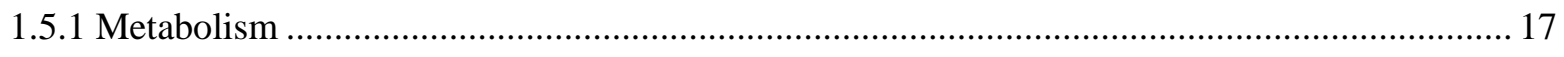

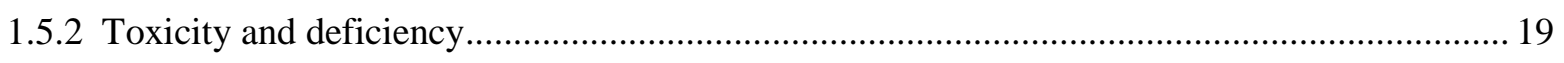

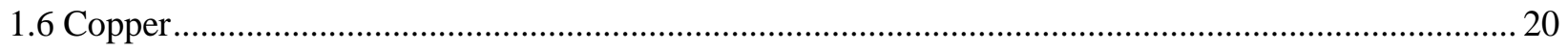

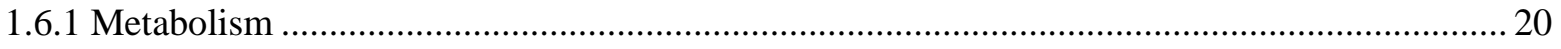

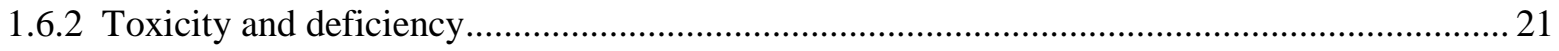

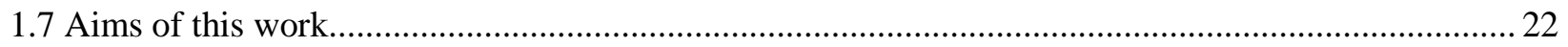

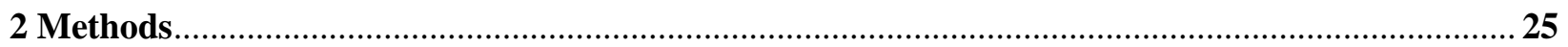

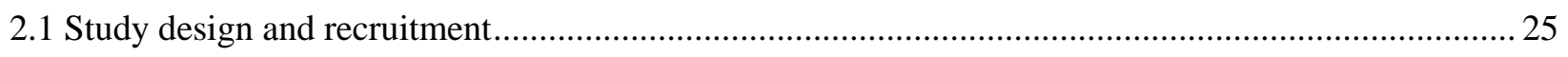

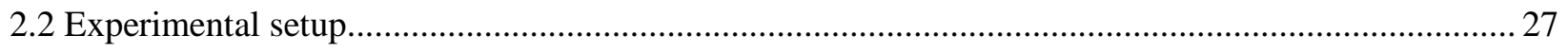

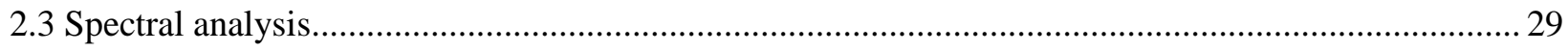




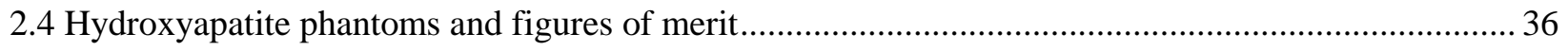

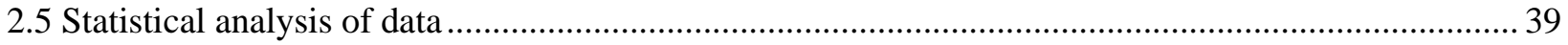

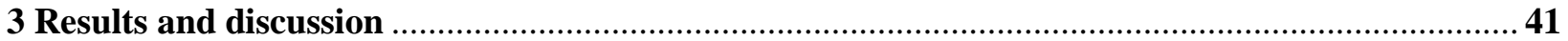

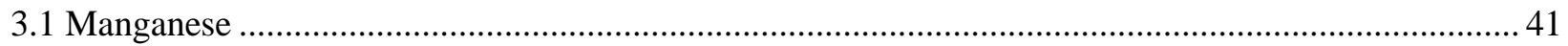

3.1.1 Relationships between manganese in enamel and exposure pathways ................................ 43

3.1.2 Relationships between manganese and children's height .................................................. 50

3.1.3 Relationships between manganese in enamel and neurological test scores .............................53

3.1.4 Relationships between manganese and other metals in enamel .............................................. 58

3.2 Iron

3.2.1 Relationships between iron in enamel and exposure pathways ............................................6 63

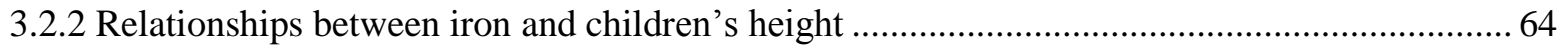

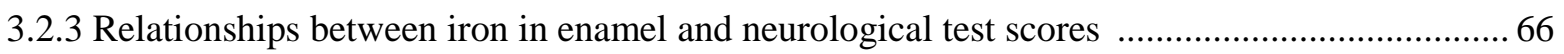

3.2.4 Relationships between iron and other metals in enamel ....................................................... 71

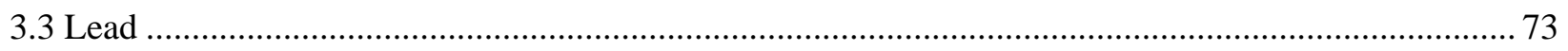

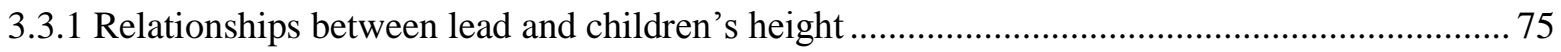

3.3.2 Relationships between lead in enamel and neurological test scores ....................................... 76

3.3.3 Relationships between lead and other metals in enamel ....................................................... 77

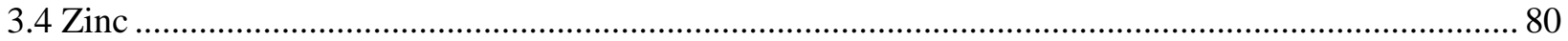

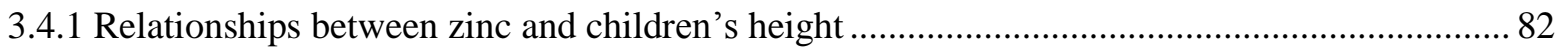

3.4.2 Relationships between zinc in enamel and neurological test scores ...................................... 83

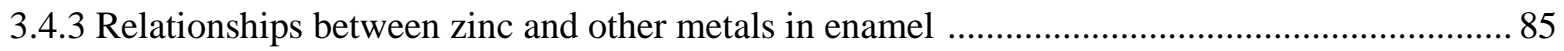

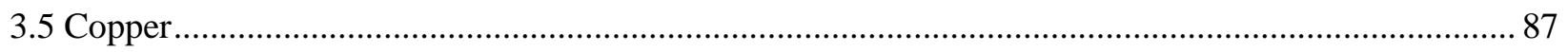

3.5.1 Relationships between copper and children's height …................................................... 89

3.5.2 Relationships between copper in enamel and neurological test scores .................................. 90

3.5.3 Relationships between copper and other metals in enamel ................................................. 92

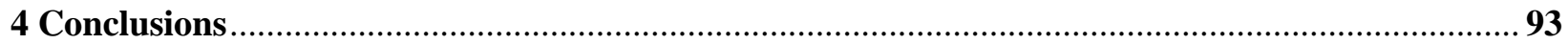

5 Future work

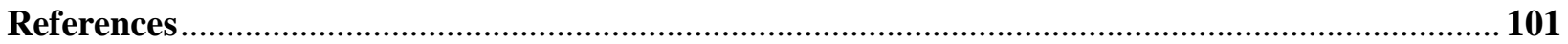




\section{List of tables}

\section{Introduction}

1.1 Timeline of enamel formation 3

\section{Methods}

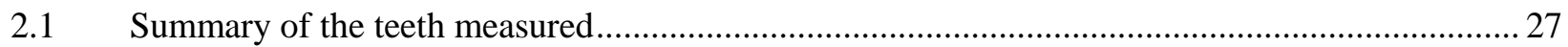

2.2 Critical thickness of XRF measurements in tooth enamel .......................................................... 29

2.3 Figures of merit for the EDXRF measurement of divalent metals in tooth enamel...................... 36

\section{Results and discussion}

\section{Manganese}

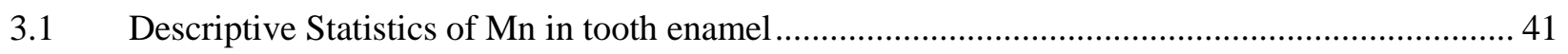

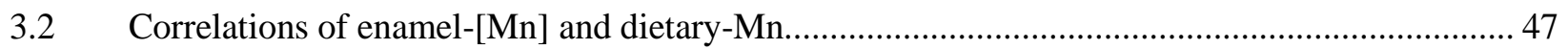

3.3 Correlations of enamel-[Mn] and tap water intake of $\mathrm{Mn}$..................................................... 29

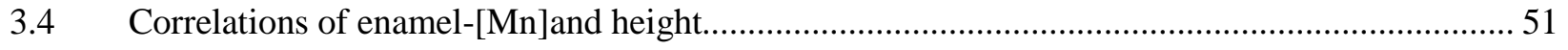

3.5 Correlations of enamel-[Mn] and full WASI IQ test scores ...................................................... 53

3.6 Correlations of enamel-[Mn] and Santa Ana dominant hand scores ........................................ 54

3.7 Correlations of enamel-[Mn] and Santa Ana non-dominant hand scores .................................... 56

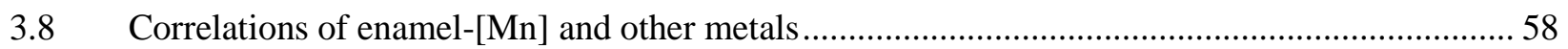

Iron

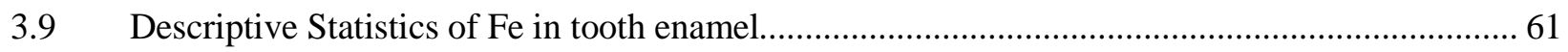

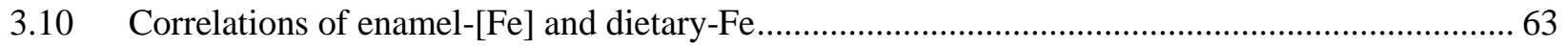

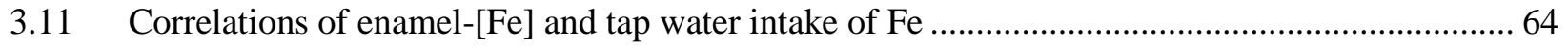

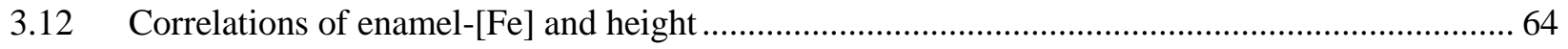

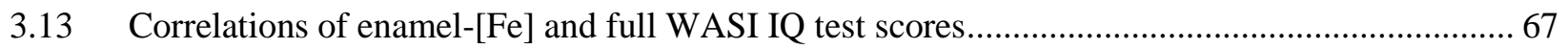

3.14 Correlations of enamel-[Fe] and Santa Ana dominant hand scores ............................................ 67

3.15 Correlations of enamel-[Fe] and Santa Ana non-dominant hand scores................................... 69

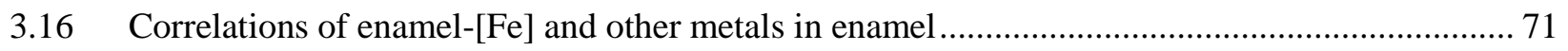




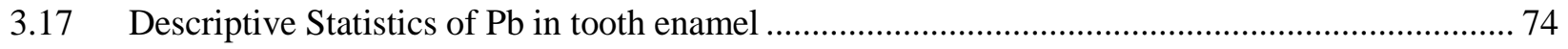

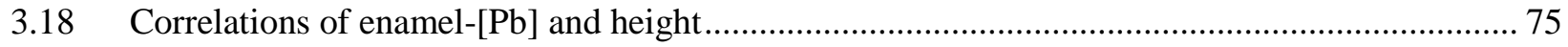

3.19 Correlations of enamel-[Pb] and full WASI IQ test scores..................................................... 76

3.20 Correlations of enamel-[Pb] and Santa Ana dominant hand scores.......................................... 76

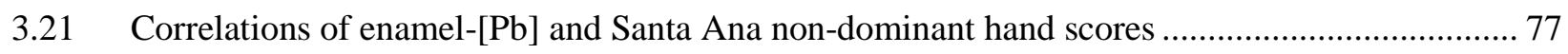

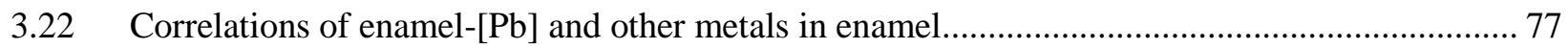

Zinc

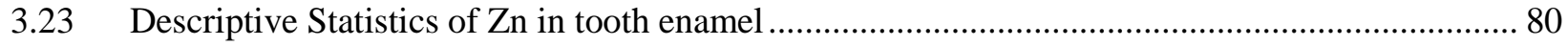

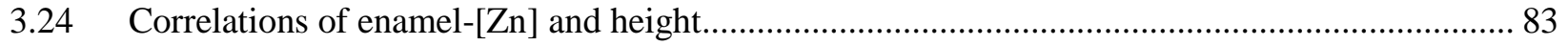

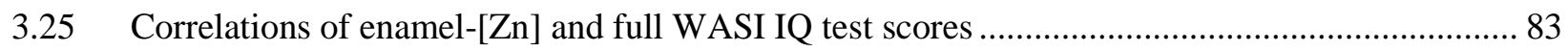

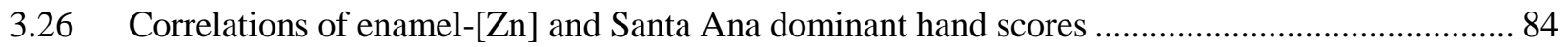

3.27 Correlations of enamel-[Zn] and Santa Ana non-dominant hand scores ..................................... 84

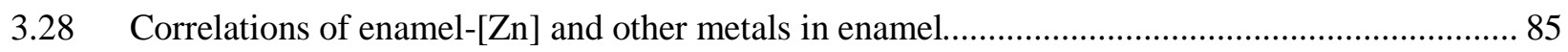

\section{Copper}

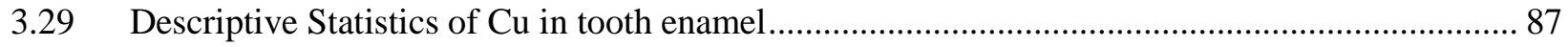

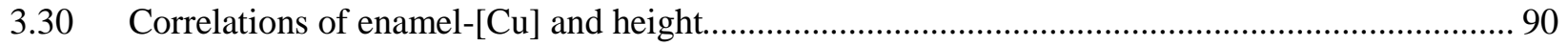

3.31 Correlations of enamel-[Cu] and full WASI IQ test scores ..................................................... 91

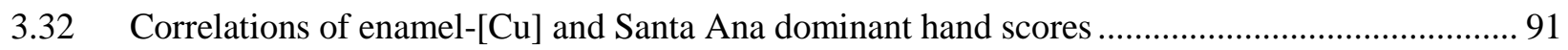

3.33 Correlations of enamel-[Cu] and Santa Ana non-dominant hand scores .................................... 92

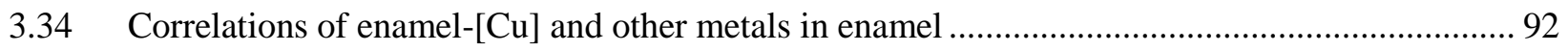

\section{Conclusions}

4.1 Figures of merit and quantification statistics for the EDXRF measurement of divalent metals in tooth enamel 


\section{List of figures}

\section{Introduction}

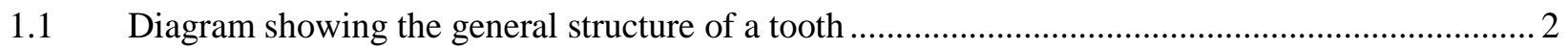

1.2 Ionic substitutional energies by divalent cations for $\mathrm{Ca}-1$ in HAp as a function of $\mathrm{pH}$ measurements

\section{Methods}

2.1 Experimental setup used for the quantification of trace metals in deciduous dental enamel 28

2.2 a) The complete energy spectrum of a tooth sample analyzed in this work with peaks labeled. Phosphorus-K $\alpha$ and calcium- K $\alpha$ escape peaks overlap at $2 \mathrm{keV}$. b) A cutout of the region between 4.5 and $11.5 \mathrm{keV}$ showing transition metals photopeaks and artifacts is shown. Bragg peaks are at 6.3 and $9.4 \mathrm{keV}$. Escape peaks of $\mathrm{Cu}$ and $\mathrm{Zn}$ are centered at 6.3 and $6.9 \mathrm{keV}$, respectively. Photopeak energies were taken from the National Institute for Standards and Technology (NIST) X-ray Transition Energies Database (150). The background was modeled as constant between 5-7 keV ( $\mathrm{Mn}$ and $\mathrm{Fe}$ ). $\mathrm{Cu}$ and $\mathrm{Zn}$ were fit separately with a background that was linear between 7.5 and $9 \mathrm{keV}$. $\mathrm{Pb}$ was fit separately with a linear background between 10.2 and $10.8 \mathrm{keV}$ for $\mathrm{L} \alpha$, and 12.2 and 12.8 for $L \beta$

2.3 A 2-dimensional error surface for over-lapping $\mathrm{Mn}$ and $\mathrm{Cr}$ peaks. For visual representation of the convexity of the error surface, all parameters other than $\mathrm{Mn}$ and $\mathrm{Cr}$ peak heights were fixed.

2.4 Plots showing unconstrained optimization of over-lapping gaussian peaks. The upper plot shows the deterministic model of $\mathrm{Mn}-\mathrm{K} \alpha$ (red) and $\mathrm{Cr}-\mathrm{K} \beta$ (blue) peaks. The $\mathrm{Cr}-\mathrm{K} \alpha$ peak cannot be seen due to overlap by the overall fit line. The lower plot shows the results of fitting five plots with different stochastic noise.

2.5 Plots showing the results of constrained optimization of over-lapping gaussian peaks. The bottom plot shows the results of the fitting of five data sets with stochastic noise. The reduction of fluctuations in parameter estimates is clearly visible and the accuracy of the fits compared to the model in the upper plot of figure 2.3 can be seen also. 


\section{Results and discussion}

\section{Manganese}

3.1 Histogram showing the distribution of manganese concentrations of all teeth measured in this study

3.2 Boxplot showing the concentration of manganese for incisors, canines and molars. A Kruskal-Wallis test showed that at least one group had a median that was significantly different from the population median $(\mathrm{p}<0.001)$. The median value is depicted as a black line in the center of the box. The second and third quartiles are the boxes on either side and the first and fourth quartiles are depicted by the whiskers below and above the boxes. Outliers are shown as points outside of the whiskers.

3.3 A linear regression line showing the relationship between manganese in incisor-[Mn] and dietary-Mn. Confidence intervals at the $95 \%$ level are shown above and below the regression line. Associated statistics are shown in table 3.2.

3.4 A linear regression line showing the relationship between manganese in all teeth-[Mn] and dietary-Mn. Confidence intervals at the $95 \%$ level are shown above and below the regression line. Associated statistics are shown in table 3.2.

3.5 A linear regression line showing the relationship between manganese in average-[Mn] measured tooth enamel of each child and dietary-Mn. Confidence intervals at the 95\% level are shown above and below the regression line. Associated statistics are shown in table 3.2

3.6 A linear regression line showing the relationship between average-[Mn] in all measured tooth enamel from each child and tap water intake of Mn. Confidence intervals at the 95\% level are shown above and below the regression line. Associated statistics are shown in Table 3.3.

3.7 Correlation coefficients of dietary- $\mathrm{Mn}$ and enamel-[Mn] as a function of the duration at current residence. All data points correspond to $\mathrm{p}<0.01$ except for those with marked *. Legend entries r, Rho, and Tau correspond to the Pearson, Spearman and Kendall correlation coefficients, respectively. The number of samples decreases with increasing minimum time spent living at the current residence as children who moved more recently are excluded.

3.8 A linear regression line showing the relationship between manganese in all teeth enamel and the children's height. Confidence intervals at the 95\% level are shown above and below the regression line. Associated statistics are shown in Table 3.4. 
3.9 A linear regression line showing the relationship between average manganese in all measured tooth enamel from the same child and the children's height. Confidence intervals at the $95 \%$ level are shown above and below the regression line. Associated statistics are shown in Table 3.4.

3.10 A linear regression line showing the relationship between average manganese in all measured tooth enamel from the same child and the children's age. Confidence intervals at the $95 \%$ level are shown above and below the regression line.

3.11 A linear regression line showing the relationship between canine-[Mn] and full WASI IQ test scores. Confidence intervals at the 95\% level are shown above and below the regression line. Associated statistics are shown in Table 3.5.

3.12 A linear regression line showing the relationship between all teeth-[Mn] and Santa Ana dominant hand test scores. Confidence intervals at the 95\% level are shown above and below the regression line. Associated statistics are shown in Table 3.6.

3.13 A linear regression line showing the relationship between average-[Mn] in teeth from each child and Santa Ana dominant hand test scores. Confidence intervals at the $95 \%$ level are shown above and below the regression line. Associated statistics are shown in Table 3.6. .56

3.14 A linear regression line showing the relationship between all teeth-[Mn] enamel and Santa Ana non-dominant hand test scores. Confidence intervals at the 95\% level are shown above and below the regression line. Associated statistics are shown in Table 3.7.

3.15 A linear regression line showing the relationship between average-[Mn] from each child and Santa Ana non-dominant hand test scores. Confidence intervals at the 95\% level are shown above and below the regression line. Associated statistics are shown in Table 3.7.

3.16 A linear regression line showing the relationship between manganese and iron in all teeth. Confidence intervals at the $95 \%$ level are shown above and below the regression line. Associated statistics are shown in Table 3.8.

3.17 Histogram showing the distribution of iron concentrations of all teeth measured in this study. Shapiro-Wilk test $(\mathrm{W}=0.92, \mathrm{p}<0.001)$. 
3.18 Boxplot showing the concentration of iron for incisors, canines and molars. A KruskalWallis test showed that at least one group had a median that was significantly different from the population median ( $\mathrm{p}<0.001)$. The median value is depicted as a black line in the center of the box. The second and third quartiles are the boxes on either side and the first and fourth quartiles are depicted by the whiskers below and above the boxes. Outliers are shown as points outside of the whiskers.

3.19 A linear regression line showing the relationship between iron in all teeth enamel and children's height. Confidence intervals at the 95\% level are shown above and below the regression line. Associated statistics are shown in Table 3.12.

3.20 A linear regression line showing the relationship between average-[Fe] in each child's teeth enamel and children's height. Confidence intervals at the $95 \%$ level are shown above and below the regression line. Associated statistics are shown in Table 3.12

3.21 A linear regression line showing the relationship between molar-[Fe] and WASI IQ test scores. Confidence intervals at the 95\% level are shown above and below the regression line. Associated statistics are shown in Table 3.13

3.22 A linear regression line showing the relationship between all teeth-[Fe] and Santa Ana dominant test scores. Confidence intervals at the $95 \%$ level are shown above and below the regression line. Associated statistics are shown in Table 3.14.....

3.23 A linear regression line showing the relationship between average-[Fe] and Santa Ana dominant test scores. Confidence intervals at the 95\% level are shown above and below the regression line. Associated statistics are shown in Table 3.14

3.24 A linear regression line showing the relationship between in all teeth-[Fe] and Santa Ana non-dominant test scores. Confidence intervals at the 95\% level are shown above and below the regression line. Associated statistics are shown in Table 3.15.

3.25 A linear regression line showing the relationship between average-[Fe] and Santa Ana dominant test scores. Confidence intervals at the 95\% level are shown above and below the regression line. Associated statistics are shown in Table 3.15.

3.26 A linear regression line showing the relationship between copper and iron in all teeth. Confidence intervals at the $95 \%$ level are shown above and below the regression line. Associated statistics are shown in Table 3.16. 
3.27 Histogram showing the distribution of lead concentrations of all teeth measured in this study. Shapiro-Wilk test $(\mathrm{W}=0.91, \mathrm{p}<0.001)$.

3.28 Boxplot showing the concentration of lead for incisors, canines and molars. A KruskalWallis test showed that at least one group had a median that was significantly different from the population median $(\mathrm{p}<0.001)$. The median value is depicted as a black line in the center of the box. The second and third quartiles are the boxes on either side and the first and fourth quartiles are depicted by the whiskers below and above the boxes. Outliers are shown as points outside of the whiskers.

3.29 A linear regression line showing the relationship between zinc and lead in all teeth. Confidence intervals at the $95 \%$ level are shown above and below the regression line. Associated statistics are shown in Table 3.22

Zinc

3.30 Histogram showing the distribution of zinc concentrations of all teeth measured in this study. Shapiro-Wilk test $(\mathrm{W}=0.93, \mathrm{p}<0.001)$.

3.31 Boxplot showing the concentration of zinc for incisors, canines and molars. A KruskalWallis test showed that no group had a median that was significantly different from the population median $(\mathrm{p}=0.18)$. The median value is depicted as a black line in the center of the box. The second and third quartiles are the boxes on either side and the first and fourth quartiles are depicted by the whiskers below and above the boxes. Outliers are shown as points outside of the whiskers.

3.32 A linear regression line showing the relationship between zinc and copper in all teeth. Confidence intervals at the $95 \%$ level are shown above and below the regression line. Associated statistics are shown in Table 3.28

\section{Copper}

3.33 Histogram showing the distribution of copper concentrations of all teeth measured in this study. Shapiro-Wilk test $(\mathrm{W}=0.58, \mathrm{p}<0.001)$. 
3.34 Boxplot showing the concentration of copper for incisors, canines and molars. A KruskalWallis test showed that at least one group had a median that was significantly different from the population median ( $\mathrm{p}=0.001)$. The median value is depicted as a black line in the center of the box. The second and third quartiles are the boxes on either side and the first and fourth quartiles are depicted by the whiskers below and above the boxes. Outliers are shown as points outside of the whiskers.

3.35 A linear regression line showing the relationship between the average copper in all measured tooth enamel of each child and the children's height. Confidence intervals at the $95 \%$ level are shown above and below the regression line. Associated statistics are shown in Table 3.30 . 
"If one went to see Windsor-Castle, or Hampton-Court, it would be strange not to observe and remember the Situation, the Building, the Gardens, Fountains, \&c. that make up the Beauty and Pleasure of such a Seat? And yet few People know themselves; No, not their own Bodies, the Houses of their Minds, the most curious Structure of the World; a living walking Tabernacle: Nor the World of which it was made, and out of which it is fed; which would be so much our Benefit, as well as our Pleasure, to know."

-William Penn, 1682 



\section{Chapter 1}

\section{Introduction}

\subsection{Human deciduous teeth}

There are twenty deciduous teeth in the human dentition. Of these, there are ten on the upper jaw (maxillary teeth) and ten on the lower jaw (mandibular teeth). Each jaw holds two central and two lateral incisors, the front teeth used for cutting; two canines, the round, pointed teeth on either side of the incisors used for tearing; two first and two second molars that are that are used for chewing.

Human teeth can be divided into two parts: the crown and the root. The crown of a tooth is the part that protrudes into the mouth while the root is the part that fastens the tooth to the bony structure of the jaw. The surface of the crown is covered in dense mineral enamel. Dental enamel is the most dense, hard and highly conserved tissue in the human body (1). Beneath the enamel lies a tough, partly mineralized tissue that runs down into the root and is known as the dentine. Beneath the dentine there is a soft tissue containing vasculature and nerve cells that is called the pulp. Teeth are fastened to the bony structure of the jaw by a network of fibrous tissues that are collectively known as the periodontal ligament. 


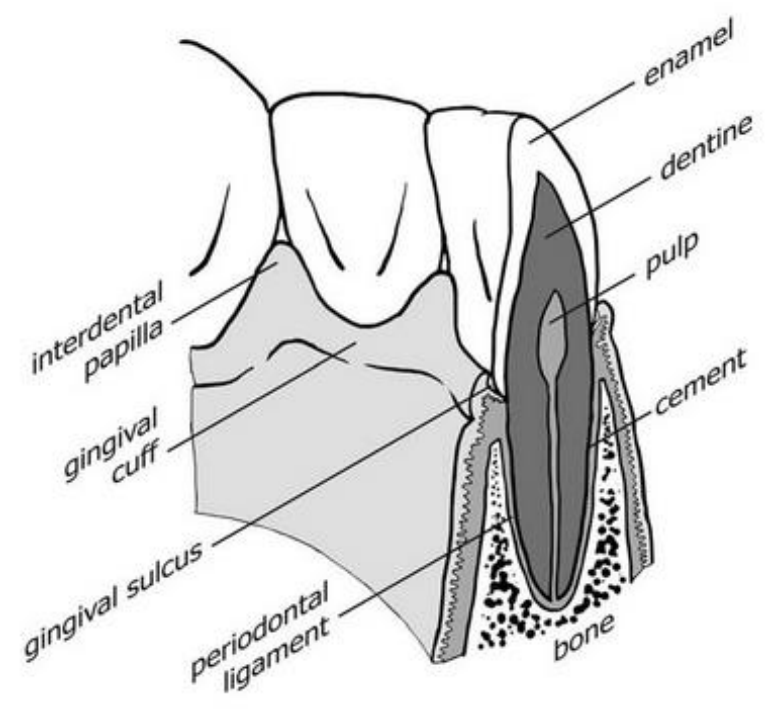

Figure 1.1: Diagram showing the general structure of a tooth. Image taken from (1).

There are several terms used to describe the relative positioning between teeth and the positioning of features and landmarks on a tooth. The dentition can be divided by a median sagittal plane down its center that intersects the dentition at the incisors. The mesial side of a tooth is the side along the dental arcade that is closest to this intersection. The distal side is the side furthest from it. The lingual side of a tooth is that which is closest to the tongue and the buccal side is that which faces the cheeks (or in the case of incisors and canines, the lips). The surface of the crown that is used for chewing is the occlusal surface and surface on the sides of the crown closer to the gums is the cervical surface.

Deciduous tooth enamel is of particular interest as a biomarker because of its highly conservative nature. The formation of enamel (amelogenesis) begins at 14 weeks in utero and continues until the eruption of the tooth into the oral cavity. This timeline of formation makes it an attractive candidate as a biomarker for in utero and neo-natal exposures to trace elements. Recent work published in Nature has shown a distinct increase in the barium content of enamel that was formed after birth, showing that barium present in mother's milk is incorporated during mineralization of the enamel (2). 


\subsubsection{Amelogenesis}

Amelogenesis begins at approximately 14 weeks in utero. The process begins with the differentiation of cells in the enamel epithelium into specialized ameloblasts at the cusp region of the central incisors.

Differentiation rapidly spreads down the cusp slope of the tooth until the entire internal enamel

epithelium has differentiated to ameloblasts. Differentiation begins sequentially at the cusp tips of the enamel epithelium of teeth distal to the central incisors until finally the maxillary second molars begin amelogenesis. A timeline for the formation of enamel from its initial calcification until its completion just prior to eruption is given for all deciduous teeth in Table 1.1.

Enamel formation takes place in two stages: secretion and maturation. The secretion stage involves polarized, columnar ameloblasts forming and secreting enamel matrix proteins and enzymes in a 24-hour cycle while pulling outward, away from the center of the tooth, at a rate of approximately $4 \mu \mathrm{m} / \mathrm{day}$. The extracellular matrix excreted by the ameloblasts is called enamel matrix. Once the secretion of enamel matrix has continued to a point where the thickness of the enamel of the tooth has been delineated, the secretory stage is complete and the maturation stage begins. The secretory stages comprises about $35 \%$ of the time of enamel formation (3).

\begin{tabular}{|c|c|c|c|c|c|}
\hline $\begin{array}{l}\text { Maxillary } \\
\text { Teeth }\end{array}$ & $\begin{array}{l}\text { Central } \\
\text { Incisor }\end{array}$ & $\begin{array}{l}\text { Lateral } \\
\text { Incisor }\end{array}$ & Canine & $\begin{array}{l}\text { First } \\
\text { Molar }\end{array}$ & $\begin{array}{c}\text { Second } \\
\text { Molar }\end{array}$ \\
\hline $\begin{array}{l}\text { Initial } \\
\text { calification }\end{array}$ & $\begin{array}{c}14 \\
\text { weeks in } \\
\text { utero }\end{array}$ & $\begin{array}{c}16 \\
\text { weeks in } \\
\text { utero }\end{array}$ & $\begin{array}{c}17 \\
\text { weeks in } \\
\text { utero }\end{array}$ & $\begin{array}{c}15.5 \\
\text { weeks in } \\
\text { utero }\end{array}$ & $\begin{array}{c}19 \\
\text { weeks in } \\
\text { utero }\end{array}$ \\
\hline $\begin{array}{l}\text { Crown } \\
\text { completed }\end{array}$ & $\begin{array}{c}1.5 \\
\text { months }\end{array}$ & $\begin{array}{c}2.5 \\
\text { months }\end{array}$ & $\begin{array}{c}9 \\
\text { months }\end{array}$ & $\begin{array}{c}6 \\
\text { months }\end{array}$ & $\begin{array}{c}11 \\
\text { months }\end{array}$ \\
\hline $\begin{array}{l}\text { Mandibular } \\
\text { Teeth }\end{array}$ & $\begin{array}{l}\text { Central } \\
\text { Incisor }\end{array}$ & $\begin{array}{l}\text { Lateral } \\
\text { Incisor }\end{array}$ & Canine & $\begin{array}{l}\text { First } \\
\text { Molar }\end{array}$ & $\begin{array}{l}\text { Second } \\
\text { Molar }\end{array}$ \\
\hline $\begin{array}{l}\text { Initial } \\
\text { calification }\end{array}$ & $\begin{array}{c}14 \\
\text { weeks in } \\
\text { utero }\end{array}$ & $\begin{array}{c}16 \\
\text { weeks in } \\
\text { utero }\end{array}$ & $\begin{array}{c}17 \\
\text { weeks in } \\
\text { utero }\end{array}$ & $\begin{array}{c}15.5 \\
\text { weeks in } \\
\text { utero }\end{array}$ & $\begin{array}{c}18 \\
\text { weeks in } \\
\text { utero }\end{array}$ \\
\hline $\begin{array}{l}\text { Crown } \\
\text { completed }\end{array}$ & $\begin{array}{c}2.5 \\
\text { months }\end{array}$ & $\begin{array}{c}3 \\
\text { months }\end{array}$ & $\begin{array}{c}9 \\
\text { months }\end{array}$ & $\begin{array}{c}5.5 \\
\text { months }\end{array}$ & $\begin{array}{c}10 \\
\text { months }\end{array}$ \\
\hline
\end{tabular}


The maturation stage is characterized by the mineralization of enamel. In this stage, the ameloblasts change structure and function. The cell membrane adjacent to the enamel matrix folds into a ruffled form, increasing its surface area near the enamel matrix. Organelles that were involved in the formation and secretion of enamel matrix proteins move away from the distal edge of the cell and a rapid transport of material across the plasma membrane of the ameloblast begins. There are many processes that occur during this stage including the absorption of water and organic material from the enamel matrix by the ameloblast, but this introduction will focus only on ion transport of inorganic material into the enamel.

Dental enamel is comprised mainly of a calcium phosphate mineral hydroxyapatite $\left[\mathrm{Ca}_{10}\left(\mathrm{PO}_{4}\right)_{6}(\mathrm{OH})_{2}\right]$.

The driving force for precipitation of enamel crystals in the enamel matrix is controlled by three general processes (5):

1. The changes in ionic concentrations of hydroxyapatite lattice constituents in circulating blood and their transport through intercellular spaces and across ameloblast cell membranes.

2. Diffusion of lattice constituents through the enamel matrix.

3. The modulation of precipitation kinetics by various regulators.

Radiolabeled calcium ions have been shown to move from the bloodstream into newly secreted enamel matrix in less than 30 seconds through intercellular spaces and ruffle-ended ameloblasts (6). Divalent zinc and magnesium are known to adsorb onto the HAP crystals but with lower affinity than calcium (7). In a more recent work, Matsunaga measured ionic substitution energies of various divalent cations in saturated hydroxyapatite solutions, with some findings shown in figure 1.2 (8). Although the exact energies from Matsunaga's work are specific to the controlled conditions of the experiment, the pattern of decreasing substitution energy is understood to be related to the increasing electronegativity of the cations and also to their ionic radius (8). 


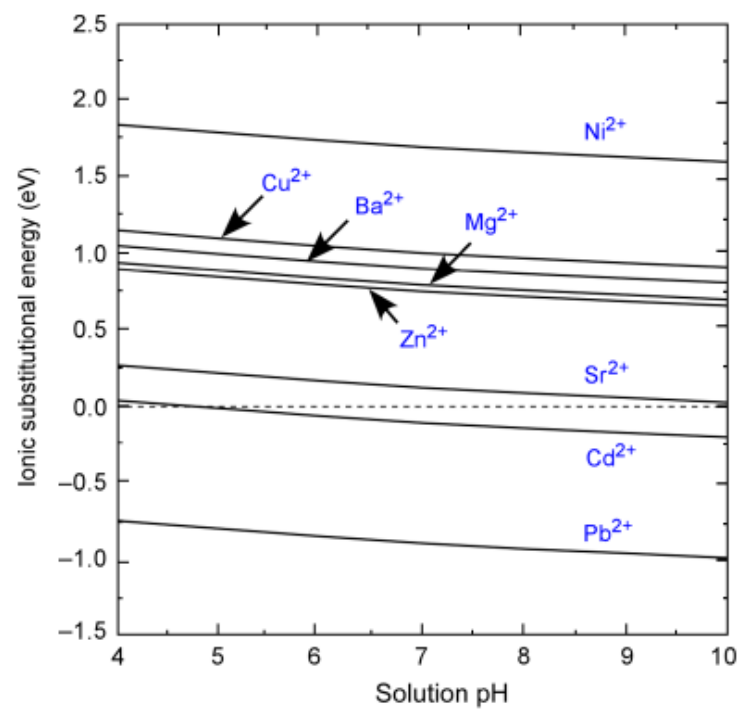

Figure 1.2: Ionic substitutional energies by divalent cations for $\mathrm{Ca}-1$ in HAp as a function of $\mathrm{pH}$. Figure taken from (8)

Modulation of factors that may influence precipitation kinetics has been described (3). These include the availability of calcium ions to move into the enamel matrix through a cycle of controlled movementsimple diffusion - no entry - simple diffusion - controlled movement and the modulation of $\mathrm{pH}$ with bicarbonate ions.

The mineralization of enamel continues until the enamel is formed of approximately $96 \%$ mineral by weight (mostly hydroxyapatite). Once this mineralization is complete, the ameloblasts form a protective layer around the teeth, preventing mineral resorption in the body before eruption. Upon eruption, the epithelial layer that includes ameloblasts is worn off the surface of the teeth and the enamel is exposed to the oral environment.

Once enamel is formed it cannot regenerate. Therefore, wear from grinding and acid erosion are permanent (9). However, hydroxyapatite has a very low solubility product, on the order of $10^{-117}$, and is therefore resistant to acid erosion at physiological $\mathrm{pH}(9)$. Its resistance to change and ionic substitution make it an attractive candidate for obtaining information about the concentrations of its lattice constituents including $\mathrm{Mn}^{2+}, \mathrm{Fe}^{2+}, \mathrm{Cu}^{2+}, \mathrm{Zn}^{2+}$ and $\mathrm{Pb}^{2+}$. 


\subsection{Manganese}

\subsubsection{Metabolism}

Manganese is an essential trace element for humans. The most common source of $\mathrm{Mn}$ is dietary intake of cereals, legumes, nuts, coffee and tea (10). For adults, average dietary intake of Mn is between 2-6 mg per day. This range of intake is sufficient to maintain healthy levels of Mn (11).

Dietary absorption of Mn varies as a function of age and sex. Absorption has been shown to be as high as $15.4 \%$ in premature infants at 10 days, while term newborns absorbed $8 \%$ and healthy adults absorb between 1 to $3 \%$ of dietary Mn (10). Mn absorption has been shown to be sex-dependent, with women absorbing the element more than men while men have greater retention than women (12). The sexdependence in retention and absorption has been proposed to be the result of varying iron status between men and women (12).

Uptake of $\mathrm{Mn}$ from the gut occurs in the small intestine. $\mathrm{Mn}^{2+}$ ions have higher solubility than $\mathrm{Mn}^{3+}$ ions and therefore cross the mucosal lining of the digestive tract preferentially. Free molecular oxygen then acts as an oxidizing agent, converting $\mathrm{Mn}^{2+}$ to $\mathrm{Mn}^{3+}$, thus enabling the $\mathrm{Mn}$ ions to bind tightly to transferrin (Tf) molecules $(13,14)$. Transferrin is a common transporter of iron molecules throughout the body (10).

In 1997, a new transport mechanism was discovered in the duodenum of rats that facilitated direct uptake of divalent cations into enterocytes and blood plasma (15). The discovery of a non-specific transport mechanism for divalent cations including iron, lead, manganese, zinc and copper led to an explosion of research in this field. Divalent metal transporter-1 (DMT-1) has since been found to be present in the duodenum and blood-brain barrier of humans, elucidating a simple mechanism of transport from oral intake of trace metals to potential neurotoxicity. Other mechanisms for Mn transport in the blood-brain barrier include $\mathrm{Ca}^{2+}$ channels (16) as well as zinc transport mechanisms ZIP8 (17) and ZIP14 (18). 
$\mathrm{Mn}$ is primarily taken up by the liver, kidneys, pancreas and skeleton. It is estimated that $25 \%$ of the 10 $20 \mathrm{mg}$ of $\mathrm{Mn}$ present in the human body is found in the skeleton. The presence of $\mathrm{Mn}$ in the skeleton has led to the investigation of bone as a biomarker for Mn body burden (10, 19-21). Mn homeostasis is regulated by excretion via the biliary system, often against a concentration gradient (22). Because of this, the amount of Mn found in the urine is very small and urine's usefulness as a biomarker is questionable (23).

Significant variance of Mn metabolism between subjects and a lack of clear relationships between Mn exposure and biological outcomes has made the study of low-level Mn toxicity challenging (23). Whole blood has been found to be an effective biomarker of recent exposure to Mn but not of long-term, cumulative exposure (23). A commonly used biomarker for cumulative exposure is hair, although there are known problems regarding exogenous contamination of hair samples (24). In vivo neutron activation analysis (IVNAA) has been shown to effectively measure elevated levels of $\mathrm{Mn}$ in the skeletal system of welders (21). The use of whole teeth as a biomarker for prenatal exposure to manganese has been carried out using ion mass spectrometry, showing a positive correlation between early Mn exposure and behavioral disinhibition (25). Arora and colleagues are the first to have suggested the use of teeth as a biomarker of Mn exposure $(26,27)$.

Deficiency of dietary manganese is extremely rare. In animal studies where Mn deficiency was induced, symptoms observed included impaired growth, skeletal abnormalities, impaired reproductive functioning ataxia of the newborn and defects in lipid and carbohydrate metabolism (11).

\subsubsection{Toxicity and deficiency}

Over-exposure to manganese induces neurotoxicity known as manganism. Mn toxicity presents symptoms similar to idiopathic Parkinson's Disease (IPD) that include tremors, gait changes, 
bradykinesia and stiffness. Manganism was first reported by John Couper in 1837 after he observed manganese grinders who presented with similar neurological symptoms (28). Since then, most of the scientific literature regarding manganism has focused on high levels of occupational exposure to manganese through inhalation of dust or aerosols. However, liver disease $(29,30)$ and total parenteral nutrition (31) have also been implicated in manganism.

Although the symptoms of manganism and IPD are markedly similar, there are clear neuropathological differences between them. IPD is a disorder associated with the loss of dopamine function in neurons of the substantia nigra of the basal ganglia. Examination of the brain of a man chronically exposed to Mn revealed that the substantia nigra of the Mn worker's brain was left intact, whereas the pallidum showed a marked decrease in the number of cells, cell size, and myelinated fibers (32). However, it has been suggested that Mn toxicity may play a role in IPD through oxidative stress in astrocytes as well as disruption of dopaminergic functioning of neurons (33).

Mn neurotoxicity has been hypothesized to result from the disruption of activity and expression of glutamine transporters in astrocytes of the basal ganglia $(34,35)$. Astrocytes are involved in many central nervous system (CNS) processes including growth, energy and metabolism, synapse function and transmitter homeostasis $(36,37)$. There is also evidence that Mn inhibits dopaminergic systems in neuronal cells via oxidative stress $(38,39)$.

Aschner and colleagues (40) have highlighted some of the difficulties of investigating molecular mechanisms of Mn neurotoxicity. Firstly, it is necessary to inject a bolus of tracer-Mn that may not accurately reflect the oxidation states and/or functional forms of $\mathrm{Mn}$ in vivo. Given the manifold biochemical pathways of $\mathrm{Mn}$ transport, data obtained from tracer techniques may be difficult to interpret. Secondly, blood ligands for Mn may exist in saturation which would leave an excess of free form Mn that does not mimic physiological conditions. Lastly, Mn concentrations in human neurological tissues are 
below 2 ppm (41), making analytical uncertainty important. For these reasons, transport kinetics of Mn must be regarded in the context of considerable experimental uncertainty.

There is substantial epidemiological evidence to support the claim that between optimal neurological function and manganism, there is a gradient of decreased neurological functioning related to Mn exposure (42). Whole blood Mn concentrations of 58 men working in a ferroalloy plant were found to correlate to levels of Mn exposure and decreased motor neuron functioning (43). This study is somewhat unique in that urine-Mn concentrations correlated with blood-Mn levels and neurological outcomes. A similar survey of 141 men working in a Belgian salt production plant showed a correlation between Mn exposure and motor neuron deficits, as well as a relationship between airborne Mn exposure and reduced pulmonary health (44).

More recently, there has been an increased focus on Mn toxicity during pre- and neonatal stages of neurological development (45). In Quebec, a pilot study investigating correlations between Mn concentrations in children's hair, Mn concentrations in their drinking water and behavioral disinhibition found positive correlations between all three (46). A subsequent investigation of the complete neurological profile of children including IQ test scores found that Mn in children's drinking water was correlated with lower IQ test scores (47). A study in rural Bangladesh found a $6.4 \%$ decrease in standardized mathematics test scores among children who drank water with Mn levels higher than the World Health Organization guideline of $400 \mu \mathrm{g} / \mathrm{L}$ (48).

Recent evidence suggests that sex and gender may also play a role in manganese neurotoxicity (49-51). Bouchard and colleagues observed an inverse relationship between Mn exposure in drinking water and IQ test scores that was stronger in girls than in boys (47). A cohort of Mexican children between the ages of 7 and 11 were found to have a similar inverse relationship between Mn exposure (from dust near a mine) and lowered IQ that was stronger in girls than boys (52). Although the reasons of the sex, gender and age 
dependence of Mn toxicity are not yet known, homeostatic mechanisms involved in the regulation of essential trace metals and overall nutritional status may play an important role.

Manganese has also been shown to interact with -- and in many cases to interfere with -- homeostasis of other trace metals. Iron and manganese are known to compete for binding sites on transferrin molecules and exert a strong influence on the uptake and transport of trace metals (53). Cowen and colleagues have suggested using $\mathrm{Mn} / \mathrm{Fe}$ ratio in whole blood as a biomarker of Mn exposure after observing environmental exposure to Mn decreased iron content in blood $(54,55)$.

Manganese exposure is known to affect uptake of iron. Exposure to elevated levels of Mn results in the upregulation of Tf receptors within neuronal cells, leading to iron overload and exposing cells to oxidative stress (56). Ingestion of $\mathrm{Mn}$ in drinking water fed to pregnant rats has been shown to alter iron homeostasis and anxiety behavior of offspring (57). Conversely, iron metabolism genes have been shown to influence uptake of Mn (58) and anemia has been shown to increase manganese uptake $(59,60)$.

Betharia and colleagues have found a pharmacokinetic interaction between $\mathrm{Pb}$ and $\mathrm{Mn}$ exposed rats with sex-specific (incorrectly reported as "gender" specific) neurological outcomes (50). Conversely, Lucchini and co-workers examined the relationship between $\mathrm{Mn}$ and $\mathrm{Pb}$ levels in children and adolescent neurological outcomes and found that there was no $\mathrm{Mn}-\mathrm{Pb}$ interaction and that $\mathrm{Mn}$ exposures had no measurable effect on neurological functioning (61). 


\subsection{Iron}

\subsubsection{Metabolism}

Iron is an essential element that plays a role in a broad range of metabolic functions in humans including the Kreb's cycle and oxygen transport. It is commonly found in many foods; particularly in red meat, poultry and fish. Despite its known essential role in human health, it is estimated that 2 billion people worldwide suffer from iron deficiency (62).

Two forms of iron exist in dietary sources: heme and non-heme. Heme proteins, one of which is shown in figure 1.2, are more bioavailable than inorganic iron although its mechanism of intestinal absorption is not yet known (63). Non-heme iron is less effectively absorbed in the intestine, but the mechanisms of absorption are better understood.

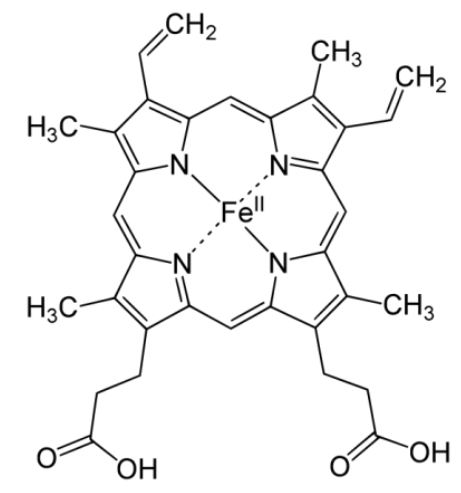

Figure 1.3: Chemical structure of heme B protein (Image taken from (64))

Non-heme iron is found most commonly in ferric form $\left(\mathrm{Fe}^{3+}\right)$ in dietary sources. Ferric iron is reduced to ferrous $\left(\mathrm{Fe}^{2+}\right)$ iron in the duodenum. This process is thought to be mediated by the enzyme duodenal cytochrome B (DcytB), although DcytB has been shown to not affect iron absorption in mice (65). Uptake of ferrous iron is then regulated by DMT-1. It has been shown that both DcytB and DMT-1 are highly regulated by iron status (10). 
The understanding of iron metabolism has increased dramatically in recent years. One of the most important findings regarding iron metabolism was the discovery of hepcidin (66). Hepcidin regulates the efflux of iron from cells that store excess iron in ferritin, a protein that keeps iron in a non-toxic state, thereby preventing redox reactions known as the Haber-Weiss-Fenton sequence (shown below):

$$
\begin{gathered}
\mathrm{Fe}^{2+}+\mathrm{O}_{2} \rightarrow \mathrm{Fe}^{3+}+\mathrm{O}_{2}^{-} \bullet \\
2 \mathrm{O}_{2}^{-} \bullet+2 \mathrm{H}^{+} \rightarrow \mathrm{H}_{2} \mathrm{O}_{2}+\mathrm{O}_{2} \\
\mathrm{Fe}^{2+}+\mathrm{H}_{2} \mathrm{O}_{2} \rightarrow \mathrm{OH} \bullet+\mathrm{OH}^{-}+\mathrm{Fe}^{3+}
\end{gathered}
$$

Hepcidin reduces the efflux of iron from intestinal enterocytes, macrophages, hepatocytes and placental cells by binding to ferroportin on the cell membrane and causing it to internalize and degrade (67). Since hepcidin production is upregulated by the presence of iron (68), a feedback loop exists that keeps iron levels within a margin that enables iron to perform its metabolic roles without subjecting cells to oxidative stress through Haber-Weiss-Fenton reactions.

Iron is not excreted via urine or sweat and the regulation of iron body load occurs strictly at the site of intestinal absorption. Common biomarkers for iron status include serum ferritin, total serum iron, total iron-binding capacity, transferrin saturation, and transferrin (69). All of these biomarkers involve taking blood samples from subjects. These methods may be confounded by the fact that plasma/serum ferritin levels are known to increase in the presence of inflammation, ethanol consumption, hyperglycemia and ferritin levels are directly correlated to body mass index (70).

To date, there has been no investigation of calcified tissue as a biomarker of iron exposure or status in humans. The presence of heme-iron in tooth enamel is extremely unlikely given the size and structure of the heme molecule. However, divalent cations such as ferrous iron may substitute at the isovalent calcium sites of hydroxyapatite $\left[\mathrm{Ca}_{10}\left(\mathrm{PO}_{4}\right)_{6}(\mathrm{OH})_{2}\right]$, the principal component of tooth enamel (71). Therefore 
dental enamel may be considered as a potential marker of the presence of trace metals in a divalent chemical state during the formation of the enamel, including iron.

\subsubsection{Toxicity and deficiency}

The most common health detriment associated with iron is deficiency. As stated above, approximately 2 billion people worldwide are iron deficient, making iron deficiency one of the most widespread nutritional disorders in the world. In Canada, iron deficiency is far less common, although $8 \%$ of pregnant women were found to have inadequate iron stores between 2009 and 2011 (72). Iron deficiency can lead to a condition characterized by lowered red blood cell production, called anemia. However, iron status has a full spectrum ranging from toxic overload to healthy to deficient to anemic.

Low iron status is known to cause developmental neurotoxicity via several mechanisms that are reviewed by Nyaradi et al (73). Umbilical cord serum has been used as a biomarker to show significant neurological deficits associated with iron deficiency in utero (74). Interestingly, umbilical cord blood is itself significant for neonatal iron stores. A delay of 2-3 minutes in the cutting of the umbilical cord imparted an additional $75 \mathrm{mg}$ of iron to each child and a statistically significant difference could be measured in iron stores of these children at six months of age (75). On the other hand, studies have shown that mothers in developed countries given iron supplements had children who failed to outperform children born to mothers given a placebo $(76,77)$. 


\subsection{Lead}

\subsubsection{Toxicokinetics}

Lead $(\mathrm{Pb})$ is a well-known neurotoxin. It has been used by humans for thousands of years but interest in $\mathrm{Pb}$ toxicity is currently focused on environmental and industrial exposures. Pathways of exposure that lead to neurotoxicity are similar to those of other trace metals: primarily inhalation and ingestion, although organic lead can pass through dermal tissue (78).

Lead exposures in Canada have decreased considerably since the 1970s. Between 1978 and 1979, it was estimated that $25 \%$ of Canadians had blood-lead levels $>10 \mu \mathrm{g} / \mathrm{dL}$, an amount that is currently considered toxic (79). By 2008, the percentage of Canadians with blood-lead levels above the guideline of $10 \mu \mathrm{g} / \mathrm{dL}$ had been reduced to $<1 \%$, mostly due to the discontinued use of leaded gasoline, paints and lead solder in food cans that were common in the 1970s (80).

There are still sources of environmental $\mathrm{Pb}$ in Canada that currently pose a toxicity risk, however. Recent evidence suggests that $\mathrm{Pb}$ paint and pipes in older, urban homes are a significant source of $\mathrm{Pb}$ dust (81). After nearly100 years of coal-fired power production and 40 years of leaded gasoline use in St. Johns, $\mathrm{NF}$, more than half of soil samples taken from the city exceed the national soil-Pb guidelines of $140 \mathrm{ppm}$ (82). The highest levels of $\mathrm{Pb}$ found in soil by Bell and colleagues came from houses built in the 1920s or earlier, where decay of leaded paint on clapboarded houses contributed significantly to some soil-Pb levels that exceeded $1200 \mathrm{ppm}(82)$.

By comparison to other industrialized countries, Canadian environmental lead levels are quite low. A review of investigations from across China found that $24 \%$ of children in who participated in studies had blood-Pb levels that exceeded $10 \mu \mathrm{g} / \mathrm{dL}$ between 2001 and 2004 (83). In many underdeveloped countries in Africa, Asia and South America, the prevalence and severity of lead toxicity is shocking. In 2010, an outbreak of lead poisoning related to artisanal gold mining in Nigeria resulted in the deaths of as many as 
78 children in a single village (84). It was found that more than $97 \%$ of the children in four Nigerian villages that were investigated had blood-lead levels $>45 \mu \mathrm{g} / \mathrm{dL}$ (84). Artisanal mining is a major industry, with an estimated production of $20-30 \%$ of the gold on the global market and more than 100 million people directly or indirectly dependent on artisanal mining for their livelihood (85). An extensive review of lead concentrations in the human environment, as well as age- and sex-specific intake estimates in the American population is given in the $6^{\text {th }}$ and $7^{\text {th }}$ chapters of Mushak's textbook (78).

Uptake of $\mathrm{Pb}$ from the environment depends on the bioavailability of $\mathrm{Pb}$, which varies as a function of age, with younger people generally absorbing more than adults (78). There are several models of toxicokinetics of lead once it has been absorbed into the system. Each has advantages and disadvantages with respect to accurately modeling exposures from industrial or environmental exposures.

The first model discussed here was developed by Rabinowitz and colleagues and is a three compartment model for lead once it is absorbed into the system (86). The first compartment of the model is blood. Blood-lead was found to have a mean life of $36 \pm 5$ days. The second compartment is soft tissues; a compartment that is partly comprised of biomarkers such as hair and nails and has a mean life that varied between 30 to 55 days. The third compartment is the skeletal system. The mean lifetime of lead in bone was reported to be "much greater" than the other compartments although at the time that this model was developed, data were unavailable for a more thorough investigation of skeletal lead kinetics (86). Although there were only 5 participants used in this work, the dietary ingestion of Pb-tracer as lead nitrate closely reflects environmental exposure conditions of healthy adults and provides useful information regarding various biomarkers. However, it was noted that the model is unable to account for the accumulation of lead in brain tissue, and therefore more complex models of Pb kinetics would be necessary for accurate modeling of lead kinetics (87).

The second model is used by the International Commission for Radiological Protection (ICRP) for exposure to lead radioisotopes and is based on the model given by Legget and colleagues $(88,89)$. This 
model is considerably more complex than that proposed by Rabinowitz and co-workers and comprises data that were published including kinetics of lead in soft tissues. Data were collected from multiple animal and human studies and compiled into age-related models for lead kinetics. This model was the first to move away from strictly first-order kinetics as it introduced non-linear kinetics between blood ligands and plasma.

Subsequent post-mordem examinations of subjects exposed to low levels of lead throughout their lives showed excellent agreement with model predictions although the sample size was too small to provide definitive results (88). A notable feature of this model is that children tend to have increased uptake of $\mathrm{Pb}$ into their bones relative to adults. Consequently, blood- $\mathrm{Pb}$ measurements, even if taken over long periods of time during childhood, may give an underestimate of lead body burden of children compared to adults. Despite this, blood- $\mathrm{Pb}$ concentrations remain the standard biomarker of $\mathrm{Pb}$ body burden in children and the blood-Pb level that is considered toxic for children remains $10 \mu \mathrm{g} / \mathrm{dL}$. It is interesting to note that there is evidence showing neurotoxicity at blood-Pb levels well below this accepted threshold in children (90).

A third model of interest is a physiological model similar to the ICRP model, but was derived by different means. The O'Flaherty physiology-based model was developed through a sequence of models and experiments beginning with rats, then humans, then age-specific models of human physiology (91-95). This model was further adjusted by Fleming and colleagues after taking bone lead measurements of workers at a lead smelter in New Brunswick using an in vivo system of bone-Pb measurement developed by Chettle and co-workers. $(96,97)$

Teeth have been used as a biomarker for cumulative lead exposure (98-107). However, the amount of lead found in a tooth was found to be related to the type of tooth $(108,109)$, the presence or absence of caries (enamel demineralization) $(110,111)$ and the presence or absence of a tooth root (111). The distribution of $\mathrm{Pb}$ in deciduous enamel has been shown to be heterogeneous, with maximum $\mathrm{Pb}$ concentrations at the 
enamel surface. $(112,113)$ It should be noted here that Brudevolde and colleagues (113) found that $\mathrm{Pb}$ concentrations were highest at the enamel surface of unerupted teeth as well as erupted teeth---showing that the observed distribution is not necessarily the result of exogenous contamination. However, they also examined a subset of teeth from an older population and found that they had higher concentrations of lead in their surface enamel compared to the younger population. It was not possible to determine if this difference resulted from the older generation having higher pre-eruption exposures or accumulating $\mathrm{Pb}$ at the enamel surface over time (113).

\subsection{Zinc}

\subsubsection{Metabolism}

Zinc is an essential element that functions in catalytic, structural and regulatory roles in human metabolism (10). The richest food sources of zinc are flesh and organs of fish and meat (10). Recommended intake levels of zinc are $8 \mathrm{mg}$ per day for female adults and $11 \mathrm{mg}$ per day for male adults while children are recommended to ingest 3-9 mg per day depending on their age and sex (114).

There are many factors that affect the bioavailability of zinc. The fractional absorption of zinc is nearly $100 \%$ when less than $5 \mathrm{mg}$ are ingested in an aqueous solution in a fasting state (115). When zinc is consumed with food, the absorbed fraction has been found to range between $5 \%$ to greater than $50 \%$ (116). Zinc absorption from animal source foods is higher than zinc absorption from plant source foods because plant source foods contain phytate, an inhibitor of zinc ingestion $(10,117)$.

Bioavailability of zinc is also affected by the presence of other divalent metals in the intestinal lumen. There is evidence that suggests that intestinal zinc absorption of $\mathrm{Zn}^{2+}$ ions in aqueous solution is reduced by the presence of high amounts of $\mathrm{Fe}^{2+}$ in aqueous solution (118). This may result from competition for uptake via non-specific absorption pathways such as DMT-1 in the intestinal lumen. 
Many metabolic pathways of zinc remain to be discovered. Two classes of zinc transporters have been elucidated to date. The first of these is the $\mathrm{ZnT}$ class, which has ten carriers that have been discovered so far (ZnT1 to ZnT10) (119). ZnT carriers facilitate the efflux of Zn across the cell membrane. The second class of $\mathrm{Zn}$ transporters is the ZIP transporters (ZIP1 to ZIP14). These are thought to facilitate the influx of $\mathrm{Zn}$ into cells from the extracellular environment or from within vesicles inside the cell (119). ZIP8 displays ion non-specificity between Zn and Mn and ZIP14 displays non-specificity between Zn, ferrous iron and Mn.

It is known that the gastrointestinal tract plays a key role in zinc homeostasis (10). The fractional intake of zinc has been shown to be reduced in response to an increase of zinc ingestion within 24 hours of the intake (117). However, intestinal absorption has not been shown to respond efficiently to changes in zinc status (120). Zinc uptake in late stages of pregnancy and lactation was shown to be increased in an animal study (121).

Tracer kinetics studies using radioactive ${ }^{69 \mathrm{~m}} \mathrm{Zn}$ and ${ }^{65} \mathrm{Zn}$ have been used to quantify zinc absorption and metabolism throughout the body $(122,123)$. These studies have shown that there is a very low turnover of zinc once it has entered calcified tissue. In 1993, the ICRP published a kinetic model for zinc for the purpose of internal dosimetry (89). This model used first order kinetics for all tissue compartments and $97.5 \%$ of zinc in bone (which accounts for $19.5 \%$ of zinc in the body) was estimated to have a biological half-life of 400 days (89). More recently, Legget has compiled data from various tracer kinetics studies and has proposed several modifications to the model provided by the ICRP (124). The model suggested by Legget does not provide any additional information about the metabolism of zinc during early stages of childhood, nor does it mention teeth as a distinct compartment of the skeletal system. To date, tooth enamel has not been used as a biomarker for cumulative zinc exposure.

$\mathrm{Zn}^{2+}$ ions are required to activate tissue non-specific alkaline phosphatase (125). This suggests a major role for zinc in the formation of dental enamel since alkaline phosphatases are required to cleave calcium 
and phosphate ions from organic molecules so that they may incorporate into the enamel structure (126). Zinc has also been shown to incorporate into the superficial layer of demineralized enamel in the presence of calcium phosphate-containing chewing gum (127). Because there are pathways for both exogenous and endogenous incorporation of $\mathrm{Zn}$ in dental enamel, it may be difficult to establish and quantify the $\mathrm{Zn}$ in enamel that is specific from each source.

\subsubsection{Deficiency and toxicity}

In North America, zinc deficiency is uncommon because most dietary intakes are sufficient to maintain healthy $\mathrm{Zn}$ stores (114). Zinc deficiency is characterized by symptoms that include growth retardation, skin lesions, delayed healing of wounds, hypogonadism and several others (10). The impairment of growth and hypogonadism are thought to result from the maintenance of functional Zn levels in certain tissues at the expense of those that are most metabolically active (10). In humans, severe Zn deficiency is rare due to the efficacy of homeostatic mechanisms of uptake. Causes of zinc deficiency include inadequate intake, Crohn's disease (128), celiac disease (129) and intestinal bypass surgery (130).

It has been estimated that the total amount of zinc that is required by a growing fetus during pregnancy is approximately $100 \mathrm{mg}$ (131). This additional zinc requirement may be met with zinc supplements, additional dietary intake, or increased intestinal absorption during pregnancy.

The effects and possible mechanisms of zinc neurotoxicity have been reviewed by Morris and colleagues (132). There are three general mechanisms of neurotoxicity involving zinc that are discussed. The first mechanism is excitotoxicity. Excess Zn from pre-synaptic neurons binds to post-synaptic NDMA glutamate receptors and blocks functioning, resulting in impairments to learning and memory. A second mechanism of neurotoxicity is oxidative stress by the creation of reactive oxygen species (ROS). The last category is impairment of cellular energy production. Energy impairment takes place by the inhibition of nicotinamideadenine dinucleotide (NAD+), an essential redox coenzyme for cellular glycolysis. 
Despite the potential for involvement of zinc in neurotoxicity, homeostatic mechanisms generally prevent dietary intakes from having an adverse effect on human health. In cases where homeostatic mechanisms are circumvented, such as inhalation during long term occupational exposures, it has been noted that copper homeostasis was affected. In a study of 111 subjects working at a steel mill that galvanizes materials with zinc, workers who had high levels of serum zinc had reduced levels of both copper and calcium in their serum (133).

\subsection{Copper}

\subsubsection{Metabolism}

Copper $(\mathrm{Cu})$ is an essential element in humans that is involved in many catalytic and physiological functions (10). Sources of dietary copper include shellfish, seeds, nuts, grains and chocolate (10).The human adult body contains approximately $100 \mathrm{mg}$ of copper with a range from 50 to $120 \mathrm{mg}$ (10). Approximately $40 \%$ of the copper in the body is stored in bone tissue (10).

Intestinal absorption of copper in children has been measured to decrease with increasing age (134). The mean intake of healthy infants receiving human milk during the first year of life is $200-220 \mu \mathrm{g} /$ day (114). The recommended dietary allowance for copper increases throughout development into adulthood when it remains at $900 \mu \mathrm{g} / \mathrm{day}(114)$. Although pathological consequences of high dietary copper consumption are rare, upper levels of intake are $1000 \mu \mathrm{g} /$ day for infants and it is recommended that copper intake should be from food only during the first year of life (114).

The bioavailability and metabolism of copper is known to be related to the absorption of other metals such as iron. The metabolic relationships between copper and iron have been reviewed by Collins and colleagues (135). It has been observed that deficiency of copper is associated with low hemoglobin and serum iron levels (136). Conversely, iron deficiency induces expression of copper ATPase (ATP7a), 
suggesting that iron deficiency causes an increase in the absorption of copper into enterocytes (137). This same investigation found that iron deficiency induced expression of DMT-1, suggesting a second mechanism of increased absorption of (divalent) copper in response to depressed iron status.

Copper bioavailability is inhibited by the presence of dietary zinc (117). It has been suggested that competition for absorption is due to the similar complex formations and electron structure of these elements (138). Depletion of copper has been observed in humans who supplemented $50 \mathrm{mg}$ of $\mathrm{Zn}$ per day for extended periods of time (10). This observation forms the basis for the Upper Intake Levels of $\mathrm{Zn}$ given by the Food and Nutrition Board (114).

\subsubsection{Deficiency and toxicity}

The literature on the neurotoxicity of copper is focused primarily on its role in neurodegenerative diseases such as Alzheimer's Disease (AD). Copper's metabolic activity is heavily dependent on its redox capacity and so there is inherent potential for Fenton and Fenton-like chemistry to produce oxidative damage in tissues where copper is present (139).

The observation of dyshomeostasis of copper and other trace metals in the brain tissue of AD patients has led to the development of a "Metal theory of Alzheimer's Disease" (140). It is worth noting that homeostatic changes in mitochondrial function and associated trace metals concentrations are normal in old age; however, the dyshomeostasis that was observed was between AD patients and age- and sexmatched control groups (141). Despite the attention that this theory has received, it has been noted that there are concerns about the analytical methods used to quantify metals and that there is a heavy citation bias in the literature in favor of positive results (142). The need to for better understanding of the role of metals in the pathology of neurodegenerative diseases, and AD in particular, presents an opportunity for the use of x-ray fluorescence spectrometry as a method of performing multi-elemental analysis of cumulative exposure to these essential elements. 
Copper deficiency is rarely observed in humans and is generally associated with individuals receiving total parenteral nutrition, excessive zinc supplementation, or long-term peritoneal dialysis (10). Excessive or inadequate copper retention at the cellular level may occur in individuals suffering from one of two recessive genetic disorders: Wilson's Disease (WD) and Menkes Disease (MD), respectively. A review of the global prevalence, symptoms and pathology of WD was given by Mak and Lam (143). Measurement of hepatic copper has been indicated in the diagnosis of WD (144). A review of the pathology of Menkes disease is given by Mercer (145).

\subsection{Aims of this work}

The primary aim of this work is to develop a non-destructive method for multi-elemental quantification of manganese, iron, copper, zinc and lead in surface dental enamel using EDXRF. This included optimizing the measurement parameters of the EDXRF system and developing reliable data fitting routines for overlapping peaks for $\mathrm{Mn}$ and $\mathrm{Cr}$, as well as spectral artifacts such as sum peaks, silicon escape peaks, and Bragg diffraction peaks. This multi-elemental approach enables the investigation of relationships between metals in surface enamel.

A secondary aim of this work is to investigate enamel as a biomarker for exposure to manganese and iron because complete data regarding exposure pathways to these elements have been collected as part of a larger study involving the children in this work (47).

Criteria for the establishment and validation of a biomarker of exposure, and more generally, of cause and effect in occupational and environmental health, are given by Hill (146). One of these criteria is the establishment of a dose-effect relationship. Donald Smith and colleagues (23) present this requirement in the context of manganese exposure, suggesting that "biological markers of exposure should reflect an 
integration of the internalized dose over time." The ability of tooth enamel to reflect the integration of dietary and tap water sources of iron and manganese was investigated by correlations of estimated oral intakes with measured concentrations of manganese and iron in enamel.

Further information regarding each child was collected including their age, sex, and height, as well as pertinent information regarding the duration that they lived in the households where tap water and dietary data were collected. Parametric and non-parametric analysis of all trace metal concentrations compared with specific neurological outcomes including Santa Ana dexterity test scores and Weschler Abbreviated Scale of Intelligence (WASI) test scores were also investigated. 



\section{Chapter 2}

\section{Methods}

\subsection{Study design and recruitment}

This work is part of a larger study of the effect of low levels of exposure to Mn through drinking water sources that was carried out by Dr. Maryse Bouchard and colleagues (47). Municipalities in southern Quebec with groundwater aqueduct water supply were considered for participation in the study. Eight municipalities were chosen in order to achieve a gradient of exposure to Mn from groundwater.

Recruitment of children was carried out by explaining the study to principals and school teachers of schools in the municipalities who agreed to distribute recruitment letters to children's families. The response rate of families was $60 \%$ and the participation rate of families was $52 \%$. Of the 362 children who participated in the study, 80 children donated a total of 180 teeth for analysis. Ethical approval was obtained from The Human Research Ethics Board of the Université du Québec à Montréal for this work.

Measurements of pathways of exposure to manganese included tap water and dietary intakes. Tap water measurements were performed on $50 \mathrm{~mL}$ water samples using inductively coupled plasma-mass spectrometry (ICP-MS). Parents of each of the children answered interview questions that were used as a 
basis for estimating monthly intakes of tap water. Estimates of dietary manganese intake were made by an orally administered semi-quantitative food frequency questionnaire. Intelligence quotients (IQ) of each child were measured by a Weschler Abbreviated Scale of Intelligence (WASI) test assessment (147). Manual dexterity was measured by Santa Ana dexterity tests of both dominant and non-dominant hands. Santa Ana tests evaluate the ability of a subject to turn pegs 180 degrees successively during a 30 second period. The test evaluates dexterity and visuomotor coordination in both the dominant and non-dominant hands.

Hair was investigated as an indicator of exposure to manganese by Dr. Bouchard and colleagues. Hair manganese quantification was carried out using ICP-MS. Our lab was contacted with a request to perform non-destructive quantification of manganese in the teeth collected from participants in this work. In addition to developing a method for in situ quantification of manganese, other elements that may be related to manganese metabolism and/or neurotoxicity were also considered. Further elements, such as chromium and strontium, are visible in the spectrum of the teeth but are not known to be directly related to manganese neurotoxicity or to the manganese metabolism, and were therefore not quantified.

Each of the teeth measured in this study were delivered by mail with approval from the research ethics board of Ryerson University (REB\#: 2008-106-2). Along with the teeth, information was sent including the type of tooth and the condition of the tooth (presence/absence of fragmentation, wear, cavity, filling, tarter, root and/or caries). Teeth removed from the envelopes were handled with powder-free nitrile gloves (VWR, Radnor, PA, USA).

In total, 180 teeth were donated by 80 children who participated in this work. There were two teeth that were excluded from the statistical analysis due to fillings that were present in the tooth that made analysis of the enamel impossible. Each of the children who donated these teeth had also donated others, so in the analysis, 178 teeth were included from the 80 children who participated. A summary of the teeth that were measured is given in Table 2.1 . 
Table 2.1: Summary of the teeth measured

\begin{tabular}{llccccc}
\hline & \multicolumn{5}{c}{ Cases } \\
\cline { 2 - 7 } & \multicolumn{2}{c}{ Valid } & \multicolumn{2}{c}{ Missing } & \multicolumn{2}{c}{ Total } \\
\cline { 2 - 7 } Tooth type & $\mathrm{N}$ & Percent & $\mathrm{N}$ & Percent & $\mathrm{N}$ & Percent \\
\hline Incisor & 45 & $100.0 \%$ & 0 & $0 \%$ & 45 & $100.0 \%$ \\
Canine & 46 & $100.0 \%$ & 0 & $0 \%$ & 46 & $100.0 \%$ \\
Molar & 87 & $97.8 \%$ & 2 & $2.2 \%$ & 89 & $100.0 \%$ \\
\hline
\end{tabular}

It is important to note that there is a sampling bias in the teeth that were measured in this work. Older children generally donated molars, presumably because their incisors and canines had fallen out before they were contacted regarding this study. On the other hand, younger children generally donated incisors and/or canines. This makes sense considering that deciduous molars are the last of the dentition to be shed. Consequently, statistical analyses in this work had to account for age as a covariate in linear regression models, particularly for metrics such as height and manual dexterity tests.

\subsection{Experimental setup}

A previous, custom EDXRF system for the quantification of strontium in tooth enamel used iodine-125 brachytherapy seeds as an excitation source with a $\mathrm{Si}(\mathrm{Li})$ detector at a $180^{\circ}$ backscatter geometry (148). The experimental setup in this work used an S2 Ranger (Bruker AXS, Madison, USA) EDXRF system with a $40 \mathrm{kV}$ palladium anode $\mathrm{x}$-ray tube as an excitation source with a silicon drifted detector (SDD) at a $90^{\circ}$ geometry to the excitation source. The SDD had an energy resolution of $130 \mathrm{eV}$ at $5.9 \mathrm{keV}(\mathrm{Mn}-\mathrm{K} \alpha)$. A $500 \mu \mathrm{m}$ aluminum filter was used to remove low energy photons from the excitation source. The tube current was optimized to maintain a count rate of approximately $5 \times 10^{4}$ counts/s and a dead time of 
approximately $5 \%$. The tube current was maintained at $1250 \mu \mathrm{A}$, giving the tube a total power output of approximately $50 \mathrm{~W}$. A schematic of the experimental setup is shown in figure 2.1 .

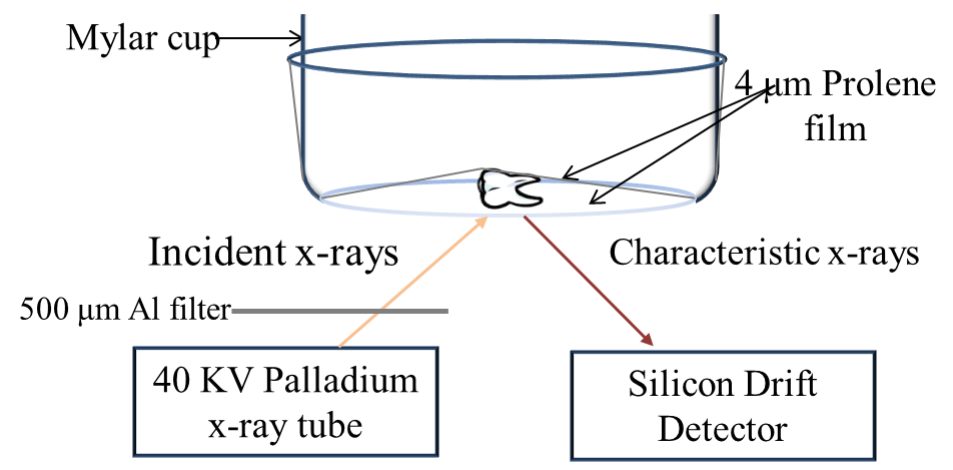

Figure 2.1: Experimental setup used for the quantification of trace metals in deciduous dental enamel

Each tooth sample was placed between two sheets of $4 \mu \mathrm{m}$ thick Prolene ${ }^{\circledR}$ film (Chemplex Industries, Palm City, USA) across the bottom of the sample cup with its buccal surface at $45^{\circ}$ to the excitation beam and detector, respectively. For teeth that fragmented during transit in the mail, the fragment containing the largest intact portion of the buccal surface enamel was used for the analysis. Each tooth sample was run in triplicate for $3600 \mathrm{~s}$ live time under high vacuum conditions to gather spectra for analysis. During the run time of each sample, the Mylar cup was rotated in the horizontal plane.

The critical depth of measurement---the depth from which $99 \%$ of the fluorescent signal is collected--was estimated for each of the elements using the following formula (149):

$$
t_{\text {critical }}=\frac{4.61}{\csc \left(\frac{\pi}{4}\right) \mu_{i} \rho+\csc \left(\frac{\pi}{4}\right) \mu_{t} \rho}
$$


where $\mu_{i}$ is the mass attenuation coefficient of hydroxyapatite for the incident excitation beam, $\mu_{t}$ is the mass attenuation coefficient of hydroxyapatite for the characteristic x-ray and $\rho$ is the density of dental enamel $\left(3.15 \mathrm{~g} / \mathrm{cm}^{3}\right)$. The approximate critical thicknesses are given in table 2.2 . The value of the critical thickness should not be misinterpreted as a thickness that is measured homogeneously since approximately $90 \%$ of the measured signal comes from the outer $50 \%$ of the critical thickness (149).

\begin{tabular}{lcc}
$\begin{array}{l}\text { Table 2.2: Critical thickness of XRF measurements } \\
\text { in tooth enamel }\end{array}$ & \\
\hline \multirow{3}{*}{ Element } & $\begin{array}{c}\text { Characteristic } \\
\text { X-ray energy } \\
(\mathrm{keV})\end{array}$ & t-critical $(\mu \mathrm{m})$ \\
Calcium & 3.7 & 20 \\
Manganese & 5.9 & 28 \\
Iron & 6.4 & 34 \\
Copper & 8.0 & 64 \\
Zinc & 8.6 & 73 \\
Lead & 12.5 & 140 \\
\hline
\end{tabular}

\subsection{Spectral analysis}

Quantification of trace elements is carried out by fitting gaussian curves to the photopeaks of analytes present in the sample. Accuracy of curve fitting depends on having an accurate model that accounts for background radiation and spectral artifacts as well as photopeaks. Spectral artifacts that are present in the spectra of dental enamel include silicon escape peaks, sum peaks, and Bragg diffraction peaks.

Silicon escape peaks are caused by photoelectric absorption of characteristic x-rays from the sample near the entrance of the SDD. When this occurs, the Si-K $\alpha$ photon that is emitted may escape the detector, causing the pulse height to be measured approximately $1.74 \mathrm{keV}$ lower than the incident photon. Sum peaks are caused by two photons entering the detector simultaneously and being detected as a single 
photon with an energy equivalent to the sum of the two incident photons. Finally, Bragg diffraction peaks in HAp are caused by the repetitive pattern of the second nearest neighbor bonds between calcium-1 and oxygen atoms in the HAp lattice $(0.28 \mathrm{~nm})$. The Bragg condition for constructive interference is

$$
\lambda n=2 d \sin (\phi)
$$

where $n$ is an integer, $\lambda$ is the photon wavelength, $d$ is the bond length $(0.28 \mathrm{~nm})$, and $\phi$ is the photon angle of incidence $\left(\frac{\pi}{4} \mathrm{rad}\right)$. All artifacts and photopeaks are modeled as gaussian curves. Photopeaks and artifacts are shown in figure 2.2 . 

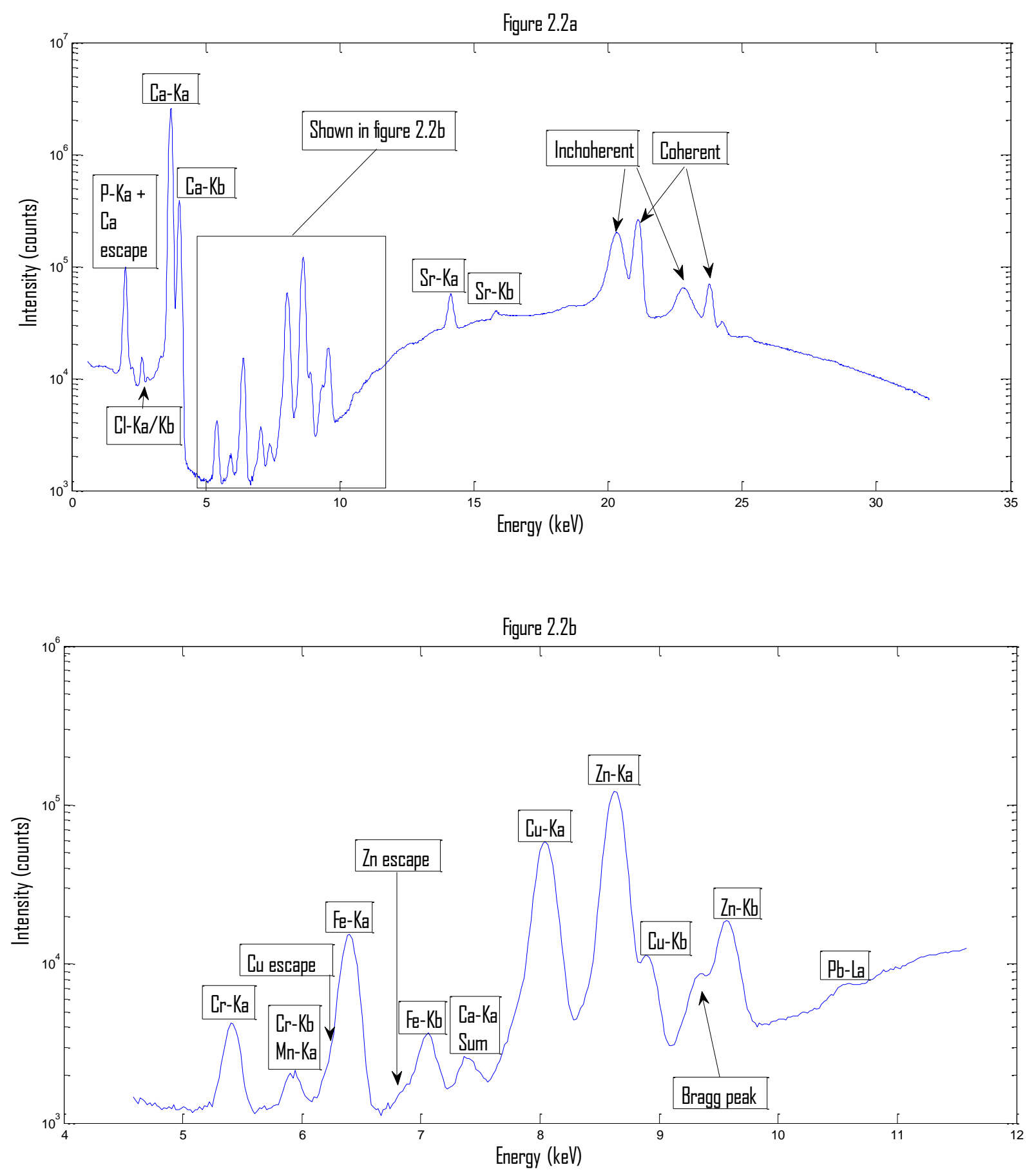

Figure 2.2: a) The complete energy spectrum of a tooth sample analyzed in this work with peaks labeled. Phosphorus-K $\alpha$ and calcium- K $\alpha$ escape peaks overlap at $2 \mathrm{keV}$. b) A cutout of the region between 4.5 and $11.5 \mathrm{keV}$ showing transition metals photopeaks and artifacts is shown. Bragg peaks are at 6.3 and $9.4 \mathrm{keV}$. Escape peaks of $\mathrm{Cu}$ and $\mathrm{Zn}$ are centered at 6.3 and $6.9 \mathrm{keV}$, respectively. Photopeak energies were taken from the National Institute for Standards and Technology (NIST) X-ray Transition Energies Database (150). The background was modeled as constant between 5-7 keV ( $\mathrm{Mn}$ and $\mathrm{Fe}$ ). $\mathrm{Cu}$ and $\mathrm{Zn}$ were fit separately with a background that was linear between 7.5 and $9 \mathrm{keV}$. Pb was fit separately with a linear background between 10.2 and $10.8 \mathrm{keV}$ for L $\alpha$, and 12.2 and 12.8 for $\mathrm{L} \beta$. 
Since gaussians are non-linear functions, it was necessary to use non-linear least squares for the curve fitting. The methods used have been described elsewhere $(151,152)$.

The general non-linear model for $n$ observations $\left(\boldsymbol{x}_{\boldsymbol{i}}, \boldsymbol{y}_{i}\right), i=1,2, \ldots, n$, with a functional relationship $f$, is

$$
\boldsymbol{y}_{\boldsymbol{i}}=f\left(\boldsymbol{x}_{\boldsymbol{i}} ; \boldsymbol{\theta}^{*}\right)+\boldsymbol{E}_{\boldsymbol{i}}
$$

where

$\boldsymbol{E}_{\boldsymbol{i}}$ represents a stochastic error (detector noise) with $\mathrm{E}\left[\boldsymbol{E}_{\boldsymbol{i}}\right]=0$,

$f\left(\boldsymbol{x}_{\boldsymbol{i}} ; \boldsymbol{\theta}^{*}\right)$ represents the deterministic underlying model (photopeaks, artifacts, background), and

the true value $\boldsymbol{\theta}^{*}$ of $\boldsymbol{\theta}$ is known to belong to $\boldsymbol{\Theta}$, a subset of $\mathbb{R}^{\mathrm{p}}$ (the parameter space).

The proper estimation procedure depends on the errors, $\boldsymbol{E}_{\boldsymbol{i}}$, which are assumed to have the following form

$$
\boldsymbol{E}_{\boldsymbol{i}}=f\left(\boldsymbol{x}_{\boldsymbol{i}} ; \boldsymbol{\theta}^{*}\right)^{\xi} \boldsymbol{\varepsilon}_{\boldsymbol{i}}
$$

where

$\xi=1 / 2$ for Poisson noise and

$\boldsymbol{\varepsilon}_{\boldsymbol{i}}$ are identically distributed random variables with zero mean and finite variance $\sigma^{2}$.

The least squares estimator $\widehat{\boldsymbol{\theta}}$ is obtained by finding the global minimum of the error surface

$$
C(\boldsymbol{\theta} \mid \boldsymbol{Y})=\sum_{i=1}^{n} \boldsymbol{w}_{\boldsymbol{i}}\left[\boldsymbol{Y}_{\boldsymbol{i}}-f\left(\boldsymbol{x}_{\boldsymbol{i}} ; \boldsymbol{\theta}\right)\right]^{2}
$$

where

$$
\boldsymbol{w}_{\boldsymbol{i}}=\frac{1}{f\left(\boldsymbol{x}_{\boldsymbol{i}} ; \boldsymbol{\theta}\right)^{2 \xi}}
$$

Then 


$$
\widehat{\boldsymbol{\theta}}=\underset{\boldsymbol{\theta}}{\operatorname{argmin}} C(\boldsymbol{\theta} \mid \boldsymbol{Y})
$$

The optimization in equation (7) was carried out using a weighted non-linear least squares method that employed the Levenberg-Marquadt algorithm $(153,154)$ in MATLAB. The specific model for $k$ gaussians with a constant background $\left(\boldsymbol{\theta}_{1}\right)$ is given by

$$
f\left(\boldsymbol{x}_{i} ; \boldsymbol{\theta}^{*}\right)=\boldsymbol{\theta}_{1}+\sum_{n=0}^{k-1} \boldsymbol{\theta}_{3 n+2} \exp \left[\frac{-\left(\boldsymbol{x}_{i}-\boldsymbol{\theta}_{3 n+3}\right)^{2}}{2 \boldsymbol{\theta}_{3 n+4}{ }^{2}}\right]
$$

The convexity of the error surface was tested with randomized initial estimators $\boldsymbol{\theta}$ that searched for local minima on the error surface. A multistart algorithm initialized with 200 different vectors containing random values for all parameters consistently converged on the same solution, suggesting that the error surface of this model in convex.

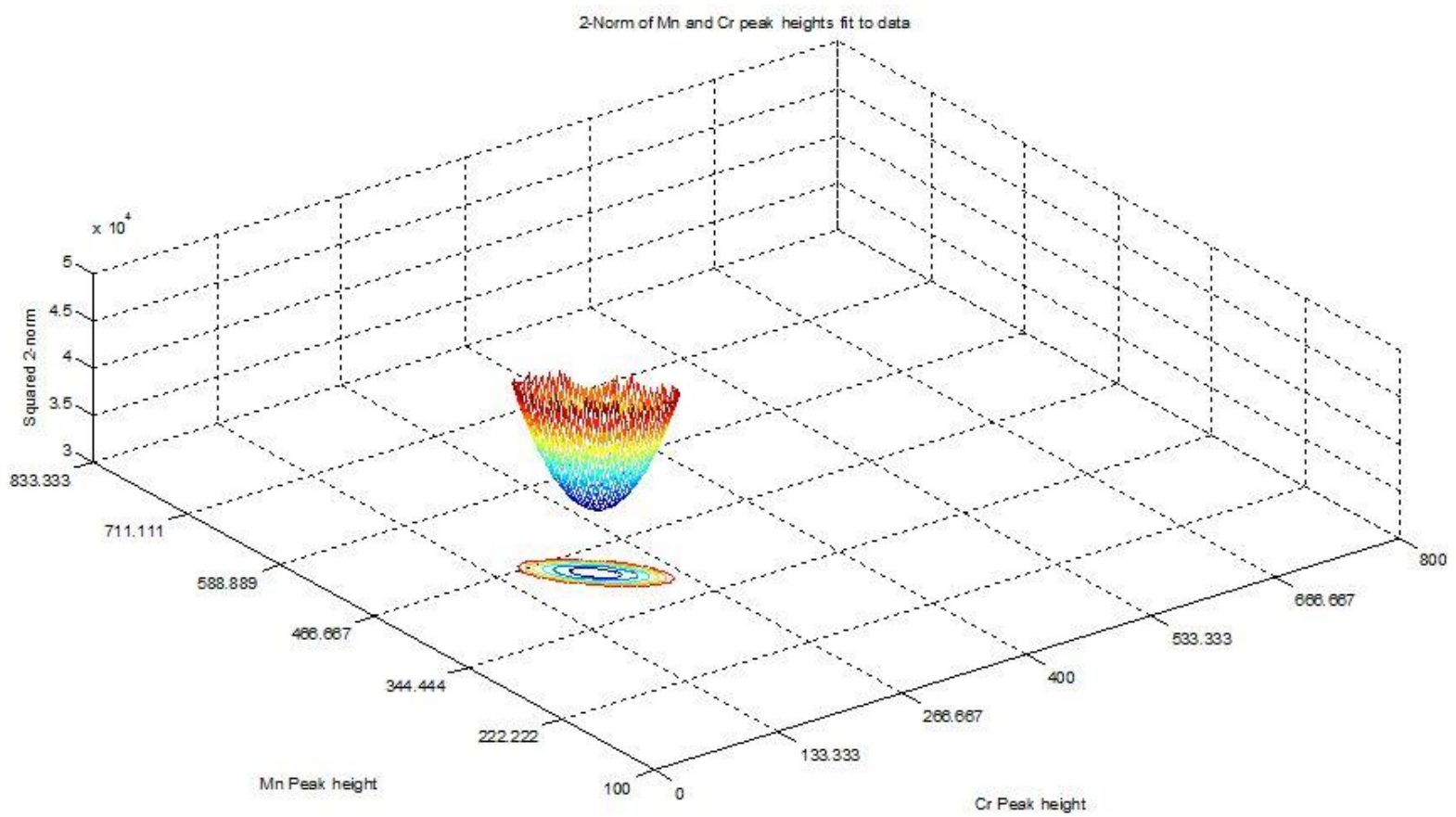

Figure 2.3: A 2-dimensional error surface for over-lapping $\mathrm{Mn}$ and $\mathrm{Cr}$ peaks. For visual representation of the convexity of the error surface, all parameters other than $\mathrm{Mn}$ and $\mathrm{Cr}$ peak heights were fixed. 
The global minimum on the error surface does not necessarily correspond to the physical reality in the sample, however. Noise in the detector can cause fluctuations on the error surface that result in nonphysical results if parameters such as the $\mathrm{K} \alpha / \mathrm{K} \beta$ intensity ratio of analytes are not fixed. To show this, synthetic data sets were created using a method described in Numerical Methods in C++ (155). Figure 2.4 shows the optimization of five synthetic data sets that were created with the same deterministic model containing overlapping $\mathrm{Cr}-\mathrm{K} \beta$ and $\mathrm{Mn}-\mathrm{K} \alpha$ peaks with the addition of stochastic Poisson noise to mimic that of the detector. Since the $\mathrm{K} \alpha / \mathrm{K} \beta$ intensity ratio of $\mathrm{Cr}$ was not fixed, fluctuations in noise caused important differences in parameter estimation, shown in figure 2.4.
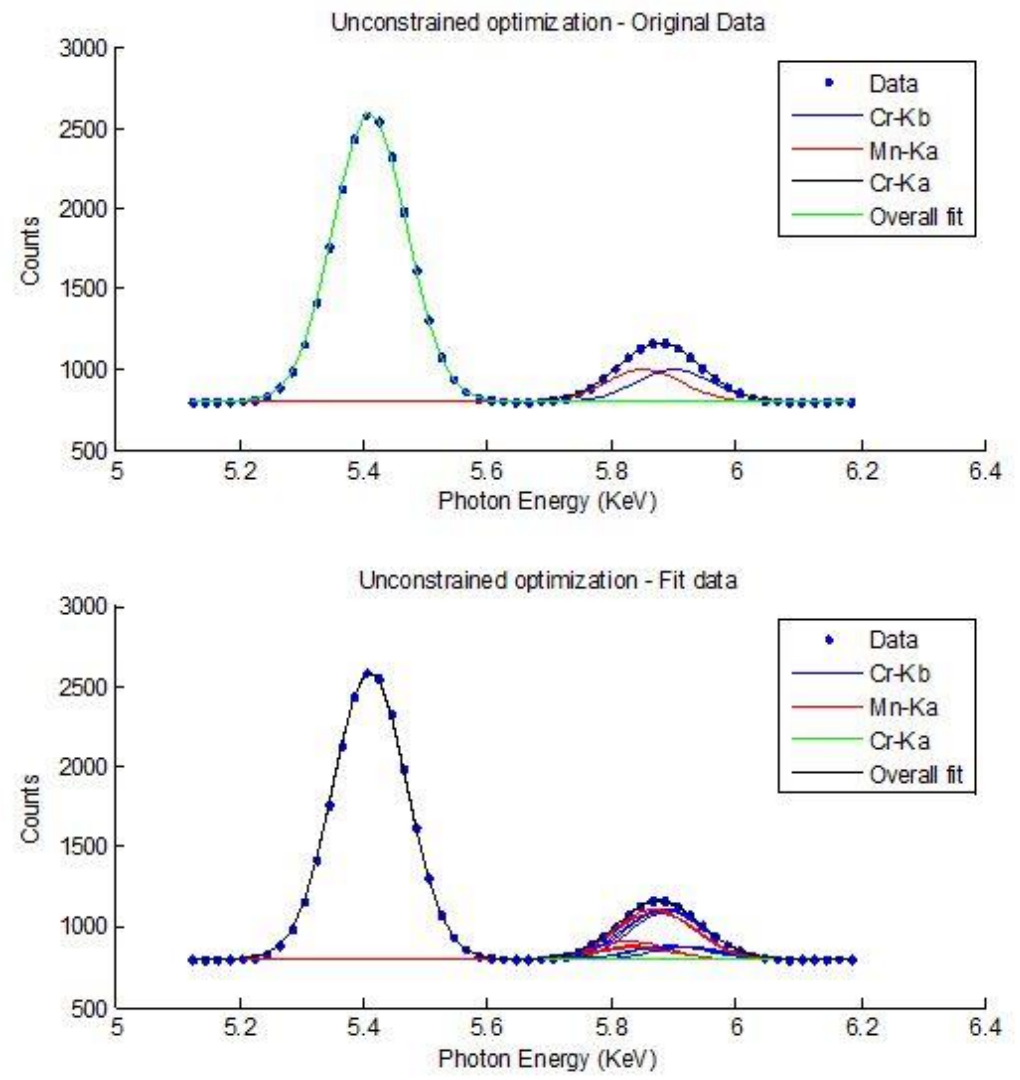

Figure 2.4: Plots showing unconstrained optimization of over-lapping gaussian peaks. The upper plot shows the deterministic model of $\mathrm{Mn}-\mathrm{K} \alpha$ (red) and $\mathrm{Cr}-\mathrm{K} \beta$ (blue) peaks. The $\mathrm{Cr}-\mathrm{K} \alpha$ peak cannot be seen due to overlap by the overall fit line. The lower plot shows the results of fitting five plots with different stochastic noise. 
However, if the $\mathrm{K} \alpha / \mathrm{K} \beta$ intensity ratio of $\mathrm{Cr}$ is fixed at the physical value of 7.3 given by Rebohle and colleagues (156) and the optimization is constrained within a physically plausible parameter space, the outcome is a more accurate and precise estimation of parameters. This constraint of the $\mathrm{K} \alpha / \mathrm{K} \beta$ peak areas $[($ height $\times$ width $) \alpha /($ height $\times$ width $) \beta]$ is set as a nlincon M-file that is called by the fmincon solver in MATLAB. Alternatively, the lsqnlinfit can be used if the height of the $\mathrm{K} \beta$ peak height is modeled as being $0.1369 \times \mathrm{Cr}-\mathrm{K} \alpha$ peak height with box constraints around both the peak height and peak area of the $\mathrm{Cr}-\mathrm{K} \beta$. Figure 2.5 shows the same model and noise that as is shown above in figure 2.4 , but with the $\mathrm{K} \alpha / \mathrm{K} \beta$ intensity ratio of $\mathrm{Cr}$ fixed in the fitting routine.
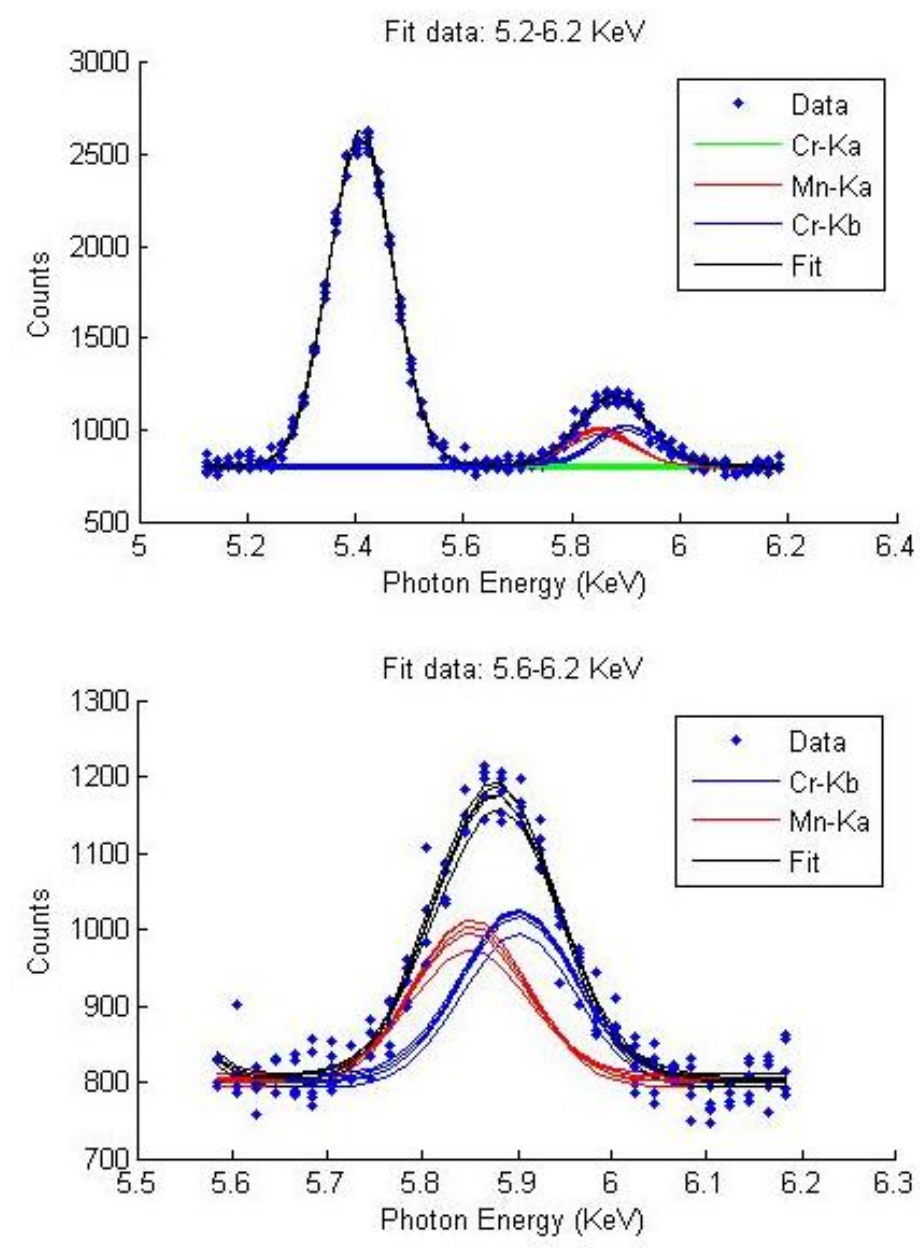

Figure 2.5: Plots showing the results of constrained optimization of over-lapping gaussian peaks. The bottom plot shows the results of the fitting of five data sets with stochastic noise. The reduction of fluctuations in parameter estimates is clearly visible and the accuracy of the fits compared to the model in the upper plot of figure 2.4 can be seen also. 


\subsection{Hydroxyapatite calibrators and figures of merit}

Calibration of the EDXRF system used in this work was carried out with novel hydroxyapatite (HAp) calibrators that were developed for the purpose of quantifying trace metals in calcified tissues (157). The preparation of synthetic HAp also enabled the development of calibrators that were free from impurities that can be detrimental to the determination of analytical figures of merit of a system.

Figures of merit for the EDXRF system that was used include limits of detection (LOD) and analytical sensitivities for various analytes. LODs are based on true blank calibrator measurements that are matrixmatched to the sample, but contain none of the analyte. The limit of detection is taken as the concentration of analyte that generates three times the standard deviation $(3 \sigma)$ of repeated measurements of a blank calibrator (149).Triplicate measurements of a true blank calibrator were run under the same experimental conditions described above. LODs are shown for each of the analytes in table 2.3. The analytical sensitivity is the net change of the photopeak area of an analyte per unit concentration change of that analyte (158). The $\mathrm{R}^{2}$ value represents the closeness of the data points of the calibration curve to the line that is fit to the data and the intercept is simply the y-intercept of the calibration line.

Table 2.3: Figures of merit for the EDXRF measurement of divalent metals in tooth enamel

\begin{tabular}{lcccc}
\hline Element & $\begin{array}{c}\text { Limit of } \\
\text { detection } \\
(\mathbf{p p m})\end{array}$ & $\begin{array}{c}\text { Analytical } \\
\text { sensitivity } \\
\left(\mathbf{p p m}^{-1} \mathbf{s}^{-\mathbf{1}}\right)\end{array}$ & $\begin{array}{c}\text { Intercept } \\
\text { (unitless) }\end{array}$ & $\mathbf{R}^{\mathbf{2}}$ \\
\hline Manganese & 1.6 & 7.9 & $10^{-19}$ & 0.99 \\
Iron & 6.5 & 6.7 & $10^{-17}$ & 0.98 \\
Copper & 1.8 & 2.3 & $10^{-17}$ & 0.98 \\
Zinc & 1.7 & 2.6 & $-10^{-17}$ & 0.97 \\
Lead & 0.6 & 9.4 & $10^{-18}$ & $0.87 \dagger$ \\
\hline$\dagger \mathrm{R}^{2}$ value for Pb-L $\alpha$ was 0.98, however, because it can potentially overlap with As in samples, \\
$\mathrm{L} \beta$ was used instead.
\end{tabular}


The high analytical sensitivity of iron and manganese suggests that there may be some secondary excitation of these elements in the sample. Sensitivity is increased by having a higher fraction of excitation photons at, or slightly above, the absorption edge of the analyte. It may be possible that x-ray diffraction in the sample caused secondary fluorescence in the sample or in the housing of the detector. However, the $\mathrm{R}^{2}$ values of 0.99 and 0.98 suggest that the response of the manganese and iron signals increase linearly with increasing concentration.

The $\mathrm{R}^{2}$ value of lead at the $\mathrm{L} \beta$ line was 0.87 . There were several challenges inherent to the analysis of the L-series of lead in HAp. Firstly, the Pb-L $\alpha(10.5 \mathrm{keV})$ overlapped completely with arsenic (As) K $\alpha$. This peak overlap makes it impossible to attribute the source of a gaussian signal at $10.5 \mathrm{keV}$ directly to $\mathrm{Pb}$. Secondly, when the excitation source is incident at $45^{\circ}$ to the c-axis of the HAp crystal, a Bragg diffraction peak will directly overlap with $\mathrm{Pb}-\mathrm{L} \beta(12.5 \mathrm{keV})$. Bragg diffraction is minimized by rotating the sample but cannot be completely eliminated. A third analytical challenge for the L-series of $\mathrm{Pb}$ was the high background at 10.5-12.5 keV. This background could not be reduced by a $\mathrm{Cu}$ filter over the x-ray tube excitation source because a medium-Z filter would significantly reduce the analytical sensitivity of the lower-Z elements Mn and Fe. As a result of necessary compromises for the multi-elemental method, the quantification of $\mathrm{Pb}$ is accompanied by a higher level of uncertainty than the other analytes in this work.

Analyte concentrations were extracted using the ratio of analyte signal intensity to calcium signal intensity (ie. calcium normalization). The use of an internal standard for in situ measurements in EDXRF analysis corrects for surface irregularities in samples relative to the flat surface of the calibrator, assuming that the analyte distributes similarly to the standard in the sample (149). Calcium normalization has previously been used for quantification of trace metals in teeth using XRF spectrometry $(148,159-161)$ and other analytical methods $(26,107,112)$. Variations in calcium content of samples represent a source of uncertainty in EDXRF measurements of enamel. Zaichick and colleagues quantified the calcium content of intact deciduous teeth to be $38.9 \pm 1.1 \%$ (162). Therefore, variations in calcium content are estimated to contribute to an uncertainty of approximately $6 \%$ of all analytes. 
An additional source of uncertainty is heterogeneity of analytes within the sample. However, since this method employs a broad excitation beam and the sample is rotated in the horizontal plane during the measurement, the effect of heterogeneity is minimized.

The mean relative standard deviation (RSD) of the analytical curve fitting between triplicate sample measurements of $\mathrm{Mn}, \mathrm{Fe}, \mathrm{Cu}, \mathrm{Zn}$ and $\mathrm{Pb}$ were $7.4 \%, 6.7 \%, 6.5 \%, 2.1 \%$ and 32\%, respectively. The RSD of $\mathrm{Zn}$ measurements in this work is an improvement on the EDXRF method of Zaichick and colleagues, which had an RSD of 9.4\% for Zn (161). Although Zaichick and colleagues quantified $\mathrm{Pb}$ in the same work, they did not report the RSD or uncertainty of $\mathrm{Pb}$ measurements, nor did they factor heterogeneity of $\mathrm{Zn}$ within samples into the uncertainty estimate (161). The relative standard error (RSE) of each measurement of $\mathrm{Mn}, \mathrm{Fe}, \mathrm{Cu}, \mathrm{Zn}$ and $\mathrm{Pb}$ were $4.3 \%, 3.9 \%, 3.8 \%, 1.2 \%$ and $18 \%$, respectively.

Considering heterogeneity within samples and variations in the calcium content of teeth (systemic uncertainty), and the RSE of measurements (statistical uncertainty), the quantitative results of this work should be considered in the context of measurement uncertainty that may be as high as $20 \%$ for $\mathrm{Mn}, \mathrm{Fe}$, $\mathrm{Cu}$ and $\mathrm{Zn}$, and as high as $40 \%$ for $\mathrm{Pb}$. For example, this means that the true value of a $[\mathrm{Pb}$ ] should fall within the range of $\pm 40 \%$ of the stated $[\mathrm{Pb}], 95 \%$ of the time $(2 \sigma)$.

Increasing the number of measurements of a given sample would reduce the RSE, thereby decreasing the statistical uncertainty. However, systemic uncertainty is inherent in each sample and could only be reduced by accurately measuring calcium concentrations within the critical depth of measurement for $\mathrm{Ca}$ in each sample.

Other methods for quantification of trace elements in tooth enamel include proton-induced x-ray excitation (PIXE), LA-ICP-MS, and XRF using synchrotron light source excitation. Unfortunately, it is difficult to determine the uncertainty of many methods in the literature as they are often unreported. For XRF measurements using synchrotron light source excitation, uncertainty for all elements, regardless of 
their concentrations, was estimated to be $15 \%(159,160)$. Uncertainty for quantification using PIXE was reported to be approximately $20 \%$ by Ahlberg and colleagues (163).

LA-ICP-MS measurements of teeth were calibrated with a single point NIST Bone Meal (SRM 1486) calibrator, and the accuracy of the method was quoted as $\pm 20 \%$ (164). The content of calcium in NIST Bone Meal is $26.58 \pm 0.24 \%$ (w/w), whereas the content of calcium in hydroxyapatite is $39.89 \%$ (w/w). That gives a 33\% difference in the concentration of internal standard of the calibrator and the primary component of the sample being measured. Furthermore, there was no test of precision by repeated measurements of low concentration analytes in any aforementioned methods, nor was there validation using a secondary method.

\subsection{Statistical treatment of data}

All statistical analysis of data was carried out using SPSS version 17. Shapiro-Wilk tests were used to show that all of the data regarding concentrations of analytes in teeth were non-normally distributed. Kruskal-Wallis tests were used as a substitute for one-way ANOVA as a non-parametric test for comparing median values of concentrations in different types of teeth (incisor, canine, molar). Correlations between analyte concentrations were carried out using Pearson's r (parametric), Spearman's $\rho$ (non-parametric) and Kendall's $\tau$ (non-parametric) tests. Where correlations were found, linear regression analyses using appropriate covariates were performed to ensure that results were unbiased. All tests of hypotheses were two-tailed. 



\section{Chapter 3}

\section{Results and discussion}

\subsection{Manganese}

Descriptive statistics for manganese in children's tooth enamel are shown in Table 3.2. The range of enamel-[Mn] in this work show close agreement with values measured in teeth by Oprea and colleagues, who found enamel-[Mn] ranged between 9.2-130 ppm (165). Some smaller samples in the literature had a more narrow range of values $(159,160)$. However, the mean value in this work of 29 ppm falls between the mean values in the two studies cited. It must also be noted that the method for quantifying Mn in enamel in these two studies used a synchrotron x-ray beamline with cross sections of molars. The scan of the x-ray beam measured the molar enamel between the occlusal surface and the dentine (159), which is not the same site of measurement as was used in this study. The average relative standard deviation between teeth donated from the same child was $23.3 \%$.

Table 3.1

\begin{tabular}{ccccc}
\hline \multicolumn{5}{c}{ Descriptive Statistics of Mn in tooth enamel } \\
\hline $\begin{array}{c}\text { Number of } \\
\text { samples }\end{array}$ & Minimum & Maximum & Mean & Variance \\
\hline 178 & $8 \mathrm{ppm}$ & $109 \mathrm{ppm}$ & $29 \mathrm{ppm}$ & $231 \mathrm{ppm}^{2}$ \\
\hline
\end{tabular}


The distribution of measured enamel-[Mn] is shown in figure 3.1 to have a tail in the distribution at higher concentrations. The non-normality of the data was confirmed with a Shapiro-Wilk test $(\mathrm{p}<0.001)$.

The average enamel-[Mn] across all of the teeth donated by each of the 80 children participating in this work was calculated. Similarly to the individual teeth, the distribution was shown to be non-normal $(\mathrm{W}=$ $0.79, \mathrm{p}<0.001)$ with a tail at higher concentrations of manganese.

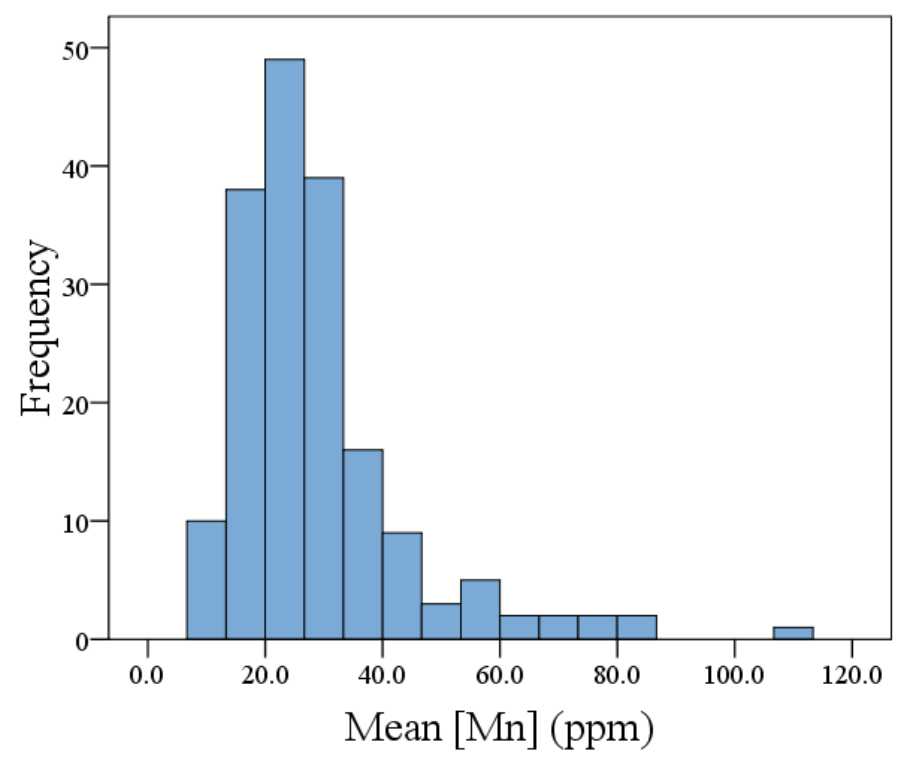

Figure 3.1: Histogram showing the distribution of manganese concentrations of all teeth measured in this study

A Kruskall-Wallis test confirmed that incisors have a higher concentration of manganese than canines and molars ( $\mathrm{p}<0.001)$. This resulted in a different approach to the analysis of enamel as a biomarker because not all children participating in this work donated the same number and same type of teeth. Separate regression analyses were performed for incisors, molars, canines, all teeth, and the average concentration for each child. As a cautionary note, it should be stated that this approach violates the assumption of independent samples that underlies regression analysis. However, since the maximum number of teeth donated by a single child is five (mean $=2.2$ ), the influence of the failure in the 
assumption should not be important. On the other hand the failure in normality implies that the reported p-values may not be accurate. The boxplot in figure 3.2 shows the concentrations of three different tooth types: incisors, canines and molars.

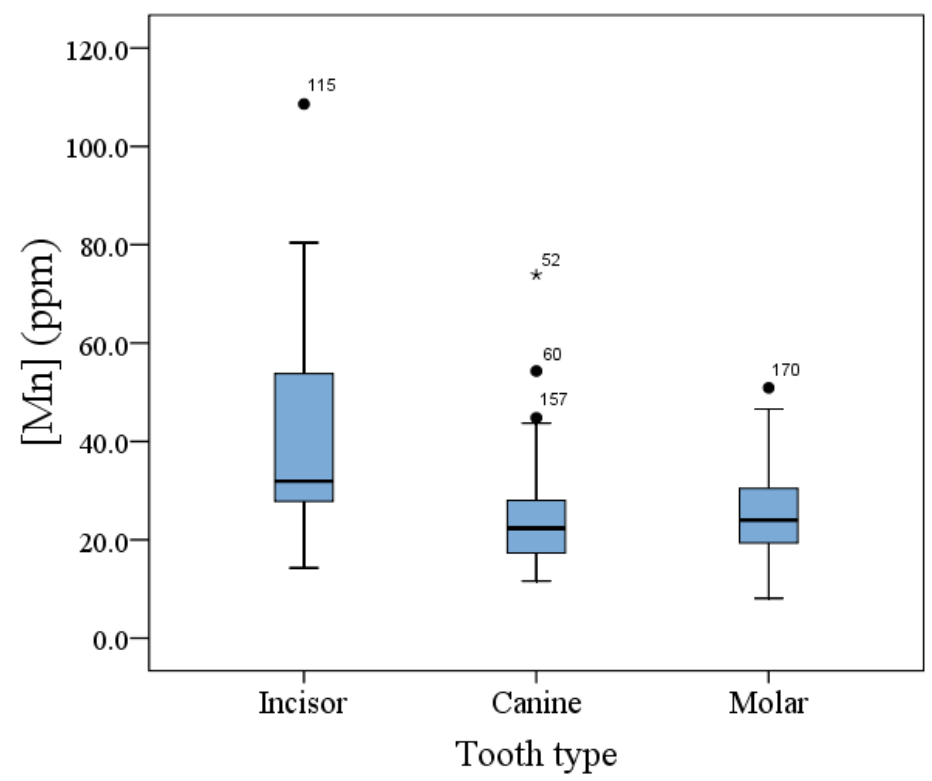

Figure 3.2: Boxplot showing the concentration of manganese for incisors, canines and molars. A Kruskal-Wallis test showed that at least one group had a median that was significantly different from the population median ( $\mathrm{p}<0.001)$. The median value is depicted as a black line in the center of the box. The second and third quartiles are the boxes on either side and the first and fourth quartiles are depicted by the whiskers below and above the boxes. Outliers are shown as points outside of the whiskers.

\subsubsection{Relationships between manganese in enamel and exposure pathways}

Divalent manganese ions have been shown to substitute for calcium in hydroxyapatite (166). To investigate the possibility of manganese substituting for calcium in erupted tooth enamel, a linear regression of the concentration of manganese as a function of the estimated dietary and tap water intakes of [Mn] was undertaken. Non-parametric (Spearman's rho and Kendall's tau) and parametric (Pearson's r) tests were used to investigate correlations between $\mathrm{Mn}$ intake and enamel-[Mn]. 
Linear regression showed that in all teeth that were measured, there was a weak positive correlation between dietary-Mn and enamel-[Mn]. This result may reflect the exchange of ions at the surface of enamel while a child is exposed to Mn from eating/drinking. It is interesting that the correlation of enamel-[Mn] and dietary-Mn was strongest among incisors. Furthermore, these teeth also have significantly higher enamel-[Mn] than canines and molars (Kruskal-Wallis, $\mathrm{p}<0.001)$.

Table 3.2: Correlations of enamel-[Mn] and dietary-Mn

\begin{tabular}{|c|c|c|c|c|c|c|c|c|c|c|}
\hline \multirow[b]{3}{*}{ Correlation } & \multicolumn{10}{|c|}{ Cases } \\
\hline & \multicolumn{2}{|c|}{ Incisor } & \multicolumn{2}{|c|}{ Canine } & \multicolumn{2}{|c|}{ Molar } & \multicolumn{2}{|c|}{ All teeth } & \multicolumn{2}{|c|}{ Average } \\
\hline & Statistic & $\mathrm{p}$ & Statistic & $\mathrm{p}$ & Statistic & $\mathrm{p}$ & Statistic & $\mathrm{p}$ & Statistic & $\mathrm{p}$ \\
\hline Pearson's r & 0.27 & 0.07 & 0.13 & 0.39 & 0.16 & 0.14 & $0.29 * *$ & $<0.001$ & $0.33 * *$ & 0.002 \\
\hline Spearman's $\rho$ & $0.31 *$ & 0.04 & 0.03 & 0.82 & 0.06 & 0.56 & $0.22 * *$ & 0.004 & $0.30 * *$ & 0.007 \\
\hline Kendall's $\tau$ & $0.23 *$ & 0.03 & 0.00 & 0.99 & 0.04 & 0.61 & $0.14 * *$ & 0.006 & $0.21 * *$ & 0.007 \\
\hline
\end{tabular}

*Significant at $\mathrm{p}<0.05$

**Significant at $\mathrm{P}<0.01$

Non-parametric tests found a significant weak correlation between incisor-[Mn] and dietary-Mn consumption. Correlation coefficients are shown in Table 3.3. Linear regression showed no significant correlation between dietary-Mn and incisor-[Mn]. This can be observed by realizing that the hypothesis of $\beta=0$ cannot be rejected at a significance level of 0.07 . The linear regression line is shown in figure 3.3.

There were no non-parametric correlations observed between canine- or molar-[Mn] dietary-Mn. Linear regression showed no significant correlation between dietary-Mn and canine-[Mn]. 


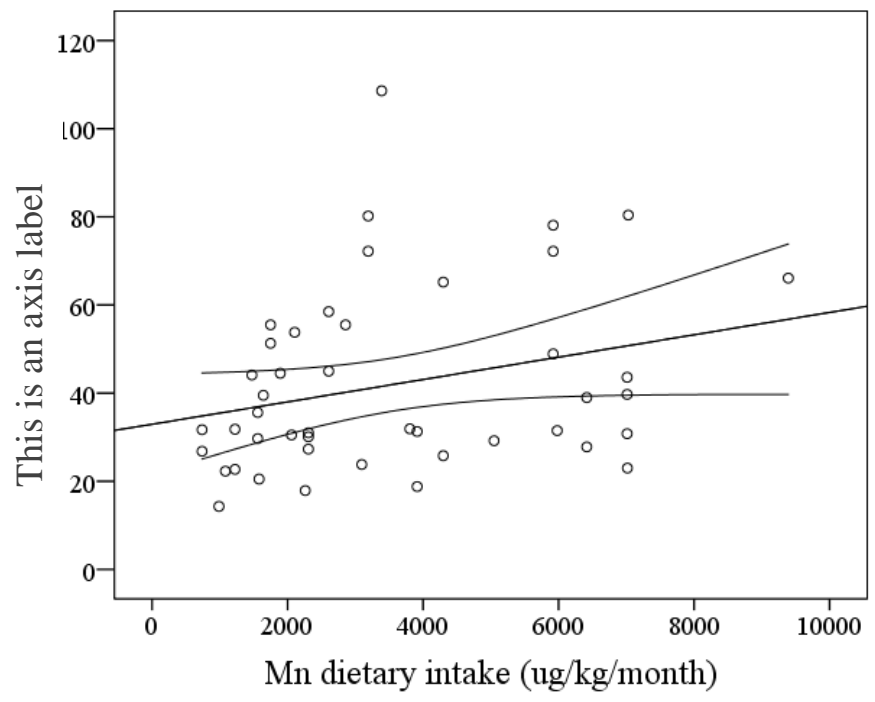

Figure 3.3: A linear regression line showing the relationship between manganese in incisor-[Mn] and dietary-Mn. Confidence intervals at the $95 \%$ level are shown above and below the regression line. Associated statistics are shown in table 3.3

Non-parametric tests found a significant weak correlation between all teeth-[Mn] and dietary-Mn. Linear regression showed significant correlation between dietary-Mn and all teeth-[Mn]. However, data were not normally distributed so this regression should be considered with knowledge that assumptions of normality are violated. The linear regression of all teeth-[Mn] and dietary-Mn is shown in figure 3.4.

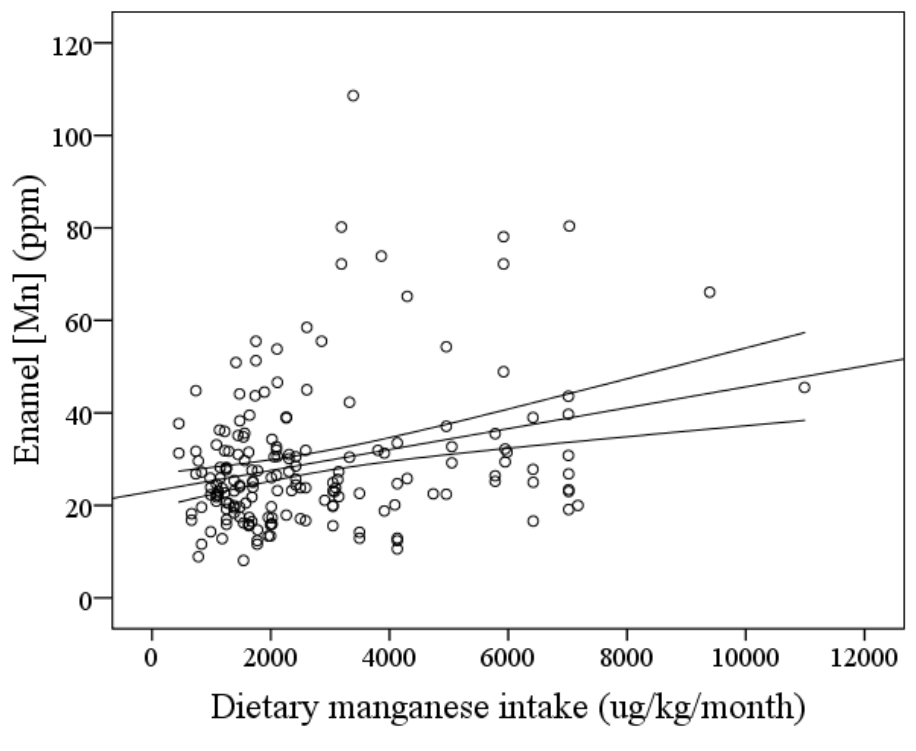

Figure 3.4: A linear regression line showing the relationship between manganese in all teeth-[Mn] and dietary-Mn. Confidence intervals at the $95 \%$ level are shown above and below the regression line. Associated statistics are shown in table 3.3 
Non-parametric tests found a significant weak correlation between the average-[Mn] across all teeth donated by each child and the dietary-Mn of each child as is shown in Table 3.3. Linear regression showed significant correlation between dietary-Mn and the average-[Mn] in all teeth from each child that participated. The hypothesis of $\beta=0$ can be rejected at a significance level of 0.002 . The linear regression line is shown in figure 3.5 .

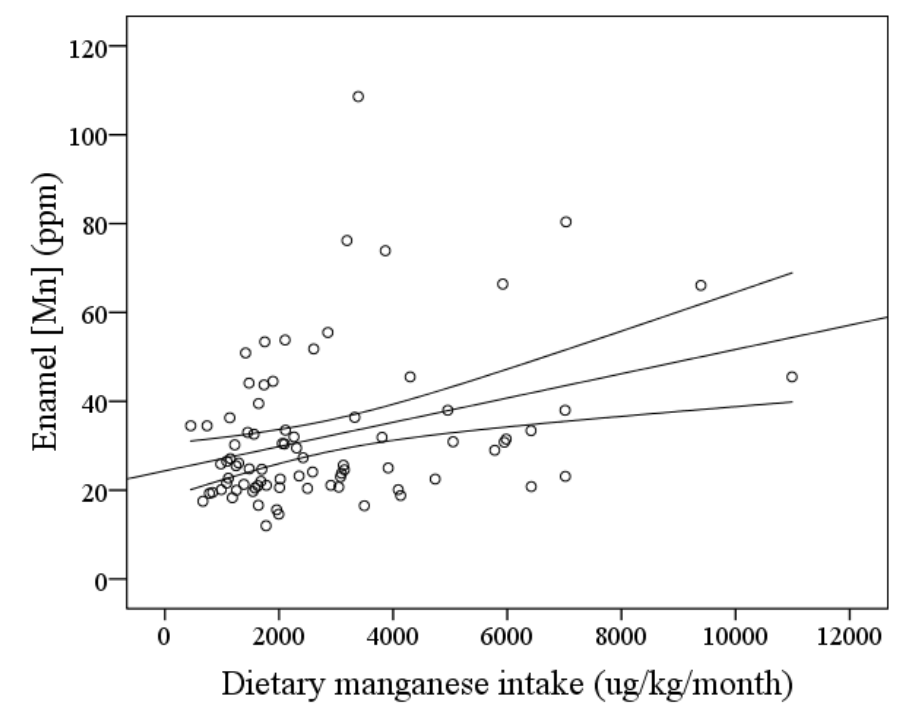

Figure 3.5: A linear regression line showing the relationship between manganese in average-[Mn] measured tooth enamel of each child and dietary-Mn. Confidence intervals at the $95 \%$ level are shown above and below the regression line. Associated statistics are shown in table 3.3

Tap water-Mn consumption estimates were made for each of the children in this work. Correlation data for tooth measurements and estimated tap water consumption are shown in table 3.4. 
Table 3.3: Correlations of enamel-[Mn] and tap water intake of $\mathrm{Mn}$

\begin{tabular}{|c|c|c|c|c|c|c|c|c|c|c|}
\hline \multirow[b]{3}{*}{ Correlation } & \multicolumn{10}{|c|}{ Cases } \\
\hline & \multicolumn{2}{|c|}{ Incisor } & \multicolumn{2}{|c|}{ Canine } & \multicolumn{2}{|c|}{ Molar } & \multicolumn{2}{|c|}{ All teeth } & \multicolumn{2}{|c|}{ Average } \\
\hline & Statistic & $\mathrm{p}$ & Statistic & $\mathrm{p}$ & Statistic & $\mathrm{p}$ & Statistic & $\mathrm{p}$ & Statistic & $\mathrm{p}$ \\
\hline Pearson's r & $0.49 * *$ & 0.001 & -0.02 & 0.89 & -0.09 & 0.41 & $0.31 * *$ & $<0.001$ & $0.41 * *$ & $<0.001$ \\
\hline Spearman's $\rho$ & 0.14 & 0.35 & 0.01 & 0.96 & 0.13 & 0.23 & 0.14 & 0.07 & 0.19 & 0.10 \\
\hline Kendall's $\tau$ & 0.09 & 0.38 & -0.01 & 0.94 & 0.09 & 0.22 & 0.10 & 0.06 & 0.12 & 0.11 \\
\hline
\end{tabular}

*Significant at $\mathrm{p}<0.05$

**Significant at $\mathrm{P}<0.01$

Non-parametric tests did not show significant correlation between incisor-[Mn] and tap water $\mathrm{Mn}$ consumption. Linear regression showed significant correlation between tap water intake of manganese and incisor-[Mn]. This correlation may be the result of very few children with high manganese intake from tap water having high enamel-[Mn]. The results of this regression may be unreliable because overall the data are not normally distributed.

There were no correlations observed between canine- or molar-[Mn] and tap water intakes of Mn. Linear regression showed no significant correlation between tap water intake of manganese and canine-[Mn], therefore the null hypothesis of $\beta=0$ cannot be rejected.

Non-parametric tests did not show a correlation between all teeth-[Mn] and tap water Mn consumption at level $<0.05$. However the p-values observed, 0.06 and 0.07 , are close enough to suggest a possible correlation between these variables. Linear regression showed a significant correlation between tap water intake of manganese all teeth-[Mn]. The results of this regression may be unreliable because overall the data are not normally distributed. However the p-value is small enough to lead to rejection of nocorrelation even under these violations. 


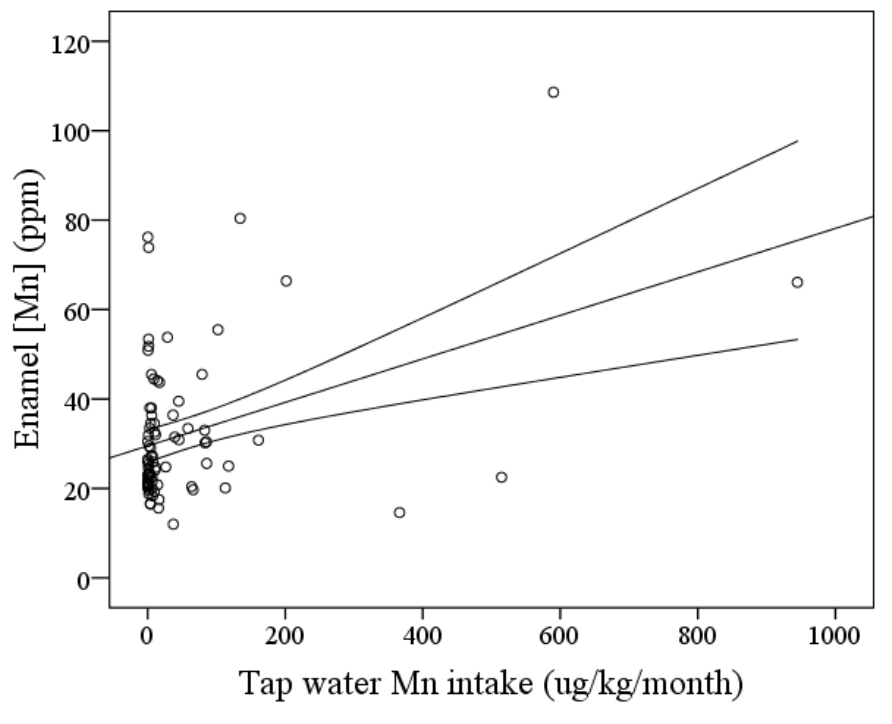

Figure 3.6: A linear regression line showing the relationship between average-[Mn] in all measured tooth enamel from each child and tap water intake of Mn. Confidence intervals at the $95 \%$ level are shown above and below the regression line. Associated statistics are shown in Table 3.4.

Non-parametric tests did not show a correlation between the average-[Mn] in teeth donated by the same child and tap water Mn consumption. The p-values of the non-parametric tests are low (0.10 and 0.11) and indicate that there is a possibility of a relationship between $\mathrm{Mn}$ in tap water and enamel-[Mn]. Furthermore, linear regression showed a significant correlation between tap water intake of manganese and average- $[\mathrm{Mn}]$ in all children measured. However, the results of this regression may be unreliable because overall the data are not normally distributed. The linear regression line is shown in figure 3.6. Many of the children participating in this work had recently moved to the location that they lived in while tests were taken and their dietary intake was estimated, potentially creating bias. To account for this, correlations were measured excluding children who had not been living in the same location for a minimum number of months, shown on the $\mathrm{x}$-axis of figure 3.8 . 


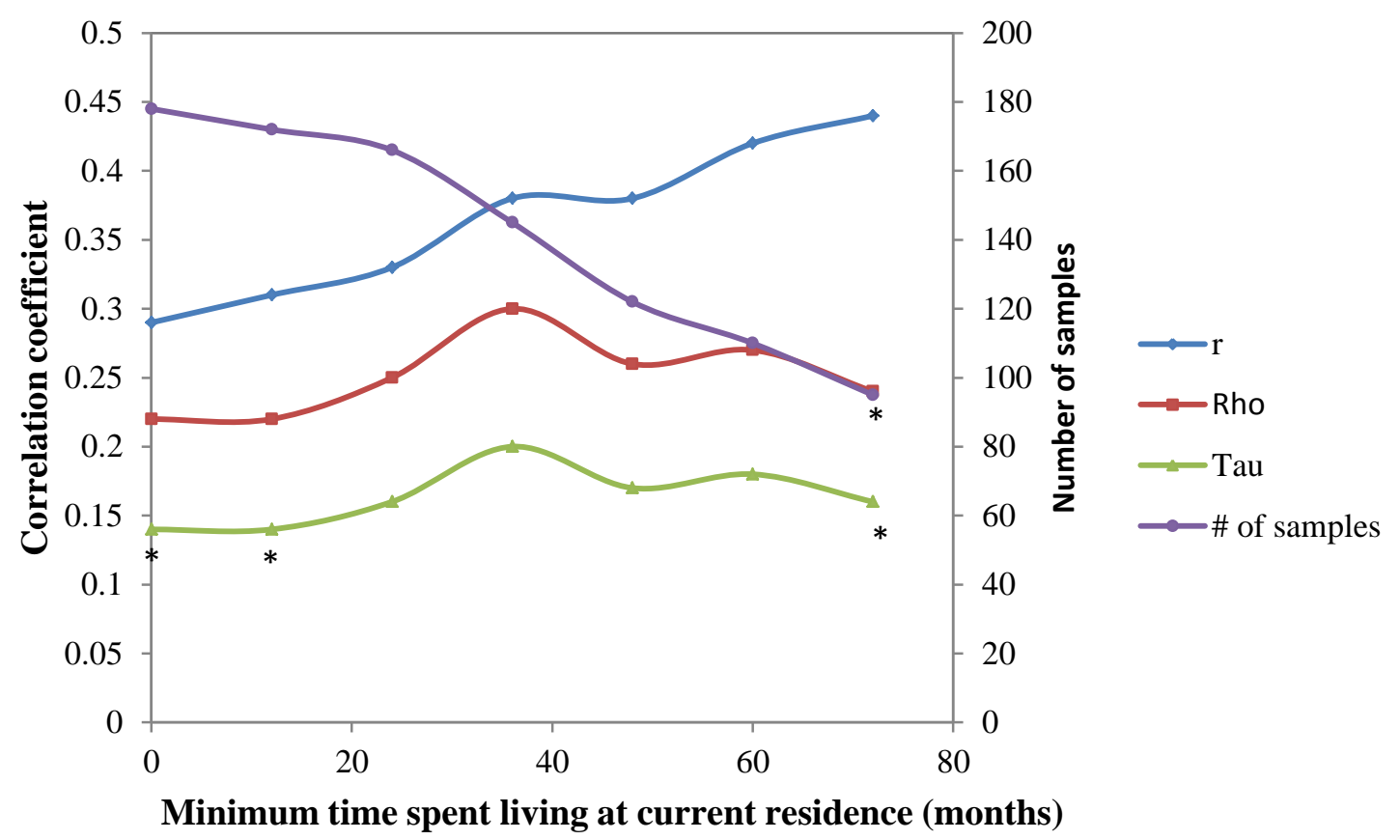

Figure 3.7: Correlation coefficients of dietary-Mn and enamel-[Mn] as a function of the duration at current residence. All data points correspond to $\mathrm{p}<0.01$ except for those with marked *. Legend entries r, Rho, and Tau correspond to the Pearson, Spearman and Kendall correlation coefficients, respectively. The number of samples decreases with increasing minimum time spent living at the current residence as children who moved more recently are excluded.

The sample population was divided into two groups: one that had been living in the residence that the dietary and tap water intake estimates had been performed for more than five years, the other had moved into the current residence within the last five years. Mann Whitney and Wilcoxon Rank Sum tests were performed to look for significant differences between the two groups. However, no significant difference was observed $(\mathrm{p}=0.46)$.

Figure 3.8 shows an increasing trend in Mn correlation as a function of the minimum time spent living in the same location. To the author's knowledge, this work is the first investigation of an exposure-effect investigation between dietary manganese and $[\mathrm{Mn}]$ in tooth enamel. There is interest in archeology in non-destructive quantification of trace metals in calcified tissue with the aim of gaining insight into dietary habits of pre-historic humans (159). 
Although the results or the current work show a weak correlation, they may provide some information about the differences in trace metals that have been observed in previous, population-based investigations (160). Pinheiro and colleagues have observed increases in the concentration of strontium (Sr) and bromine $(\mathrm{Br})$ of a fisherman relative to the $[\mathrm{Sr}]$ and $[\mathrm{Br}]$ of a miner from the same region, which was hypothesized to result from a diet rich in fish (167). Conversely, the miner had elevated levels of [Zn] and $[\mathrm{Pb}]$ in his teeth, which was suggested to originate from occupational exposures to these metals (167). The current work shows that dietary-Mn correlates weakly with enamel-[Mn] $(\mathrm{p}<0.01)$. Although there may be a very weak correlation between tap water $\mathrm{Mn}$ and enamel-[Mn], the p-value associated with the Spearman correlation $(\mathrm{p}=0.10)$ suggests that our confidence in this assertion should be low. This makes

sense considering the median tap water Mn ingested was $6.5 \mu \mathrm{g} / \mathrm{kg} / \mathrm{month}$ compared to $2100 \mu \mathrm{g} / \mathrm{kg} / \mathrm{month}$ dietary-Mn.

\subsubsection{Relationships between manganese and children's height}

Manganese may affect normative development of calcified tissues although the mechanisms of action have not been clearly defined. Manganese has been shown to increase alkaline phosphatase activity both in vitro (168) and in vivo (169), suggesting a positive role in the development of bone tissue. Conversely, manganese is has been shown to inhibit the formation of hydroxyapatite crystals (166).

Relationships between Mn and growth outcomes have been investigated. Age was included as a covariate in a linear regression model to avoid biasing the results. Correlation coefficients between enamel-[Mn] and children's height are shown in Table 3.5. 


\begin{tabular}{|c|c|c|c|c|c|c|c|c|c|c|}
\hline \multirow[b]{3}{*}{ Correlation } & \multicolumn{10}{|c|}{ Cases } \\
\hline & \multicolumn{2}{|c|}{ Incisor } & \multicolumn{2}{|c|}{ Canine } & \multicolumn{2}{|c|}{ Molar } & \multicolumn{2}{|c|}{ All teeth } & \multicolumn{2}{|c|}{ Average } \\
\hline & Statistic & $\mathrm{p}$ & Statistic & $\mathrm{p}$ & Statistic & $\mathrm{p}$ & Statistic & $\mathrm{p}$ & Statistic & $\mathrm{p}$ \\
\hline Pearson's r & 0.00 & 0.99 & -0.19 & 0.21 & -0.14 & 0.20 & $-0.31 * *$ & $<0.001$ & $-0.41 * *$ & $<0.001$ \\
\hline Spearman's $\rho$ & -0.12 & 0.43 & -0.20 & 0.18 & -0.17 & 0.12 & $-0.33 * *$ & $<0.001$ & $-0.47 * *$ & $<0.001$ \\
\hline Kendall's $\tau$ & -0.10 & 0.36 & -0.11 & 0.28 & -0.12 & 0.12 & $-0.23 * *$ & $<0.001$ & $-0.34 * *$ & $<0.001$ \\
\hline
\end{tabular}

*Significant at $\mathrm{p}<0.05$

** Significant at $\mathrm{P}<0.01$

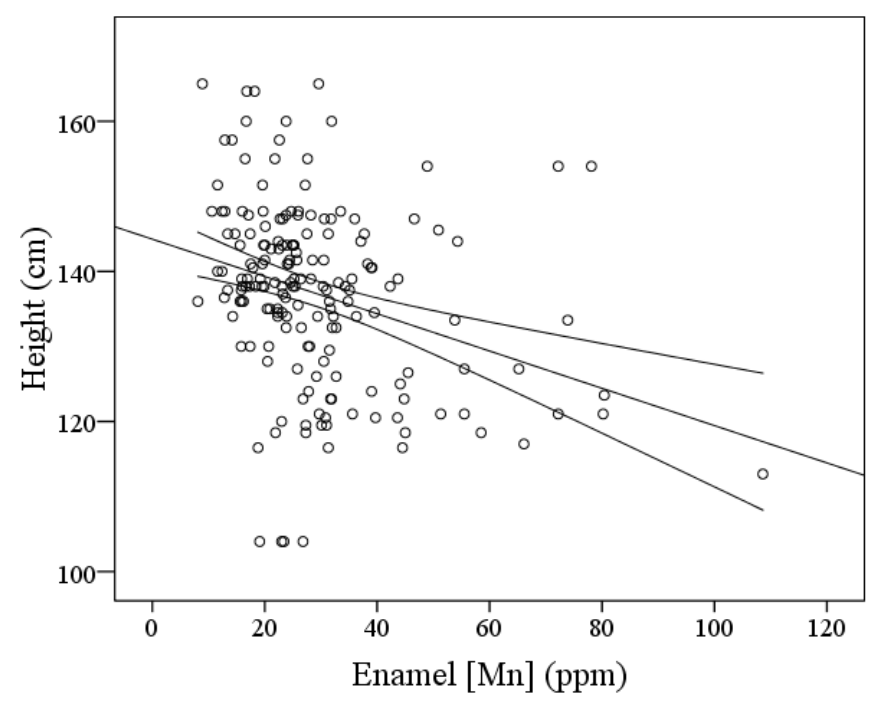

Figure 3.8: A linear regression line showing the relationship between manganese in all teeth enamel and the children's height. Confidence intervals at the 95\% level are shown above and below the regression line. Associated statistics are shown in Table 3.5.

Linear regressions using age as a covariate showed that these data are somewhat misleading. The standardized $\beta$ for the regression without covariates was $-0.31(\mathrm{p}<0.001)$. However, using age as a covariate in the model the standardized $\beta$ coefficient was $-0.05(\mathrm{p}=.24)$. It is interesting to note that there seems to be a decreasing trend in enamel-[Mn] with increasing age as shown in figure 3.10. 


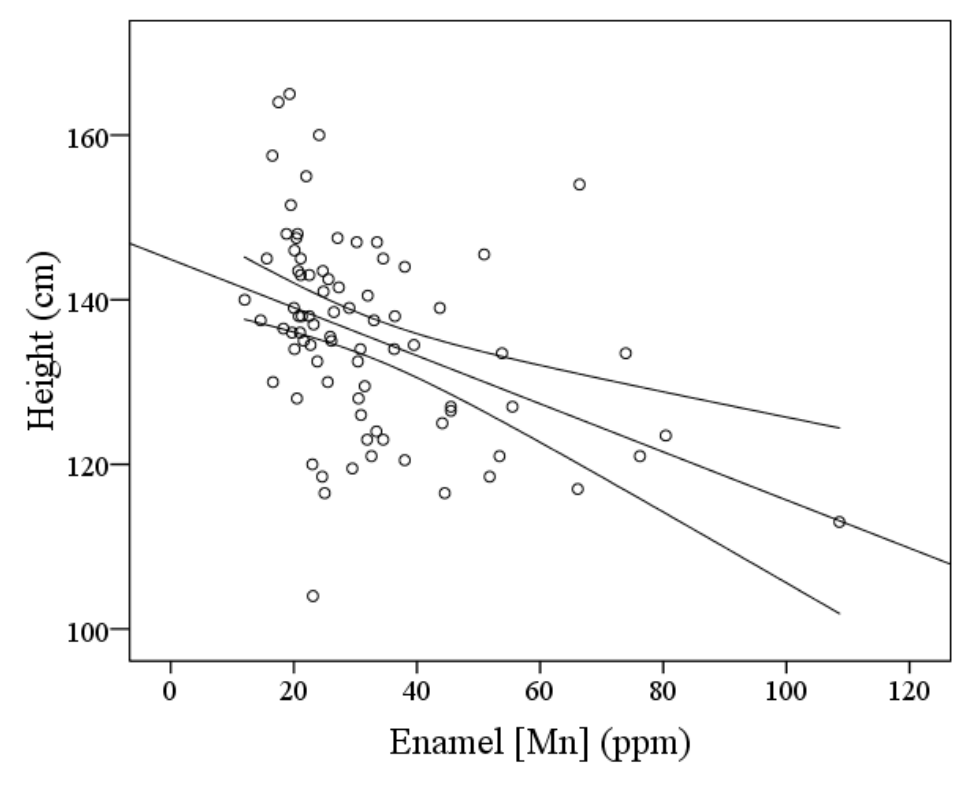

Figure 3.9: A linear regression line showing the relationship between average manganese in all measured tooth enamel from the same child and the children's height. Confidence intervals at the $95 \%$ level are shown above and below the regression line. Associated statistics are shown in Table 3.4.

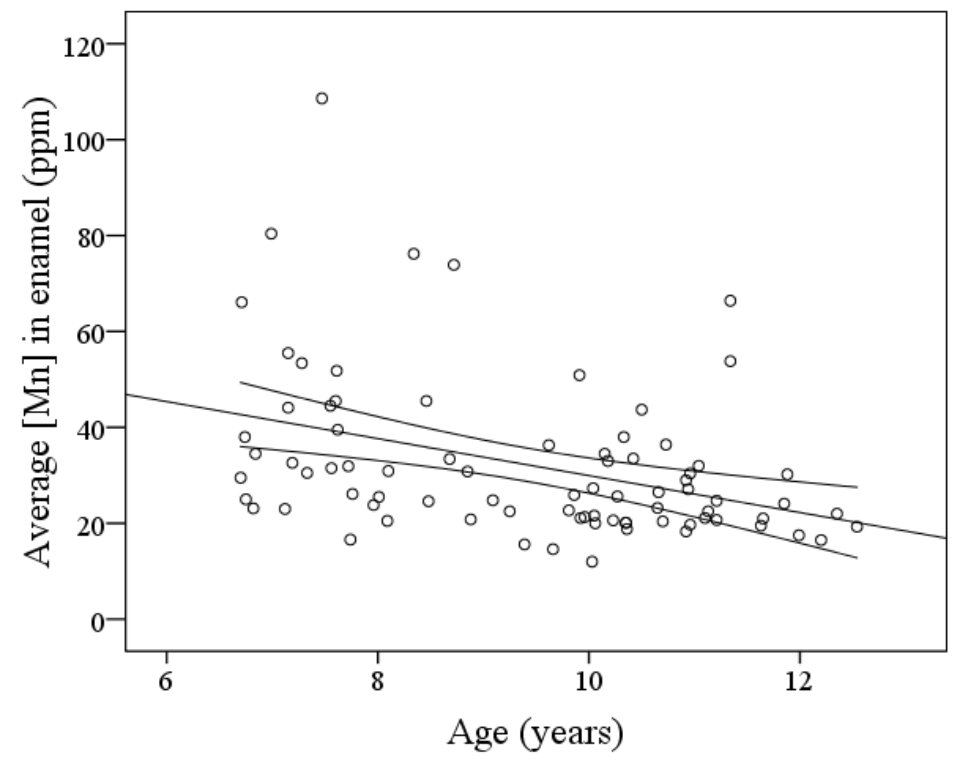

Figure 3.10: A linear regression line showing the relationship between average manganese in all measured tooth enamel from the same child and the children's age. Confidence intervals at the $95 \%$ level are shown above and below the regression line. 


\subsubsection{Relationships between manganese in enamel and neurological test scores}

Manganese can cause neurotoxic effects in high quantities. Homeostatic mechanisms exist to control intake of Mn, but these mechanisms may not be fully formed at birth and are subject to factors such as iron status and genetics. Recently, low-level manganese-induced neurotoxicity in children has been observed in several studies $(45,47,48)$.

Relationships between Mn and neurological outcomes have been investigated. Age was included as a covariate in a linear regression model to avoid biasing the results. Correlation coefficients between enamel-[Mn] and children's WASI IQ test scores are shown in Table 3.5.

Table 3.5: Correlations of enamel-[Mn] and full WASI IQ test scores

\begin{tabular}{llllllllllll}
\hline & \multicolumn{1}{c}{ Incisor } & \multicolumn{1}{c}{ Canine } & \multicolumn{2}{c}{ Molar } & \multicolumn{1}{c}{ All teeth } & \multicolumn{2}{c}{ Average } \\
\cline { 2 - 12 } Correlation & Statistic & $\mathrm{p}$ & Statistic & $\mathrm{p}$ & Statistic & $\mathrm{p}$ & Statistic & $\mathrm{p}$ & Statistic & $\mathrm{p}$ \\
\hline Pearson's $\mathrm{r}$ & 0.06 & 0.89 & $0.32^{*}$ & 0.03 & -0.14 & 0.21 & 0.00 & 1.00 & -0.05 & 0.66 \\
Spearman's $\rho$ & 0.05 & 0.74 & 0.27 & 0.07 & -0.15 & 0.15 & -0.04 & 0.61 & -0.05 & 0.54 \\
Kendall's $\tau$ & 0.02 & 0.85 & 0.20 & 0.06 & -0.10 & 0.19 & -0.03 & 0.59 & -0.07 & 0.52 \\
\hline
\end{tabular}

*Significant at $\mathrm{p}<0.05$

** Significant at $\mathrm{P}<0.01$

Non-parametric tests did not show significant correlation between [Mn] in any teeth and WASI IQ test scores. Although non-parametric tests did not show a correlation between canine-[Mn] and WASI IQ test scores, the p-values are small enough to consider a possible relationship. However, since the linear regression showed no significant correlation between WASI IQ test scores and all teeth-[Mn] or in the average-[Mn] per child, this result may be an anomaly. Furthermore, the results of this regression may be unreliable because overall the data are not normally distributed. The linear regression between canine enamel and IQ test scores is shown in figure 3.11. 


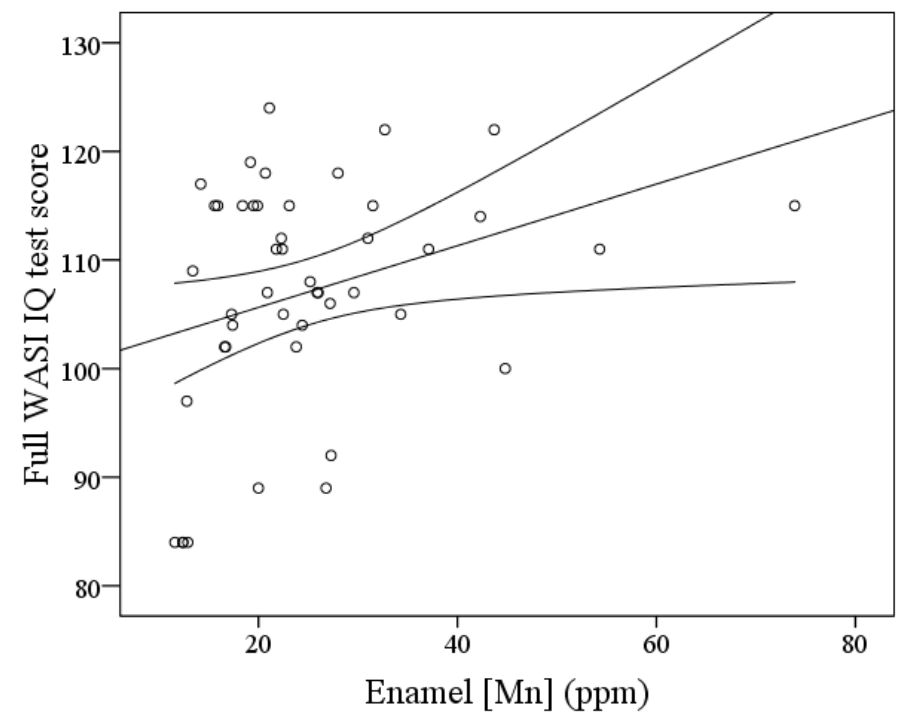

Figure 3.11: A linear regression line showing the relationship between canine-[Mn] and full WASI IQ test scores. Confidence intervals at the 95\% level are shown above and below the regression line. Associated statistics are shown in Table 3.5.

To investigate the possibility of motor neuron function being affected by low level exposures to Mn, we investigated the relationship between Santa Ana dexterity test scores and manganese concentrations. Correlations between Santa Ana test scores for children's dominant hand and manganese concentrations are shown in table 3.6. Correlations between Santa Ana test scores for children's non-dominant hand and manganese concentrations are shown in table 3.7. Linear regressions between [Mn] and Santa Ana dominant hand test scores are shown for all teeth in figure 3.12 and the average per child in figure 3.13.

Table 3.6: Correlations of enamel-[Mn] and Santa Ana dominant hand scores

\begin{tabular}{|c|c|c|c|c|c|c|c|c|c|c|}
\hline \multirow[b]{3}{*}{ Correlation } & \multicolumn{10}{|c|}{ Cases } \\
\hline & \multicolumn{2}{|c|}{ Incisor } & \multicolumn{2}{|c|}{ Canine } & \multicolumn{2}{|c|}{ Molar } & \multicolumn{2}{|c|}{ All teeth } & \multicolumn{2}{|c|}{ Average } \\
\hline & Statistic & $\mathrm{p}$ & Statistic & $\mathrm{p}$ & Statistic & $\mathrm{p}$ & Statistic & $\mathrm{p}$ & Statistic & $\mathrm{p}$ \\
\hline Pearson's r & -0.10 & 0.51 & -0.07 & 0.64 & -0.15 & 0.17 & $-0.25 * *$ & 0.001 & $-0.37 * *$ & 0.001 \\
\hline Spearman's $\rho$ & 0.05 & 0.73 & -0.10 & 0.52 & -0.15 & 0.18 & $-0.23 * *$ & 0.003 & $-0.34 * *$ & 0.002 \\
\hline Kendall's $\tau$ & 0.04 & 0.67 & -0.07 & 0.48 & -0.10 & 0.18 & $-0.16 * *$ & 0.003 & $-0.24 * *$ & 0.002 \\
\hline
\end{tabular}

*Significant at $\mathrm{p}<0.05$

**Significant at $\mathrm{P}<0.01$ 
The standardized $\beta$ for the regression of all teeth-[Mn] without covariates was $-0.25(\mathrm{p}=0.001)$.

However, using age as a covariate in the model the standardized $\beta$ was $-0.08(p=0.24)$. This seems to be related to a decreasing trend in enamel-[Mn] with increasing age as shown in figure 3.10. However, for the average- $[\mathrm{Mn}]$ across each child, $\beta$ decreased from $-0.37(\mathrm{p}=0.001)$ to $-0.18(\mathrm{p}=0.07)$ by the addition of age as a covariate in the linear model, suggesting that there may be a relationship between enamel-[Mn] and decreased Santa Ana test scores.

Hernandez-Bonilla and colleagues observed a similar decrease in Santa Ana test scores among children exposed to environmental manganese that was not statistically significant (170). Similarly, there was no significant trend in Santa Ana test scores within the gradient of exposures to Mn among workers at a smelter in South Africa (171). However, the group of workers $(n=509)$ were found to have lower test scores than a control group $(n=67)$.

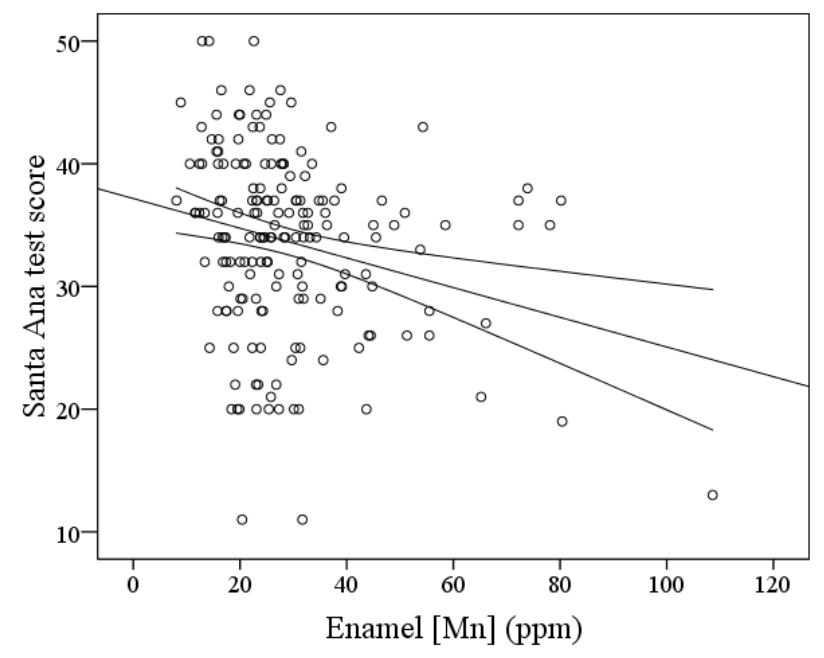

Figure 3.12: A linear regression line showing the relationship between all teeth-[Mn] and Santa Ana dominant hand test scores. Confidence intervals at the 95\% level are shown above and below the regression line. Associated statistics are shown in Table 3.6. 


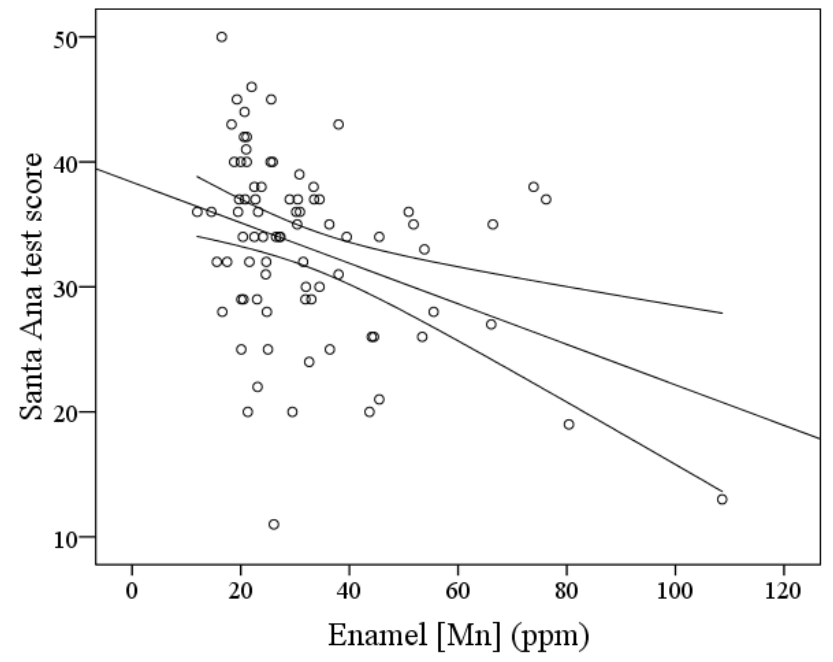

Figure 3.13: A linear regression line showing the relationship between average-[Mn] in teeth from each child and Santa Ana dominant hand test scores. Confidence intervals at the $95 \%$ level are shown above and below the regression line. Associated statistics are shown in Table 3.6.

Table 3.7: Correlations of enamel-[Mn] and Santa Ana non-dominant hand test scores

\begin{tabular}{|c|c|c|c|c|c|c|c|c|c|c|}
\hline \multirow[b]{3}{*}{ Correlation } & \multicolumn{10}{|c|}{ Cases } \\
\hline & \multicolumn{2}{|c|}{ Incisor } & \multicolumn{2}{|c|}{ Canine } & \multicolumn{2}{|c|}{ Molar } & \multicolumn{2}{|c|}{ All teeth } & \multicolumn{2}{|c|}{ Average } \\
\hline & Statistic & $\mathrm{p}$ & Statistic & $\mathrm{p}$ & Statistic & $\mathrm{p}$ & Statistic & $\mathrm{p}$ & Statistic & $\mathrm{p}$ \\
\hline Pearson's r & -0.14 & 0.36 & -0.12 & 0.44 & $-0.22 *$ & 0.04 & $-0.31 * *$ & $<0.001$ & $-0.37 * *$ & 0.001 \\
\hline Spearman's $\rho$ & -0.09 & 0.55 & -0.10 & 0.52 & -0.19 & 0.08 & $-0.30 * *$ & $<0.001$ & $-0.40 * *$ & $<0.001$ \\
\hline Kendall's $\tau$ & -0.05 & 0.64 & -0.07 & 0.49 & -0.13 & 0.08 & $-0.21 * *$ & $<0.001$ & $-0.28 * *$ & $<0.001$ \\
\hline
\end{tabular}

*Significant at $\mathrm{p}<0.05$

**Significant at $\mathrm{P}<0.01$

Linear regression of [Mn] vs. Santa Ana non-dominant test scores using age as a covariate showed that the data in table 3.8 must be interpreted with caution. The standardized $\beta$ for the regression without covariates was $-0.31(\mathrm{p}<0.001)$. However, using age as a covariate in the model the standardized $\beta$ was $-0.12(\mathrm{p}=0.04)$. This seems to also be related to the decreasing trend in enamel-[Mn] with increasing age as shown in figure 3.10. However, for the average-[Mn] across each child, $\beta$ was decreased from -0.37 (p $=0.001)$ to $-0.18(\mathrm{p}=0.07)$ by the addition of age as a covariate in the linear model. 


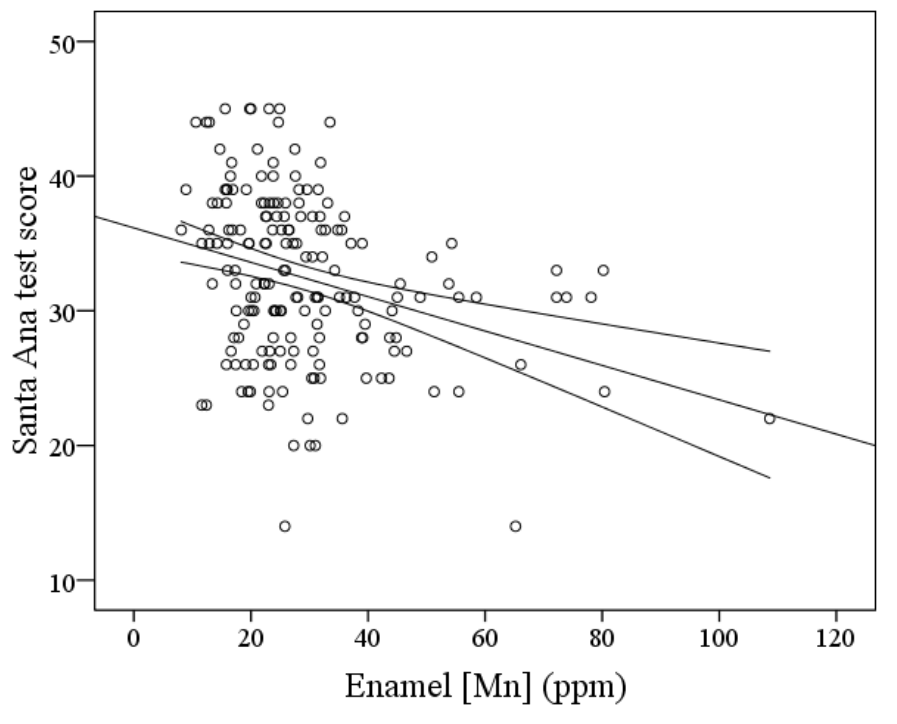

Figure 3.14: A linear regression line showing the relationship between all teeth-[Mn] enamel and Santa Ana non-dominant hand test scores. Confidence intervals at the $95 \%$ level are shown above and below the regression line. Associated statistics are shown in Table 3.7.

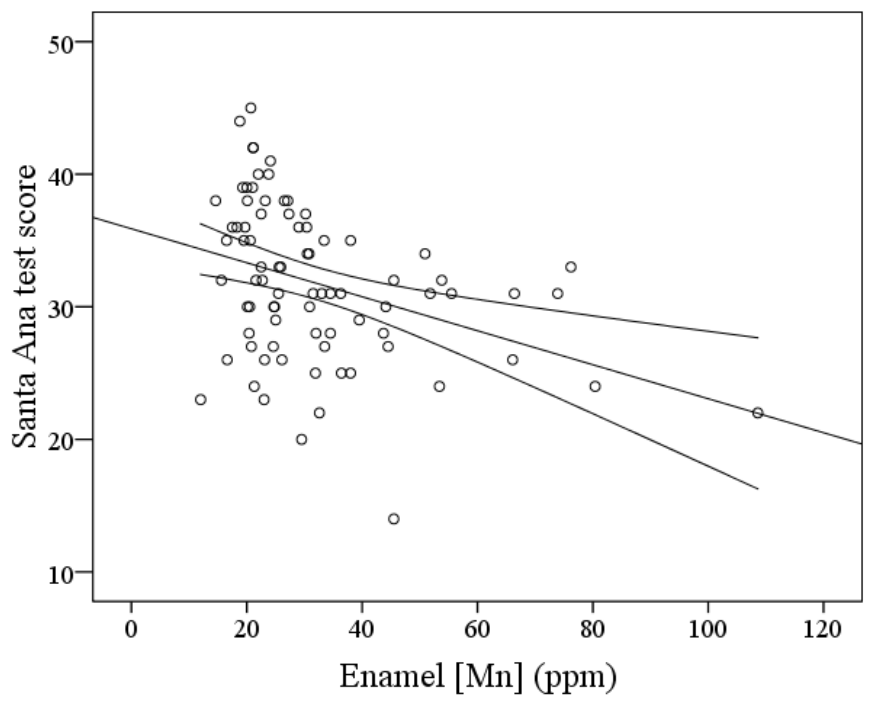

Figure 3.15: A linear regression line showing the relationship between average-[Mn] from each child and Santa Ana non-dominant hand test scores. Confidence intervals at the $95 \%$ level are shown above and below the regression line. Associated statistics are shown in Table 3.7. 


\subsubsection{Relationships between manganese and other metals in enamel}

There were correlations observed between most of the elements in this work. Some of this correlation is likely due to variations in the internal standard (calcium) in the sample material. Some fluctuation in the amount of calcium present in the enamel contributes to uncertainty of approximately $6 \%$ of the value of analytes in the sample. However, manganese and iron are chemically similar and share many metabolic pathways. There was a strong correlation observed between iron and manganese in our data $(\rho=0.74, \mathrm{p}<$ 0.001). This seems to show that divalent $\mathrm{Mn}$ and Fe follow similar metabolic pathways to dental enamel. Interestingly, it has also been shown that manganese exposure increases the concentration of both manganese and iron in saliva (55).

Oprea and colleagues reported correlations between metals in dental enamel (165). The reported correlations between $[\mathrm{Mn}]$ and other relevant metals were similar to those observed in this work (Table $3.8)$, descending in order of strength, $[\mathrm{Fe}]>[\mathrm{Cu}]>[\mathrm{Zn}]$. Lead concentrations were not reported in their study. Oprea and colleagues used $\log _{10}$ transformed concentrations and Pearson correlations, however, while the current work relied on non-parametric tests. Overall, however, the results of manganese quantification in the present work showed excellent agreement with earlier work by Oprea and coworkers.

Table 3.8: Correlations of enamel-[Mn] and other metals

\begin{tabular}{llccccccc}
\hline & \multicolumn{9}{c}{ Elements } \\
\cline { 2 - 9 } Correlation & \multicolumn{2}{c}{ Iron } & \multicolumn{2}{c}{ Lead } & \multicolumn{2}{c}{ Zinc } & \multicolumn{2}{c}{ Copper } \\
\cline { 2 - 10 }$y$ & Statistic & $\mathrm{p}$ & Statistic & $\mathrm{p}$ & Statistic & $\mathrm{p}$ & Statistic & $\mathrm{p}$ \\
\hline Pearson's r & $0.76^{* *}$ & $<0.001$ & $0.42^{* *}$ & $<0.001$ & $0.39^{* *}$ & $<0.001$ & $0.37^{* *}$ & $<0.001$ \\
Spearman's $\rho$ & $0.74^{* *}$ & $<0.001$ & $0.31^{* *}$ & $<0.001$ & $0.38^{* *}$ & $<0.001$ & $0.64^{* *}$ & $<0.001$ \\
Kendall's $\tau$ & $0.55^{* *}$ & $<0.001$ & $0.21^{* *}$ & $<0.001$ & $0.25^{* *}$ & $<0.001$ & $0.47^{* *}$ & $<0.001$ \\
\hline
\end{tabular}

*Significant at $\mathrm{p}<0.05$

** Significant at $\mathrm{P}<0.01$ 


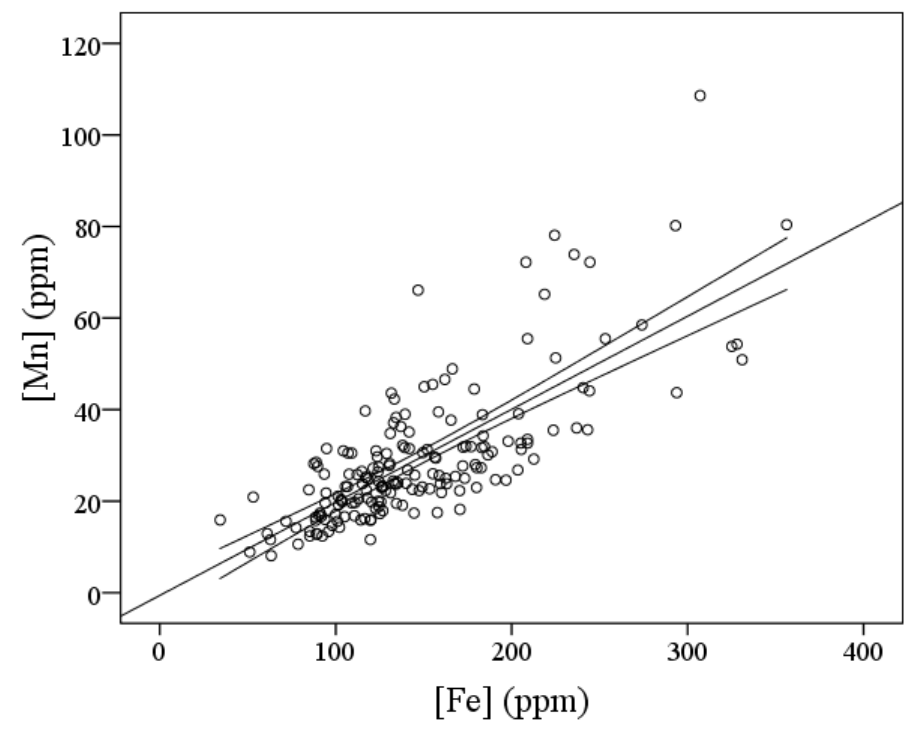

Figure 3.16: A linear regression line showing the relationship between manganese and iron in all teeth. Confidence intervals at the 95\% level are shown above and below the regression line. Associated statistics are shown in Table 3.8.

Potential biomarkers for cumulative exposure to manganese include hair and bone. Tap water-Mn consumption was found to correlate with [Mn] in children's hair and also with lowered IQ test scores in a sample of children that included those who participated in this work $(\mathrm{p}<0.05)(47)$. However, the Agency for Toxic Substances and Disease Registry (ATSDR) has noted several limitations to the use of hair as a biomarker for health outcomes (172). Potential toxins such as Mn are known to incorporate into hair from both endogenous and exogenous sources (24). Washing procedures for the removal of exogenous Mn may also remove endogenous Mn (24). It has been noted elsewhere that the color of hair is also related to hair-[Mn] (173). The manifold pathways of integration of Mn into both dental enamel and hair make the comparison of the two sites as biomarkers difficult to interpret.

Investigations of bone-Mn using in vivo neutron activation analysis (IVNAA) have been performed at the Occupational Nuclear Medicine Laboratory at McMaster University (20, 21). Welders who were exposed 
to airborne Mn occupationally showed an increased bone-[Mn] compared to control subjects $(\mathrm{p}<0.05)$ (21). That study conclusively demonstrated that the skeleton is a site of manganese accumulation during long-term, occupational exposures to airborne Mn. The MDL of the IVNAA system, defined as the mean uncertainty $(2 \sigma)$ of all subjects, was $2.1 \mathrm{ppm}$ compared to $1.6 \mathrm{ppm}$ (at $3 \sigma$ above background) in this work. To date, there has been no investigation of the correlation between $[\mathrm{Mn}]$ in teeth ---which are part of the skeleton--- and bone, although the development of the method described in the current work makes that a possibility.

The success of finding a standard biomarker of cumulative exposure to Mn has been limited. Log adjusted blood-[Mn] of bridge welders were found to have a positive correlation to estimated air exposures (Pearson's $\mathrm{R}=0.40, \mathrm{p}=0.01, \mathrm{n}=39$ ), but blood-[Mn] is known to reflect only recent exposures (23). Hair-[Mn] has shown some correlations to Mn exposures and neurological outcomes, but more work is needed to address problems related to sampling and washing of samples. Bone-[Mn] reflect long-term occupational exposures, however, levels are often below the detection limit of the system, making uncertainty significant. All teeth that were measured in this work were found to have concentrations above the detection limit of $1.6 \mathrm{ppm}$. Enamel-[Mn] showed a significant weak correlation to the primary known pathway of exposure to $\mathrm{Mn}$; that is, dietary-Mn. Correlations were observed between enamel-[Mn] and all other metals that were measured in the current work. 


\subsection{Iron}

Descriptive statistics for iron in children's tooth enamel are shown in Table 3.9. The range of enamel-

$[\mathrm{Fe}]$ is smaller than the range observed by Oprea and colleagues, which was reported to be $5.0-935 \mathrm{ppm}$

(165). Conversely, the range of values of the teeth observed in this work is larger than the range observed in similar samples in the literature $(159,160)$. However, the sample size is also larger than the studies cited. It must also be noted that the method for quantifying Fe in enamel used in these studies used a synchrotron x-ray beamline with cross sections of enamel, so the portion of enamel measured was slightly different, which could be the reason for the difference in iron concentrations reported here. The average relative standard deviation between teeth donated from the same child was $24.3 \%$.

Table 3.9

\begin{tabular}{ccccc}
\hline \multicolumn{6}{l}{ Descriptive Statistics of Fe in tooth enamel } \\
\hline $\begin{array}{c}\text { Number of } \\
\text { samples }\end{array}$ & Minimum & Maximum & Mean & Variance \\
\hline 178 & $34 \mathrm{ppm}$ & $356 \mathrm{ppm}$ & $147 \mathrm{ppm}$ & $3209 \mathrm{ppm}^{2}$ \\
\hline
\end{tabular}

The distribution of measured concentrations of iron in tooth enamel is shown in figure 3.1. There is a tail in the distribution at higher concentrations. The non-normality of the data was confirmed with a ShapiroWilk test $(\mathrm{W}=0.92, \mathrm{p}<0.001)$. 


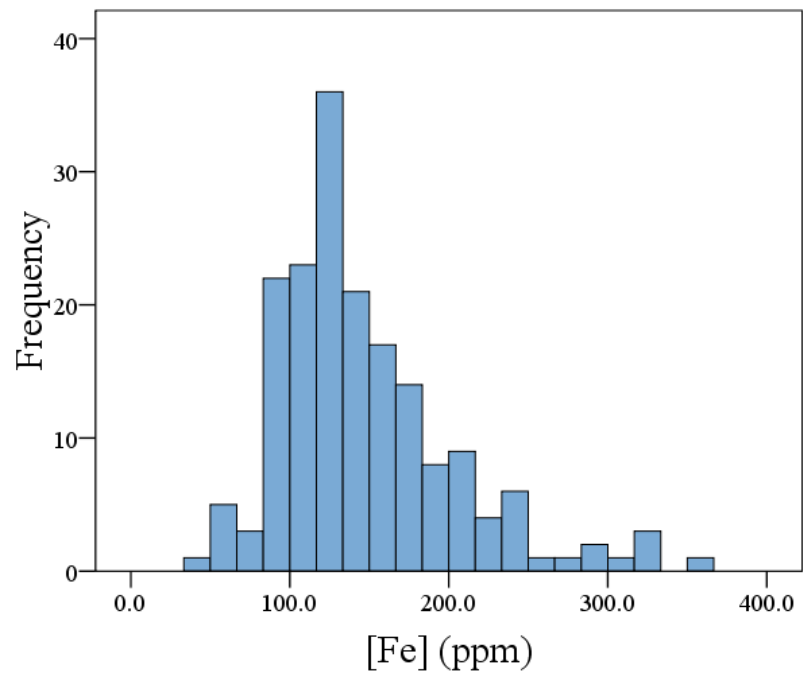

Figure 3.17: Histogram showing the distribution of iron concentrations of all teeth measured in this study. Shapiro-Wilk test $(\mathrm{W}=0.92, \mathrm{p}<0.001)$.

The boxplot in figure 3.18 shows the iron concentrations of three different tooth types: incisors, canines and molars. Similarly to $\mathrm{Mn}$, incisors were found to have significantly higher concentrations of Fe than canines and molars (Kruskal-Wallis, $\mathrm{p}<0.001)$.

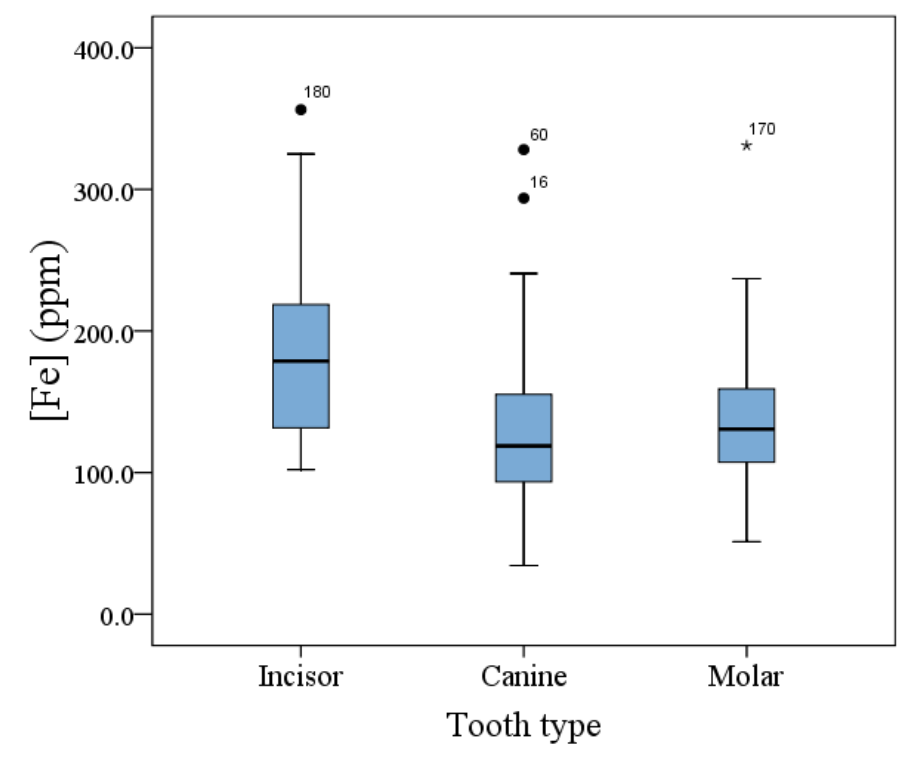

Figure 3.18: Boxplot showing the concentration of iron for incisors, canines and molars. A Kruskal-Wallis test showed that at least one group had a median that was significantly different from the population median $(\mathrm{p}<0.001)$. The median value is depicted as a black line in the center of the box. The second and third quartiles are the boxes on either side and the first and fourth quartiles are depicted by the whiskers below and above the boxes. Outliers are shown as points outside of the whiskers. 


\subsubsection{Relationships between iron in enamel and exposure pathways}

Iron, like manganese, may substitute into enamel hydroxyapatite (71). To investigate the possibility of iron substituting for calcium in erupted tooth enamel, a linear regression of the concentration of iron as a function of the estimated dietary and tap water intakes of iron was undertaken. Similarly to Mn, nonparametric (Spearman's rho and Kendall's tau) and parametric (Pearson's r) tests were used to investigate correlations between iron intake and iron concentration in incisor enamel. Table 3.10 and table 3.11 show the correlation coefficients of these data. Unlike manganese, no significant correlations were found between oral ingestion of iron and concentrations of iron in enamel. This may suggest that substitution of $\mathrm{Mn}$ and/or Fe occurs from the saliva rather than the directly from dietary or tap water intakes, since increased exposure to manganese is known to increase both [Mn] and [Fe] in saliva (174), and these two elements are strongly correlated in enamel.

Table 3.10: Correlations of enamel-[Fe] and dietary-Fe

\begin{tabular}{llccccccccccc}
\hline & \multicolumn{1}{c}{ Incisor } & \multicolumn{1}{c}{ Canine } & \multicolumn{2}{c}{ Molar } & \multicolumn{2}{c}{ All teeth } & \multicolumn{2}{c}{ Average } \\
\cline { 2 - 12 } Correlation & Statistic & $\mathrm{p}$ & Statistic & $\mathrm{p}$ & Statistic & $\mathrm{p}$ & Statistic & $\mathrm{p}$ & Statistic & $\mathrm{p}$ \\
\hline Pearson's $\mathrm{r}$ & 0.06 & 0.72 & 0.04 & 0.79 & 0.14 & 0.20 & 0.07 & 0.36 & 0.10 & 0.38 \\
Spearman's $\rho$ & 0.09 & 0.55 & -0.04 & 0.77 & 0.11 & 0.30 & 0.08 & 0.29 & 0.18 & 0.10 \\
Kendall's $\tau$ & 0.07 & 0.51 & -0.03 & 0.79 & 0.09 & 0.23 & 0.06 & 0.24 & 0.12 & 0.10 \\
\hline
\end{tabular}

*Significant at $\mathrm{p}<0.05$

**Significant at $\mathrm{P}<0.01$ 
Table 3.11: Correlations of enamel-[Fe] and tap water intake of Fe

\begin{tabular}{llcccccccccc}
\hline & \multicolumn{10}{c}{ Cases } \\
\cline { 2 - 12 } Correlation & \multicolumn{2}{c}{ Incisor } & \multicolumn{2}{c}{ Canine } & \multicolumn{2}{c}{ Molar } & \multicolumn{2}{c}{ All teeth } & \multicolumn{2}{c}{ Average } \\
\cline { 2 - 13 } & Statistic & $\mathrm{p}$ & Statistic & $\mathrm{p}$ & Statistic & $\mathrm{p}$ & Statistic & $\mathrm{p}$ & Statistic & $\mathrm{p}$ \\
\hline Pearson's $\mathrm{r}$ & 0.02 & 0.89 & 0.02 & 0.92 & 0.10 & 0.36 & 0.11 & 0.16 & 0.10 & 0.39 \\
Spearman's $\rho$ & -0.01 & 0.97 & -0.04 & 0.78 & -0.05 & 0.64 & -0.03 & 0.71 & 0.13 & 0.26 \\
Kendall's $\tau$ & -0.01 & 0.95 & -0.06 & 0.60 & -0.04 & 0.61 & -0.02 & 0.68 & 0.09 & 0.26 \\
\hline
\end{tabular}

$*$ Significant at $\mathrm{p}<0.05$

$* *$ Significant at $\mathrm{P}<0.01$

\subsubsection{Relationships between iron and children's height}

Iron deficiency may affect normative growth and development of calcified tissues, resulting in short stature (10). Therefore, relationships between Fe and growth outcomes have been investigated. Table 3.12 shows correlation coefficients between enamel iron and children's height.

Table 3.12: Correlations of enamel-[Fe] and height

\begin{tabular}{|c|c|c|c|c|c|c|c|c|c|c|}
\hline \multirow[b]{3}{*}{ Correlation } & \multicolumn{10}{|c|}{ Cases } \\
\hline & \multicolumn{2}{|c|}{ Incisor } & \multicolumn{2}{|c|}{ Canine } & \multicolumn{2}{|c|}{ Molar } & \multicolumn{2}{|c|}{ All teeth } & \multicolumn{2}{|c|}{ Average } \\
\hline & Statistic & $\mathrm{p}$ & Statistic & $\mathrm{p}$ & Statistic & $\mathrm{p}$ & Statistic & $p$ & Statistic & $p$ \\
\hline Pearson's r & 0.10 & 0.53 & -0.29 & 0.05 & -0.10 & 0.38 & $-0.31 * *$ & $<0.001$ & $-0.35^{* *}$ & 0.001 \\
\hline Spearman's $\rho$ & -0.14 & 0.38 & -0.24 & 0.11 & -0.14 & 0.19 & $-0.31 * *$ & $<0.001$ & $-0.42 * *$ & $<0.001$ \\
\hline Kendall's $\tau$ & -0.07 & 0.49 & -0.18 & 0.09 & -0.10 & 0.17 & $-0.22^{* *}$ & $<0.001$ & $-0.28 * *$ & $<0.001$ \\
\hline
\end{tabular}

*Significant at $\mathrm{p}<0.05$

** Significant at $\mathrm{P}<0.01$

It is interesting to note that there is a bias in the samples that were collected from children in this work. Older (taller) children who participated generally donated molars or canines, presumably because these teeth had fallen out most recently. Additionally, their incisors likely fell out years before the family was contacted to participate in the study. On the other hand, younger (shorter) children generally donated 
incisors, since their molars wouldn't be shed naturally until they grow older. As a result, no individual tooth type shows a correlation, but all teeth-[Fe] and average-[Fe] concentrations show a significant correlation with the height of children in this study.

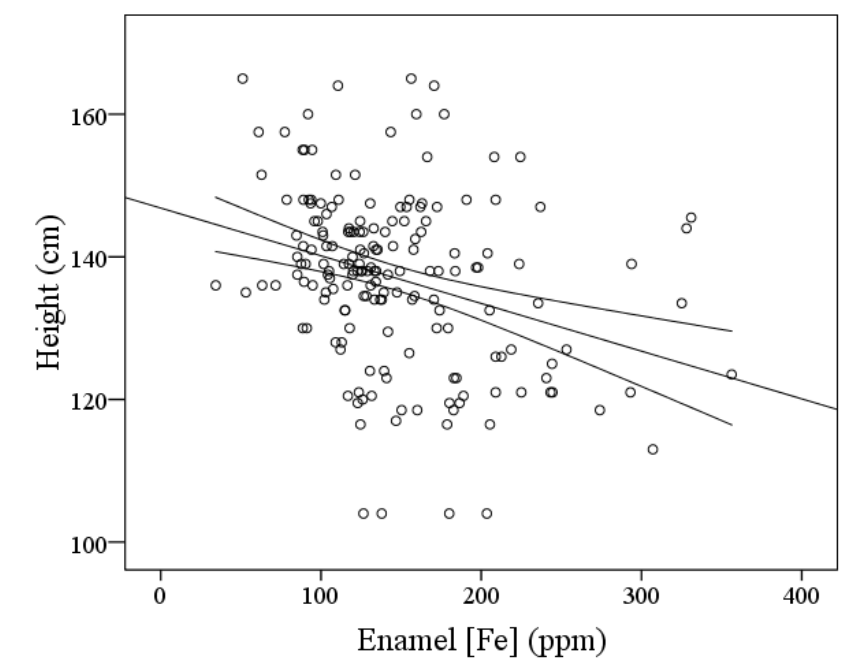

Figure 3.19: A linear regression line showing the relationship between iron in all teeth enamel and children's height. Confidence intervals at the $95 \%$ level are shown above and below the regression line. Associated statistics are shown in Table 3.12.

Linear regression of height as a function in all teeth-[Fe] using age as a covariate showed this bias in sampling. The standardized $\beta$ for the regression without covariates was $-0.31(\mathrm{p}<0.001)$. However, using age as a covariate in the model the standardized $\beta$ was $-0.05(\mathrm{p}=0.20)$. Likewise, for the average-[Fe] across each child, the standardized $\beta$ was decreased from $-0.35(p=0.001)$ to $-0.08(p=0.19)$ by the addition of age as a covariate in the linear model. 


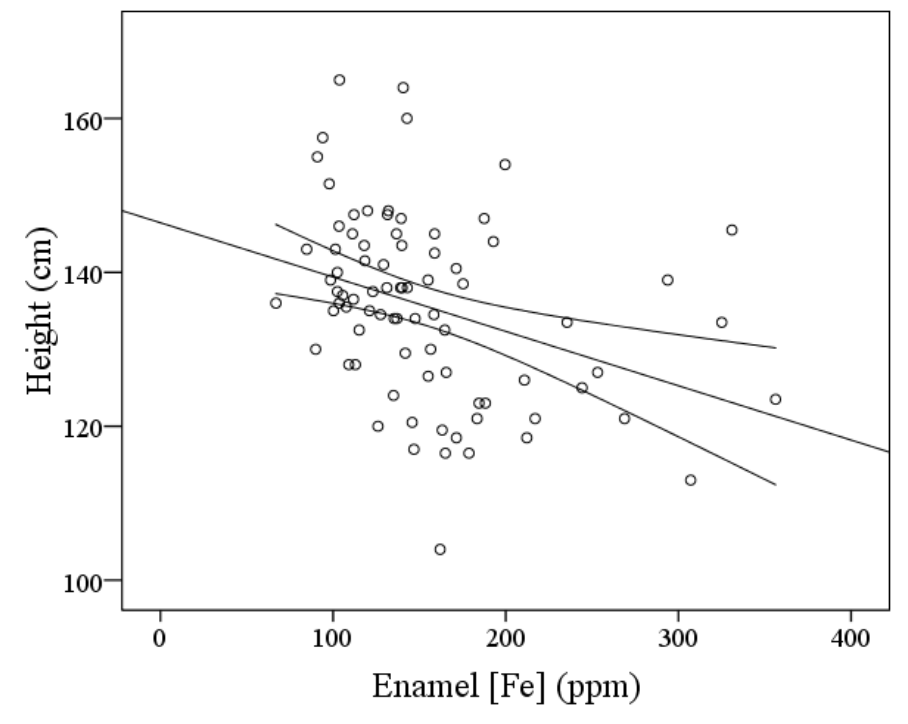

Figure 3.20: A linear regression line showing the relationship between average-[Fe] in each child's teeth enamel and children's height. Confidence intervals at the $95 \%$ level are shown above and below the regression line. Associated statistics are shown in Table 3.12.

\subsubsection{Relationships between iron in enamel and neurological test scores}

Iron has the potential to induce neurotoxicity via oxidative stress in neuronal cells through Haber-WeissFenton reactions. Since tooth enamel has not been validated as a biomarker for cumulative iron exposure, it is difficult to interpret results of any correlation (or lack of correlation). The presence of divalent iron in surface enamel may not be an accurate marker of overall iron status. However, there is potential that it can be used to measure increased divalent iron in the oral environment.

Significant negative correlations between molar [Fe] and WASI IQ test scores were observed. A linear regression model, with age as a covariate, had a $\beta$ coefficient of $-0.23(\mathrm{p}=0.03)$, while the model without covariates had a $\beta$ coefficient of $-0.24(\mathrm{p}=0.03)$, suggesting that age was not a confounder in these measurements. 


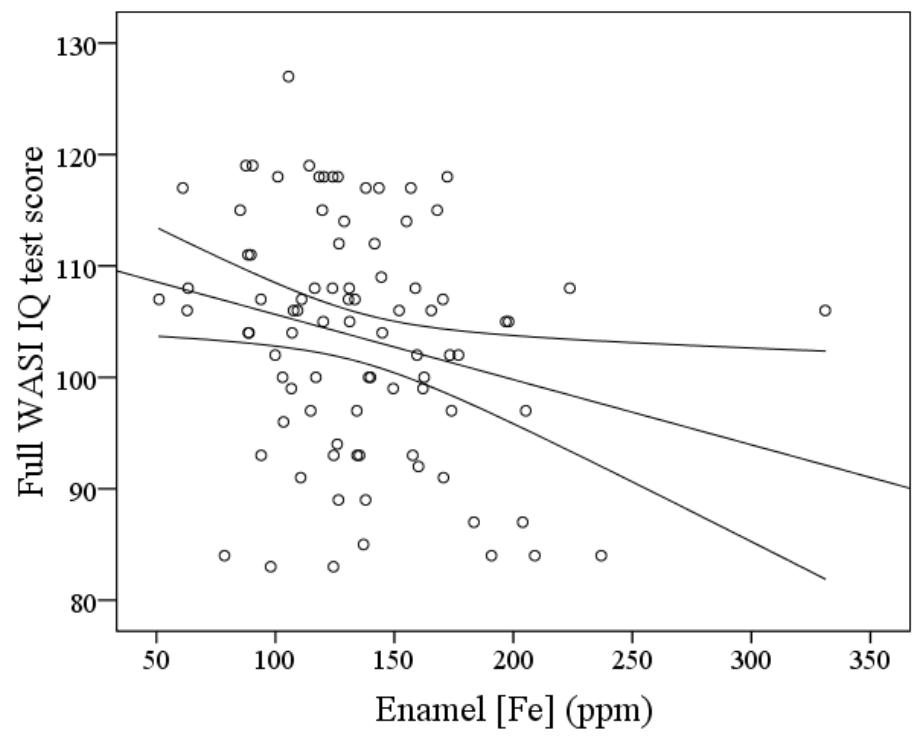

Figure 3.21: A linear regression line showing the relationship between molar-[Fe] and WASI IQ test scores. Confidence intervals at the $95 \%$ level are shown above and below the regression line. Associated statistics are shown in Table 3.13.

Table 3.13: Correlations of enamel-[Fe] and full WASI IQ test scores

\begin{tabular}{llcccccccccc}
\hline & \multicolumn{1}{c}{ Cases } \\
\cline { 2 - 11 } Correlation & \multicolumn{2}{c}{ Incisor } & \multicolumn{1}{c}{ Canine } & \multicolumn{1}{c}{ Molar } & \multicolumn{2}{c}{ All teeth } & \multicolumn{2}{c}{ Average } \\
\cline { 2 - 12 } & Statistic & $\mathrm{p}$ & Statistic & $\mathrm{p}$ & Statistic & $\mathrm{p}$ & Statistic & $\mathrm{p}$ & Statistic & $\mathrm{p}$ \\
\hline Pearson's $\mathrm{r}$ & 0.06 & 0.68 & 0.14 & 0.36 & $-0.24^{*}$ & 0.03 & -0.07 & 0.32 & -0.07 & 0.53 \\
Spearman's $\rho$ & 0.05 & 0.74 & 0.14 & 0.37 & $-0.26^{*}$ & 0.02 & -0.13 & 0.09 & -0.17 & 0.14 \\
Kendall's $\tau$ & 0.04 & 0.70 & 0.10 & 0.36 & $-0.18^{*}$ & 0.02 & -0.09 & 0.07 & -0.11 & 0.14 \\
\hline
\end{tabular}

$*$ Significant at $\mathrm{p}<0.05$

** Significant at $\mathrm{P}<0.01$

Table 3.14: Correlations of enamel-[Fe] and Santa Ana dominant hand scores

\begin{tabular}{|c|c|c|c|c|c|c|c|c|c|c|}
\hline \multirow[b]{3}{*}{ Correlation } & \multicolumn{10}{|c|}{ Cases } \\
\hline & \multicolumn{2}{|c|}{ Incisor } & \multicolumn{2}{|c|}{ Canine } & \multicolumn{2}{|c|}{ Molar } & \multicolumn{2}{|c|}{ All teeth } & \multicolumn{2}{|c|}{ Average } \\
\hline & Statistic & $\mathrm{p}$ & Statistic & $\mathrm{p}$ & Statistic & $\mathrm{p}$ & Statistic & $\mathrm{p}$ & Statistic & $\mathrm{p}$ \\
\hline Pearson's r & -0.18 & 0.25 & -0.23 & 0.12 & -0.16 & 0.15 & $-0.29 * *$ & $<0.001$ & $-0.39 * *$ & $<0.001$ \\
\hline Spearman's $\rho$ & -0.10 & 0.53 & -0.29 & 0.05 & $-0.25^{*}$ & 0.02 & $-0.32 * *$ & $<0.001$ & $-0.40 * *$ & $<0.001$ \\
\hline Kendall's $\tau$ & -0.05 & 0.63 & $-0.22 *$ & 0.04 & -0.16 & 0.04 & $-0.22 * *$ & $<0.001$ & $-0.28 * *$ & $<0.001$ \\
\hline
\end{tabular}

$*$ Significant at $\mathrm{p}<0.05$

**Significant at $\mathrm{P}<0.01$ 
Linear regression of Santa Ana test scores as a function of all teeth-[Fe] using age as a covariate was performed. The standardized $\beta$ for the regression without covariates was $-0.29(\mathrm{p}<0.001)$. However, using age as a covariate in the model the standardized $\beta$ was $-0.12(\mathrm{p}=0.06)$. Likewise, for the average$[\mathrm{Fe}]$ across each child, $\beta$ was decreased from $-0.39(\mathrm{p}<0.001)$ to $-0.23(\mathrm{p}=0.02)$ by the addition of age as a covariate in the linear model (fig. 3.23).

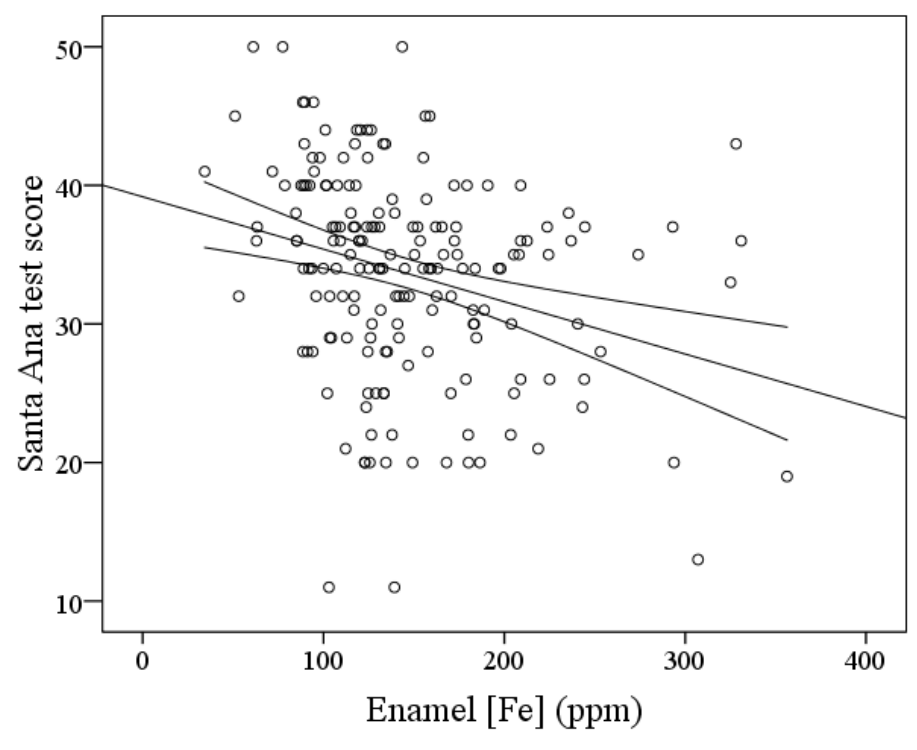

Figure 3.22: A linear regression line showing the relationship between all teeth-[Fe] and Santa Ana dominant test scores. Confidence intervals at the $95 \%$ level are shown above and below the regression line. Associated statistics are shown in Table 3.14. 


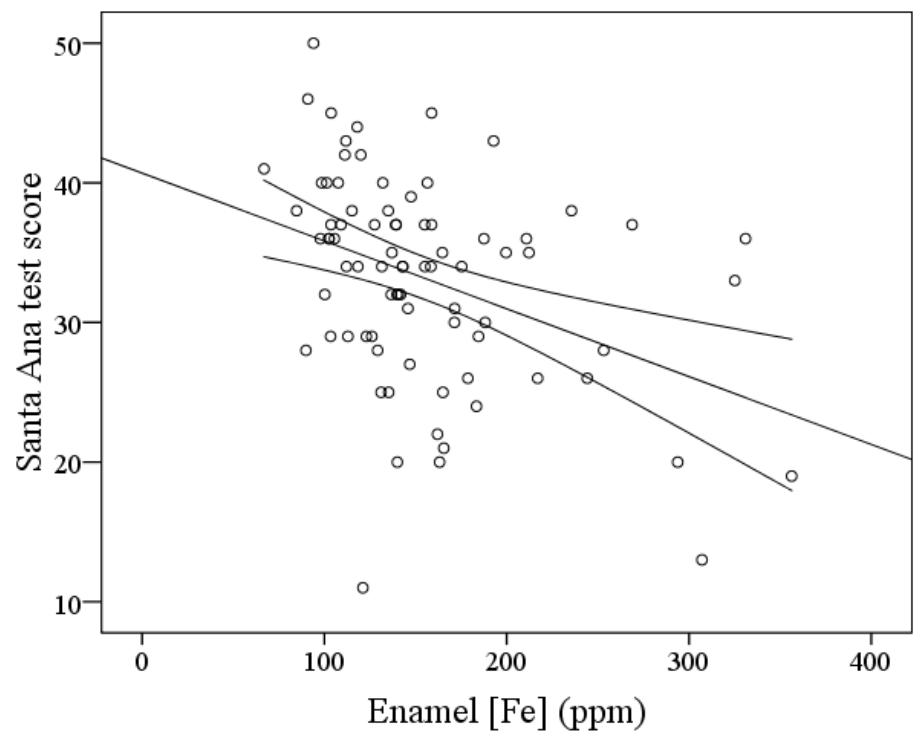

Figure 3.23: A linear regression line showing the relationship between average- $[\mathrm{Fe}]$ and Santa Ana dominant test scores. Confidence intervals at the $95 \%$ level are shown above and below the regression line. Associated statistics are shown in Table 3.14.

Table 3.15: Correlations of enamel-[Fe] and Santa Ana non-dominant hand scores

\begin{tabular}{|c|c|c|c|c|c|c|c|c|c|c|}
\hline \multirow[b]{3}{*}{ Correlation } & \multicolumn{10}{|c|}{ Cases } \\
\hline & \multicolumn{2}{|c|}{ Incisor } & \multicolumn{2}{|c|}{ Canine } & \multicolumn{2}{|c|}{ Molar } & \multicolumn{2}{|c|}{ All teeth } & \multicolumn{2}{|c|}{ Average } \\
\hline & Statistic & $\mathrm{p}$ & Statistic & $\mathrm{p}$ & Statistic & $\mathrm{p}$ & Statistic & $\mathrm{p}$ & Statistic & $\mathrm{p}$ \\
\hline Pearson's r & -0.11 & 0.47 & $-0.31 *$ & 0.04 & -0.10 & 0.36 & $-0.29 * *$ & $<0.001$ & $-0.34 * *$ & 0.002 \\
\hline Spearman's $\rho$ & -0.12 & 0.44 & $-0.44 * *$ & 0.002 & -0.18 & 0.10 & $-0.35 * *$ & $<0.001$ & $-0.43 * *$ & $<0.001$ \\
\hline Kendall's $\tau$ & -0.07 & 0.49 & $-0.30 * *$ & 0.004 & -0.12 & 0.12 & $-0.23 * *$ & $<0.001$ & $-0.29 * *$ & $<0.001$ \\
\hline
\end{tabular}

*Significant at $\mathrm{p}<0.05$

$* *$ Significant at $\mathrm{P}<0.01$

Linear regression of Santa Ana non-dominant test scores using, age as a covariate, are biased (Figure 3.24). The standardized $\beta$ for the regression without covariates was $-0.29(\mathrm{p}<0.001)$. However, using age as a covariate in the model the standardized $\beta$ was $-0.10(\mathrm{p}=0.10)$. Likewise, for the average-[Fe] across each child, $\beta$ was decreased from $-0.34(\mathrm{p}=0.002)$ to $-0.16(\mathrm{p}=0.10)$ by the addition of age as a covariate in the linear model (Figure 3.25). 


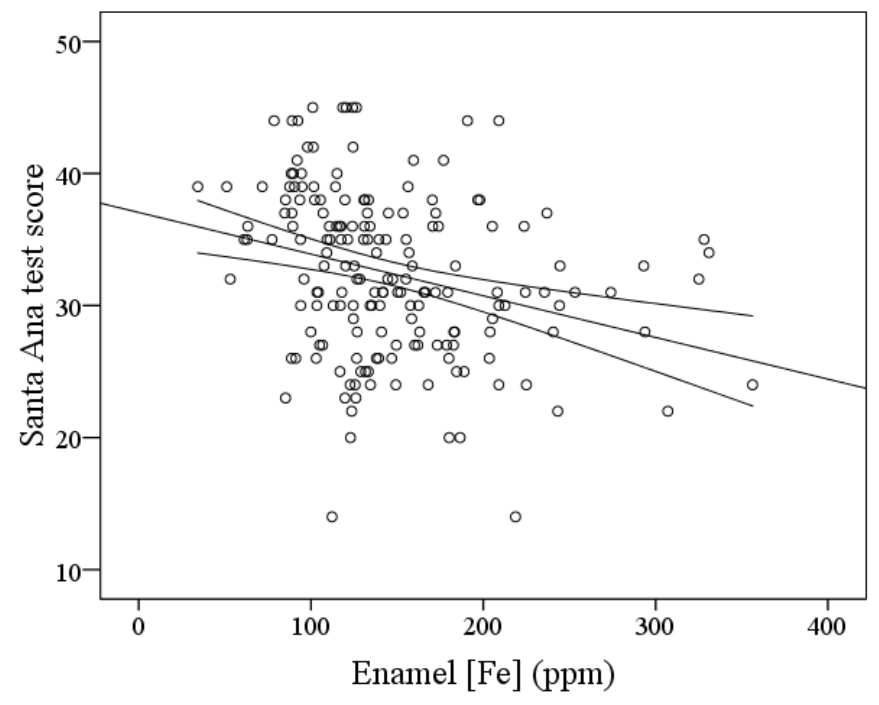

Figure 3.24: A linear regression line showing the relationship between in all teeth-[Fe] and Santa Ana non-dominant test scores. Confidence intervals at the 95\% level are shown above and below the regression line. Associated statistics are shown in Table 3.15.

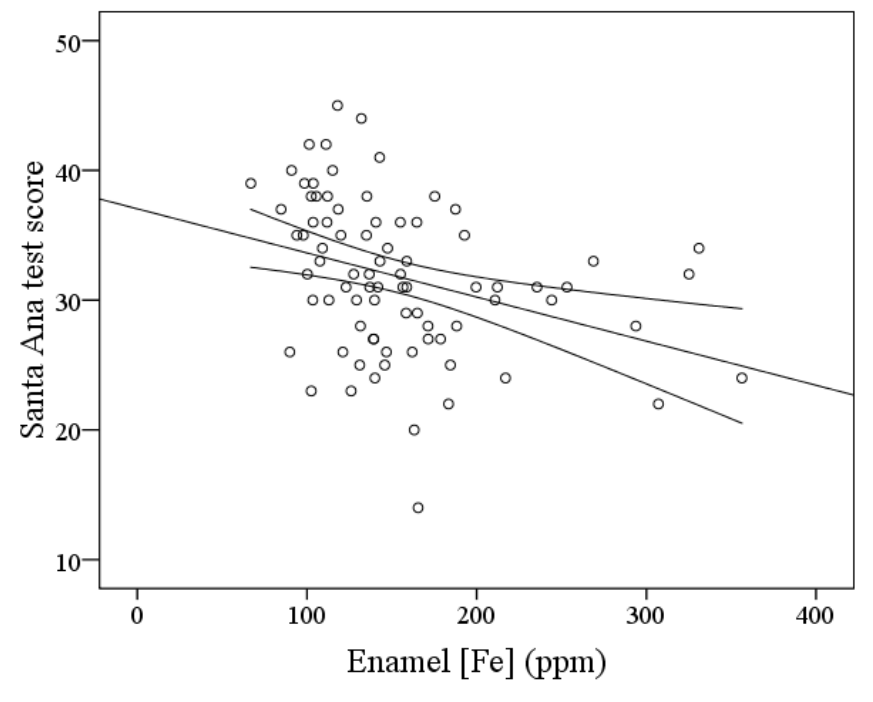

Figure 3.25: A linear regression line showing the relationship between average- $[\mathrm{Fe}]$ and Santa Ana dominant test scores. Confidence intervals at the $95 \%$ level are shown above and below the regression line. Associated statistics are shown in Table 3.15. 


\subsubsection{Relationships between iron and other metals in teeth}

Iron was observed to correlate with most metals in this work. However, copper and iron are chemically similar and share many metabolic pathways (135). There was a strong correlation observed between iron and copper in our data $(\rho=0.81, \mathrm{p}<0.001)$. This seems to show that divalent $\mathrm{Cu}$ and $\mathrm{Fe}$ follow similar metabolic pathways to dental enamel. A literature review found no articles that correlate salivary copper and iron. However, Oprea found the same patterns of correlation between metals as those observed in this work: The strongest correlations to enamel-[Fe], in descending order, were $[\mathrm{Cu}],[\mathrm{Mn}],[\mathrm{Zn}](165)$.

Table 3.16: Correlations of enamel-[Fe] and other metals in enamel

\begin{tabular}{llcccccccc}
\hline & \multicolumn{9}{c}{ Elements } \\
\cline { 2 - 10 } Correlation & \multicolumn{2}{c}{ Manganese } & \multicolumn{2}{c}{ Lead } & \multicolumn{2}{c}{ Zinc } & \multicolumn{2}{c}{ Copper } \\
\cline { 2 - 10 } & Statistic & $\mathrm{p}$ & Statistic & $\mathrm{p}$ & Statistic & $\mathrm{p}$ & Statistic & $\mathrm{p}$ \\
\hline Pearson's $\mathrm{r}$ & $0.76^{* *}$ & $<0.001$ & $0.40^{* *}$ & $<0.001$ & $0.47^{* *}$ & $<0.001$ & $0.48^{* *}$ & $<0.001$ \\
Spearman's $\rho$ & $0.74^{* *}$ & $<0.001$ & $0.35^{* *}$ & $<0.001$ & $0.46^{* *}$ & $<0.001$ & $0.81^{* *}$ & $<0.001$ \\
Kendall's $\tau$ & $0.55^{* *}$ & $<0.001$ & $0.24^{* *}$ & $<0.001$ & $0.32^{* *}$ & $<0.001$ & $0.67^{* *}$ & $<0.001$ \\
\hline
\end{tabular}

*Significant at $\mathrm{p}<0.05$

** Significant at $\mathrm{P}<0.01$

Oprea noted that concentrations of copper and iron were strongly correlated in both urban rural subjects participating in their work. Interestingly, the concentrations of these two elements were highly increased in urban participants, leading Oprea to suggest, based on environmental measurements made in earlier work (175), that the source of the elevated $[\mathrm{Fe}]$ and $[\mathrm{Cu}]$ was industrial pollution (165). Concentrations of zinc and arsenic were also elevated in enamel of subjects in urban areas (175). 


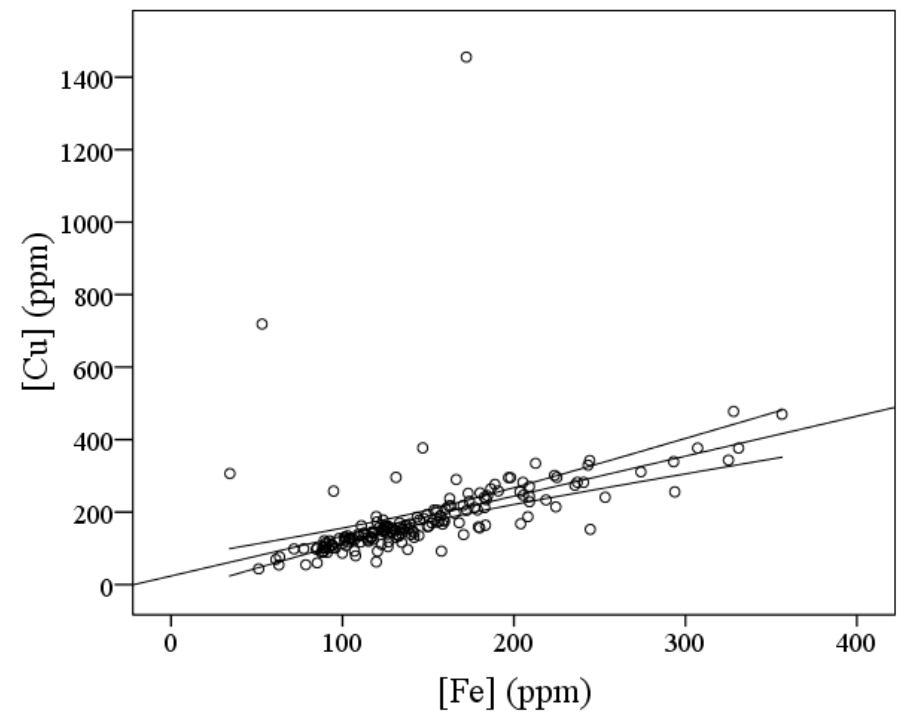

Figure 3.26: A linear regression line showing the relationship between copper and iron in all teeth. Confidence intervals at the 95\% level are shown above and below the regression line. Associated statistics are shown in Table 3.16. 


\subsection{Lead}

Lead in surface enamel has been used as a biomarker for exposure for environmental lead (176). It has been suggested that lead in saliva may be a pathway for lead to enamel, leading to cariogenesis (177). The evidence for this claim is limited, however. The sample population used was an inner-city population, lead exposures were low and dental health of the overall population was quite poor, with $83 \%$ of the population having dental caries. A Brazilian study between a group that was environmentally exposed to lead and a control group found that the exposed group had higher levels of lead in their saliva $(\mathrm{p}<0.001)$ and that there was a marginal, weak correlation between $[\mathrm{Pb}]$ in saliva and $[\mathrm{Pb}]$ in surface enamel $(\mathrm{r}=$ $0.38, \mathrm{p}=0.11)(178)$

A study of blood- $\mathrm{Pb}$, saliva- $\mathrm{Pb}$, and surface enamel lead found that surface enamel was a biomarker of pre-eruptive exposure to $\mathrm{Pb}$ circulating in blood (179). However, there was also a weak correlation between saliva- $\mathrm{Pb}$ and enamel- $\mathrm{Pb}$, suggesting that both pre-eruptive and post-eruptive sources of lead exposure may contribute to lead levels in the surface enamel of teeth. It is interesting that these authors had some experimental difficulties with the depth of measurement using an acid-etching technique. EDXRF may be an ideal solution to address this problem, given that its experimental setup is somewhat easier to keep consistent.

The range of values of the teeth observed in this work (Table 3.17) is larger than the range observed in other samples available in the literature $(159,160,180)$. However, the sample size in this work is larger and its mean value is comparable to the work that used proton-induced $\mathrm{x}$-ray emission spectrometry to measure $\mathrm{Pb}$ in enamel of 77 deciduous tooth enamel samples (180). In comparison to lead concentrations in a sample of 2613 deciduous whole teeth from children in Norway, where lead values were measured in whole teeth, the range of lead values reported here is similar (98). The mean $[\mathrm{Pb}]$ in this work $(8.4 \mathrm{ppm})$, however, is higher than the mean of the Norwegian survey $(1.60 \mathrm{ppm})$ but this may be expected because 
lead levels are generally higher at the surface enamel than at other parts of the tooth (113). The average relative standard deviation between teeth donated from the same child was $58.7 \%$.

Table 3.17: Descriptive Statistics of $\mathrm{Pb}$ in tooth enamel

\begin{tabular}{ccccc}
\hline $\begin{array}{c}\text { Number of } \\
\text { samples }\end{array}$ & Minimum & Maximum & Mean & Variance \\
\hline 176 & $<$ MDL & $30 \mathrm{ppm}$ & $8.4 \mathrm{ppm}$ & $39 \mathrm{ppm}^{2}$ \\
\hline
\end{tabular}

The distribution of measured concentrations of lead in tooth enamel is shown in figure 3.26. There is a tail in the distribution at higher concentrations. The non-normality of the data was confirmed with a ShapiroWilk test $(\mathrm{W}=0.91, \mathrm{p}<0.001)$.

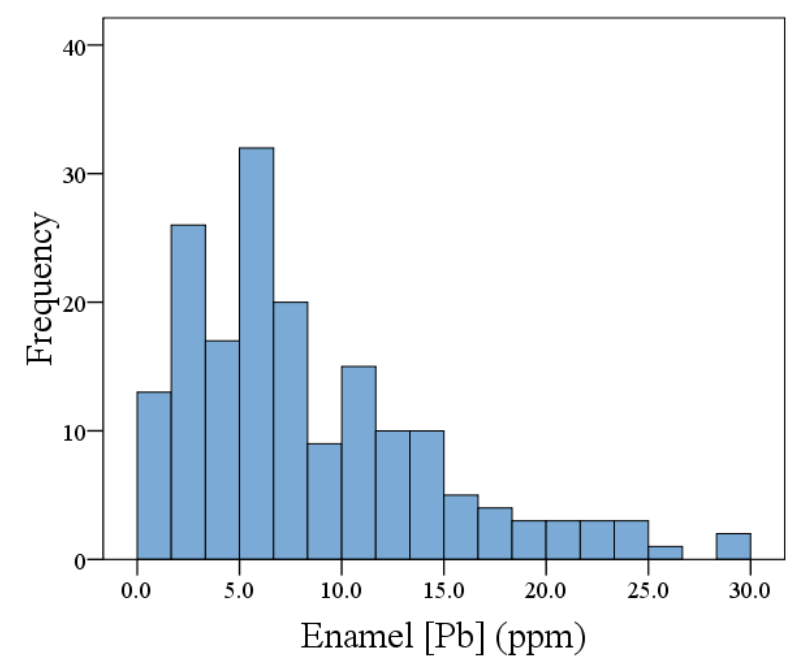

Figure 3.27: Histogram showing the distribution of lead concentrations of all teeth measured in this study. Shapiro-Wilk test $(\mathrm{W}=0.91, \mathrm{p}<0.001)$.

A Kruskall-Wallis test was used to determine that incisors have a higher concentration of lead than canines and molars ( $\mathrm{p}$ 0.001) (Figure 3.28). Increased incisor-[Pb] have also been measured in incisor dentin (109), whole teeth (108), and enamel (180). 


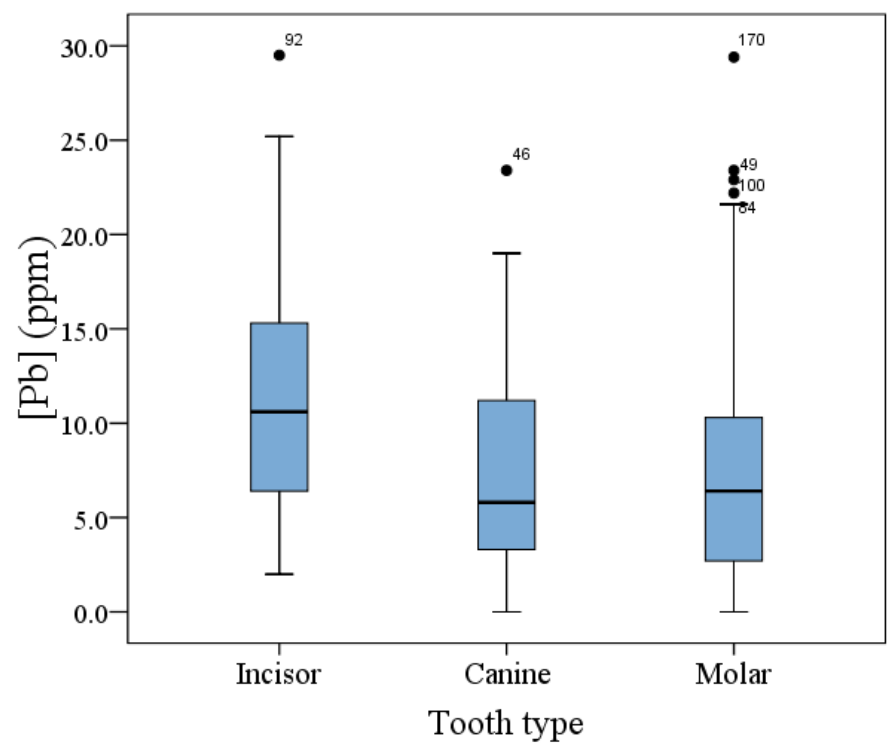

Figure 3.28: Boxplot showing the concentration of lead for incisors, canines and molars. A Kruskal-Wallis test showed that at least one group had a median that was significantly different from the population median $(\mathrm{p}<0.001)$. The median value is depicted as a black line in the center of the box. The second and third quartiles are the boxes on either side and the first and fourth quartiles are depicted by the whiskers below and above the boxes. Outliers are shown as points outside of the whiskers.

\subsubsection{Relationships between lead and children's height}

Recent evidence suggests that early childhood exposure to lead may adversely affect bone development and therefore on children's height, even at blood-lead levels $<10 \mu \mathrm{g} / \mathrm{dL}(181)$. However, in this work, no significant correlations were observed between enamel-[Pb] and children's height (Table 3.18).

Table 3.18: Correlations of enamel-[Pb] and height

\begin{tabular}{|c|c|c|c|c|c|c|c|c|c|c|}
\hline \multirow[b]{3}{*}{ Correlation } & \multicolumn{10}{|c|}{ Cases } \\
\hline & \multicolumn{2}{|c|}{ Incisor } & \multicolumn{2}{|c|}{ Canine } & \multicolumn{2}{|c|}{ Molar } & \multicolumn{2}{|c|}{ All teeth } & \multicolumn{2}{|c|}{ Average } \\
\hline & Statistic & $\mathrm{p}$ & Statistic & $\mathrm{p}$ & Statistic & $\mathrm{p}$ & Statistic & $\mathrm{p}$ & Statistic & $\mathrm{p}$ \\
\hline Pearson's r & 0.05 & 0.74 & -0.02 & 0.88 & 0.03 & 0.79 & -0.13 & 0.09 & -0.19 & 0.10 \\
\hline Spearman's $\rho$ & 0.04 & 0.79 & 0.02 & 0.91 & 0.02 & 0.82 & -0.11 & 0.16 & -0.19 & 0.09 \\
\hline Kendall's $\tau$ & 0.04 & 0.73 & 0.02 & 0.83 & 0.02 & 0.80 & -0.07 & 0.17 & -0.12 & 0.11 \\
\hline
\end{tabular}

*Significant at $\mathrm{p}<0.05$

**Significant at $\mathrm{P}<0.01$ 


\subsubsection{Relationships between lead in enamel and neurological test scores}

Cumulative exposure to low levels of lead during early neurological development could result in significant intellectual impairment (182). Deciduous dentin has been used as a biomarker for lead induced neurotoxicity in children and was found to be a valid predictor of intellectual impairment in a follow-up study 11 years after the original study $(183,184)$.

The work presented here did not detect any meaningful relationship between enamel-[Pb] and WASI IQ test scores (Tables 3.19-3.21). There were high p-values in the t-tests in the linear regressions and the Pearson correlations, and non-parametric tests (Spearman and Kendall) failed to detect correlations also. This holds for all tooth types, controlling for age as well.

Table 3.19: Correlations of enamel-[Pb] and full WASI IQ test scores

\begin{tabular}{|c|c|c|c|c|c|c|c|c|c|c|}
\hline \multirow[b]{3}{*}{ Correlation } & \multicolumn{10}{|c|}{ Cases } \\
\hline & \multicolumn{2}{|c|}{ Incisor } & \multicolumn{2}{|c|}{ Canine } & \multicolumn{2}{|c|}{ Molar } & \multicolumn{2}{|c|}{ All teeth } & \multicolumn{2}{|c|}{ Average } \\
\hline & Statistic & $\mathrm{p}$ & Statistic & $\mathrm{p}$ & Statistic & $\mathrm{p}$ & Statistic & $\mathrm{p}$ & Statistic & $\mathrm{p}$ \\
\hline Pearson's r & 0.11 & 0.49 & -0.15 & 0.33 & 0.01 & 0.94 & -0.03 & 0.74 & -0.06 & 0.60 \\
\hline Spearman's $\rho$ & 0.02 & 0.89 & -0.17 & 0.25 & 0.00 & 0.98 & -0.07 & 0.40 & -0.09 & 0.44 \\
\hline Kendall's $\tau$ & 0.00 & 0.98 & -0.13 & 0.23 & 0.00 & 0.92 & -0.05 & 0.37 & -0.06 & 0.44 \\
\hline
\end{tabular}

*Significant at $\mathrm{p}<0.05$

**Significant at $\mathrm{P}<0.01$

Table 3.20: Correlations of enamel-[Pb] and Santa Ana dominant hand scores

\begin{tabular}{|c|c|c|c|c|c|c|c|c|c|c|}
\hline \multirow[b]{3}{*}{ Correlation } & \multicolumn{10}{|c|}{ Cases } \\
\hline & \multicolumn{2}{|c|}{ Incisor } & \multicolumn{2}{|c|}{ Canine } & \multicolumn{2}{|c|}{ Molar } & \multicolumn{2}{|c|}{ All teeth } & \multicolumn{2}{|c|}{ Average } \\
\hline & Statistic & $\mathrm{p}$ & Statistic & $\mathrm{p}$ & Statistic & $\mathrm{p}$ & Statistic & $\mathrm{p}$ & Statistic & $\mathrm{p}$ \\
\hline Pearson's r & -0.05 & 0.77 & 0.02 & 0.90 & 0.13 & 0.23 & -0.04 & 0.57 & -0.09 & 0.43 \\
\hline Spearman's $\rho$ & 0.03 & 0.85 & -0.03 & 0.85 & 0.16 & 0.16 & -0.02 & 0.77 & -0.03 & 0.83 \\
\hline Kendall's $\tau$ & 0.02 & 0.88 & -0.02 & 0.84 & 0.11 & 0.15 & -0.01 & 0.80 & -0.01 & 0.86 \\
\hline
\end{tabular}

*Significant at $\mathrm{p}<0.05$

**Significant at $\mathrm{P}<0.01$ 
Table 3.21: Correlations of enamel-[Pb] and Santa Ana non-dominant hand scores

\begin{tabular}{|c|c|c|c|c|c|c|c|c|c|c|}
\hline \multirow[b]{3}{*}{ Correlation } & \multicolumn{10}{|c|}{ Cases } \\
\hline & \multicolumn{2}{|c|}{ Incisor } & \multicolumn{2}{|c|}{ Canine } & \multicolumn{2}{|c|}{ Molar } & \multicolumn{2}{|c|}{ All teeth } & \multicolumn{2}{|c|}{ Average } \\
\hline & Statistic & $\mathrm{p}$ & Statistic & $\mathrm{p}$ & Statistic & $\mathrm{p}$ & Statistic & $\mathrm{p}$ & Statistic & $\mathrm{p}$ \\
\hline Pearson's r & 0.00 & 0.98 & -0.23 & 0.13 & 0.04 & 0.70 & -0.14 & 0.06 & -0.18 & 0.10 \\
\hline Spearman's $\rho$ & 0.04 & 0.80 & -0.17 & 0.27 & 0.05 & 0.68 & -0.11 & 0.14 & -0.18 & 0.12 \\
\hline Kendall's $\tau$ & 0.02 & 0.85 & -0.11 & 0.27 & 0.03 & 0.73 & -0.08 & 0.13 & -0.12 & 0.13 \\
\hline
\end{tabular}

*Significant at $\mathrm{p}<0.05$

** Significant at $\mathrm{P}<0.01$

\subsubsection{Relationships between lead and other metals in enamel}

Lead is the only element in this work that is not an essential element to human health. It was found to have weak correlations with manganese and iron in surface enamel, but none with zinc (see Table 3.22, Figure 3.29). There appears to be a very weak correlation between lead and copper. However, since it has been shown that there is variance in the internal standard (calcium) that is used in this method (161), this very weak correlation may be at least partially due to varying calcium content in teeth.

Table 3.22: Correlations of enamel-[Pb] and other metals

\begin{tabular}{|c|c|c|c|c|c|c|c|c|}
\hline \multirow[b]{3}{*}{ Correlation } & \multicolumn{8}{|c|}{ Elements } \\
\hline & \multicolumn{2}{|c|}{ Manganese } & \multicolumn{2}{|c|}{ Iron } & \multicolumn{2}{|c|}{ Zinc } & \multicolumn{2}{|c|}{ Copper } \\
\hline & Statistic & $\mathrm{p}$ & Statistic & $\mathrm{p}$ & Statistic & $\mathrm{p}$ & Statistic & $\mathrm{p}$ \\
\hline Pearson's r & $0.42 * *$ & $<0.001$ & $0.40 * *$ & $<0.001$ & 0.02 & 0.85 & $0.26^{* *}$ & $<0.001$ \\
\hline Spearman's $\rho$ & $0.31 * *$ & $<0.001$ & $0.35 * *$ & $<0.001$ & 0.04 & 0.64 & $0.19 *$ & 0.01 \\
\hline Kendall's $\tau$ & $0.21 * *$ & $<0.001$ & $0.24 * *$ & $<0.001$ & 0.02 & 0.65 & $0.13^{*}$ & 0.01 \\
\hline
\end{tabular}

*Significant at $\mathrm{p}<0.05$

$* *$ Significant at $\mathrm{P}<0.01$ 
A weak correlation between concentrations of zinc and lead in deciduous whole teeth has been observed $(\mathrm{r}=0.22, \mathrm{p}<0.001)(185)$. This contrasts with the current work, which found no correlation between lead and zinc in tooth enamel (Figure 3.29).

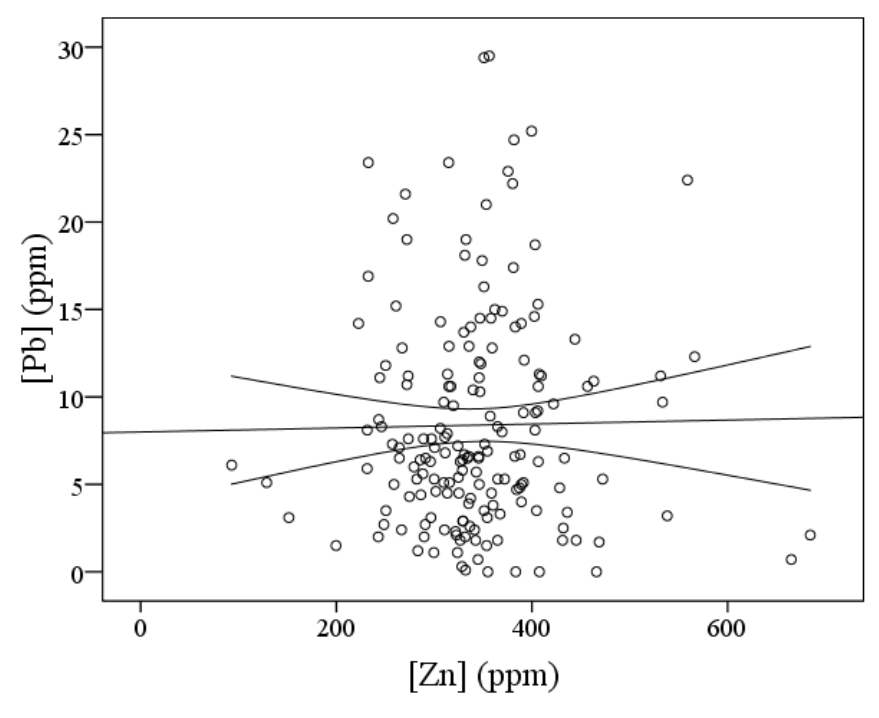

Figure 3.29: A linear regression line showing the relationship between zinc and lead in all teeth. Confidence intervals at the $95 \%$ level are shown above and below the regression line. Associated statistics are shown in Table 3.22.

Levels of both $\mathrm{Zn}$ and $\mathrm{Pb}$ in dental enamel have been suggested as a biomarker for occupational exposure to dusts in Portugese mines (167). Although these data do not suggest a correlation between $\mathrm{Zn}$ and $\mathrm{Pb}$, as was observed by Pinheiro (167), it should be noted that these children were not exposed to levels of dust that would be typical in a mine. The lack of correlation between these metals in the current work does not nullify the suggestion that enamel-[Pb] and enamel-[Zn] may be biomarkers of occupational exposure, given the drastically different level of exposure to dust in occupational settings. Further research is required to confirm enamel as a biomarker for pollution from heavy industry as suggested by Oprea (165), or from mining as suggested by Pinheiro (167). 
Further evidence for the utility of teeth as a biomarker for environmental lead was presented by Tvinherreim and colleagues, who measured a 50\% decrease in the concentration of $\mathrm{Pb}$ in deciduous whole teeth in Norway between the 1970s and the 1990s (98). The authors of that study concluded that the decrease in tooth- $[\mathrm{Pb}]$ corresponds to a decrease in environmental $\mathrm{Pb}$ burden. Lead concentrations in moss were measured as a representation of atmospheric deposition of $\mathrm{Pb}$. It was found that moss-[Pb] from 1985 correlated with the tooth-[Pb] collected in between 1990-1994 $(r=0.29, \mathrm{p}=0.03)$.

There were no known sources of environmental lead exposure for the children in the current work. The lack of correlation between enamel-[Pb] and neurological test scores may be a result of $\mathrm{Pb}$ exposures that are below the threshold for neurotoxicity. To the author's knowledge, a threshold for neurotoxicity has only been established for blood-Pb measurements $(10 \mu \mathrm{g} / \mathrm{dL})$, and not for tooth enamel. 


\subsection{Zinc}

The range of values of the teeth observed in this work (Table 3.23) is within that of a sample of 2614 deciduous teeth donated from children in Norway between 1990 and 1994 (185). However, the mean value is higher at $343 \mathrm{ppm}$ in this work compared to $181.4 \mathrm{ppm}$ in that survey. This result is to be expected, however, since the concentration of zinc in tooth enamel has consistently been observed to be highest at the surface enamel $(186,187)$.

The range of zinc concentrations reported for surface enamel by Oprea is 248-2565 ppm, with a mean value of $838 \mathrm{ppm}$ (165). This contrasts with deciduous enamel measurements made by Zaichick and Ovchjarenko that found a mean enamel-[Zn] of 269 ppm (161). Enamel-[Zn] was observed to be somewhat higher in permanent teeth, with a mean [Zn] of $428 \mathrm{ppm}$ (161). The average relative standard deviation between teeth donated from the same child was $20.6 \%$.

Table 3.23

\begin{tabular}{ccccc}
\hline \multicolumn{5}{l}{ Descriptive Statistics of $\mathrm{Zn}$ in tooth enamel } \\
\hline $\begin{array}{c}\text { Number of } \\
\text { samples }\end{array}$ & Minimum & Maximum & Mean & Variance \\
\hline 177 & $93 \mathrm{ppm}$ & $685 \mathrm{ppm}$ & $343 \mathrm{ppm}$ & $6255 \mathrm{ppm}^{2}$ \\
\hline
\end{tabular}

The distribution of measured concentrations of zinc in tooth enamel is shown in figure 3.29. The nonnormality of the data was confirmed with a Shapiro-Wilk test $(\mathrm{W}=0.93, \mathrm{p}<0.001)$. 


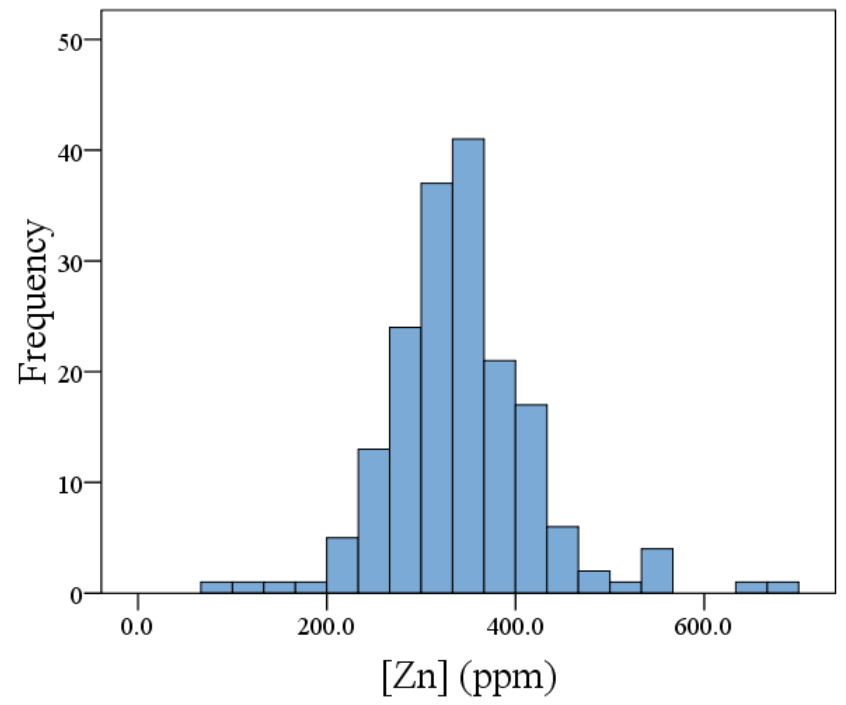

Figure 3.30: Histogram showing the distribution of zinc concentrations of all teeth measured in this study. Shapiro-Wilk test $(\mathrm{W}=0.93, \mathrm{p}<0.001)$.

A Kruskall-Wallis test determined that none of the types of tooth has a significantly higher concentration of zinc than the others $(\mathrm{p}=0.18)$. This is in contrast to whole teeth data collected in Norway that showed that molars had a higher concentration of zinc than canines and incisors $(\mathrm{p}<0.05)(185)$. It is worth noting here that the researchers in the Norwegian observational study had the same issue as the author of this work regarding children who donated more than one tooth; that is, the assumption of independence of samples was violated, and therefore the p-values may be overly confident. Therefore, a p-value that is < 0.05 may not have indicated a statistically significant relationship. 


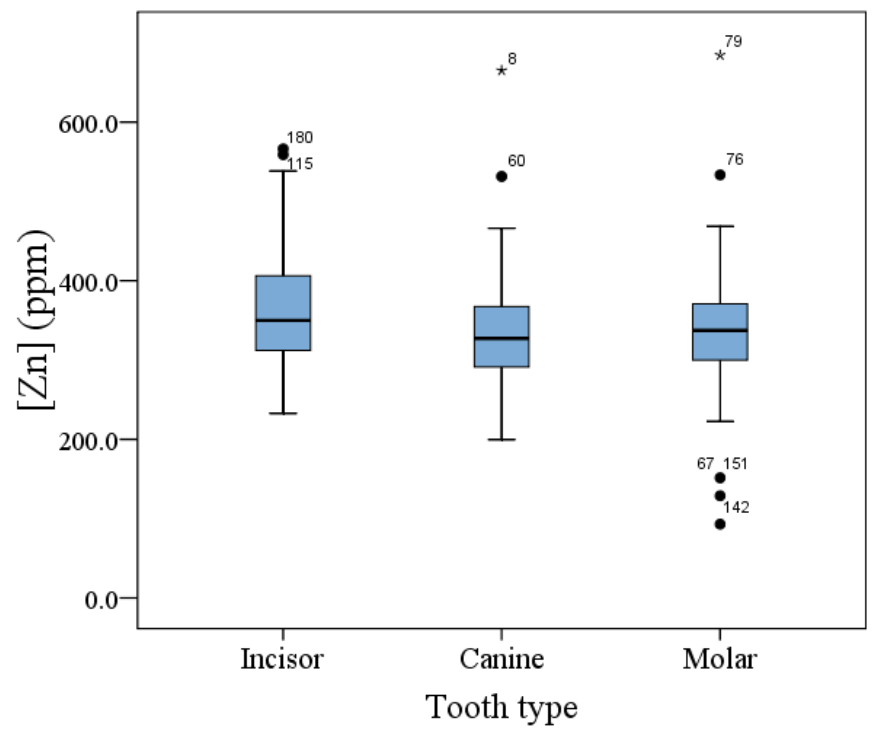

Figure 3.31: Boxplot showing the concentration of zinc for incisors, canines and molars. A Kruskal-Wallis test showed that no group had a median that was significantly different from the population median $(\mathrm{p}=0.18)$. The median value is depicted as a black line in the center of the box. The second and third quartiles are the boxes on either side and the first and fourth quartiles are depicted by the whiskers below and above the boxes. Outliers are shown as points outside of the whiskers.

Although there was no statistically significant difference in the concentration of zinc in different tooth types, the same analysis by tooth type was carried out for zinc as for the other elements in this study for completeness. The boxplot in figure 3.31 shows concentrations of zinc that are not statistically different between incisors, canines and molars.

\subsubsection{Relationships between zinc and children's height}

Zinc was not found to correlate to children's height in this work (Table 3.24). This outcome is not a surprise, since zinc deficiency is uncommon in the developed world. In the developing world, on the other hand, zinc deficiency is far more prevalent, with symptoms of zinc deficiency including growth retardation and cognitive deficits (188). 
Table 3.24: Correlations of enamel-[Zn] and height

\begin{tabular}{llllllllllll}
\hline & \multicolumn{10}{c}{ Cases } \\
\cline { 2 - 12 } Correlation & \multicolumn{2}{c}{ Incisor } & \multicolumn{1}{c}{ Canine } & \multicolumn{2}{c}{ Molar } & \multicolumn{2}{c}{ All teeth } & \multicolumn{2}{c}{ Average } \\
\cline { 2 - 13 }$y$ & Statistic & $\mathrm{p}$ & Statistic & $\mathrm{p}$ & Statistic & $\mathrm{p}$ & Statistic & $\mathrm{p}$ & Statistic & $\mathrm{p}$ \\
\hline Pearson's $\mathrm{r}$ & 0.03 & 0.86 & -0.17 & 0.26 & -0.02 & 0.83 & -0.12 & 0.13 & -0.19 & 0.09 \\
Spearman's $\rho$ & 0.05 & 0.74 & -0.27 & 0.07 & 0.02 & 0.85 & -0.07 & 0.37 & -0.19 & 0.09 \\
Kendall's $\tau$ & 0.03 & 0.76 & -0.19 & 0.07 & 0.01 & 0.85 & -0.05 & 0.36 & -0.13 & 0.08 \\
\hline
\end{tabular}

*Significant at $\mathrm{p}<0.05$

$* *$ Significant at $\mathrm{P}<0.01$

\subsubsection{Relationships between zinc in enamel and neurological test scores}

There is conflicting evidence in the literature regarding the role of zinc deficiency in the cognitive development of children in the developing world $(189,190)$. Recent work has shown that zinc

supplementation may have increased IQ test scores among 36 school-aged children whose baseline zinc levels (those before supplementation) were not considered deficient (191). However, the results of this work may be questionable since the authors did not use a control group and repeated the same IQ test before and after zinc supplementation. There was no significant correlation between zinc levels and IQ test scores in this work (Table 3.25).

Table 3.25: Correlations of enamel-[Zn] and full WASI IQ test scores

\begin{tabular}{llllllllllll}
\hline & \multicolumn{10}{c}{ Cases } \\
\cline { 2 - 12 } Correlation & \multicolumn{2}{c}{ Incisor } & \multicolumn{1}{c}{ Canine } & \multicolumn{2}{c}{ Molar } & \multicolumn{2}{c}{ All teeth } & \multicolumn{2}{c}{ Average } \\
\cline { 2 - 13 }$y$ & Statistic & $\mathrm{p}$ & Statistic & $\mathrm{p}$ & Statistic & $\mathrm{p}$ & Statistic & $\mathrm{p}$ & Statistic & $\mathrm{p}$ \\
\hline Pearson's $\mathrm{r}$ & -0.12 & 0.45 & 0.12 & 0.44 & -0.21 & 0.06 & -0.11 & 0.13 & -0.04 & 0.76 \\
Spearman's $\rho$ & -0.12 & 0.45 & 0.25 & 0.20 & -0.21 & 0.05 & -0.09 & 0.24 & -0.15 & 0.17 \\
Kendall's $\tau$ & -0.08 & 0.47 & 0.15 & 0.15 & -0.14 & 0.06 & -0.06 & 0.24 & -0.11 & 0.17 \\
\hline
\end{tabular}

*Significant at $\mathrm{p}<0.05$

*** Significant at $\mathrm{P}<0.01$ 
There were weak negative correlations between the average-[Zn] of each child and Santa Ana dexterity test scores. However, a linear regression of Santa Ana dominant hand scores and average-[Zn] showed that the standardized $\beta$ for the regression without covariates was $-0.20(p=0.08)$, while the model using age as a covariate had a standardized $\beta$ of $-0.11(\mathrm{p}=0.24)$. Similarly, Santa Ana non-dominant test scores had a standardized beta that was reduced from $0.19(\mathrm{p}=0.10)$ to $-.09(\mathrm{p}=0.32)$ by the addition of age as a covariate. This suggests that the relationship may not in fact be significant.

Table 3.26: Correlations of enamel-[Zn] and Santa Ana dominant hand scores

\begin{tabular}{llllllllllll}
\hline & \multicolumn{1}{c}{ Cases } \\
\cline { 2 - 12 } Correlation & \multicolumn{2}{c}{ Incisor } & \multicolumn{1}{c}{ Canine } & \multicolumn{2}{c}{ Molar } & \multicolumn{1}{c}{ All teeth } & \multicolumn{2}{c}{ Average } \\
\cline { 2 - 13 }$y$ & Statistic & $\mathrm{p}$ & Statistic & $\mathrm{p}$ & Statistic & $\mathrm{p}$ & Statistic & $\mathrm{p}$ & Statistic & $\mathrm{p}$ \\
\hline Pearson's $\mathrm{r}$ & -0.25 & 0.10 & -0.03 & 0.86 & -0.07 & 0.50 & -0.14 & 0.06 & -0.20 & 0.08 \\
Spearman's $\rho$ & -0.11 & 0.46 & -0.01 & 0.93 & -0.09 & 0.25 & -0.12 & 0.12 & $-0.24^{*}$ & 0.03 \\
Kendall's $\tau$ & -0.09 & 0.42 & -0.01 & 0.92 & -0.11 & 0.30 & -0.08 & 0.11 & $-0.17^{*}$ & 0.06 \\
\hline
\end{tabular}

$*$ Significant at $\mathrm{p}<0.05$

** Significant at $\mathrm{P}<0.01$

Table 3.27: Correlations of enamel-[Zn] and Santa Ana non-dominant hand scores

\begin{tabular}{|c|c|c|c|c|c|c|c|c|c|c|}
\hline \multirow[b]{3}{*}{ Correlation } & \multicolumn{10}{|c|}{ Cases } \\
\hline & \multicolumn{2}{|c|}{ Incisor } & \multicolumn{2}{|c|}{ Canine } & \multicolumn{2}{|c|}{ Molar } & \multicolumn{2}{|c|}{ All teeth } & \multicolumn{2}{|c|}{ Average } \\
\hline & Statistic & $\mathrm{p}$ & Statistic & $\mathrm{p}$ & Statistic & $\mathrm{p}$ & Statistic & $\mathrm{p}$ & Statistic & $\mathrm{p}$ \\
\hline Pearson's r & -0.14 & 0.37 & -0.05 & 0.73 & -0.07 & 0.52 & -0.14 & 0.07 & -0.19 & 0.10 \\
\hline Spearman's $\rho$ & -0.08 & 0.59 & -0.13 & 0.38 & 0.02 & 0.84 & -0.08 & 0.29 & $-0.24 *$ & 0.03 \\
\hline Kendall's $\tau$ & -0.05 & 0.61 & -0.07 & 0.48 & 0.01 & 0.87 & -0.06 & 0.29 & $-0.16^{*}$ & 0.04 \\
\hline
\end{tabular}

*Significant at $\mathrm{p}<0.05$

**Significant at $\mathrm{P}<0.01$ 


\subsubsection{Relationships between zinc and other metals in enamel}

Zinc was found to have a statistically significant correlation with manganese, iron and copper (Table 3.28). The strongest correlation was with copper. Similarly, log transformed zinc concentrations have been observed to correlate with other metals in descending order of strength: $[\mathrm{Cu}],[\mathrm{Fe}]=[\mathrm{Mn}](\mathrm{p} \leq 0.05$ for all coefficients) (165).

Zinc concentrations were also found to correlate with copper concentrations in the saliva of 225 adults (192). A review of the literature did not find additional data correlating zinc with manganese, copper, iron or lead in saliva.

Table 3.28: Correlations of enamel-[Zn] and other metals in enamel

\begin{tabular}{llcccccccc}
\hline & \multicolumn{9}{c}{ Elements } \\
\cline { 2 - 10 } Correlation & \multicolumn{2}{c}{ Manganese } & \multicolumn{2}{c}{ Iron } & \multicolumn{2}{c}{ Copper } & \multicolumn{2}{c}{ Lead } \\
\cline { 2 - 11 }$y$ & Statistic & $\mathrm{p}$ & Statistic & $\mathrm{p}$ & Statistic & $\mathrm{p}$ & Statistic & $\mathrm{p}$ \\
\hline Pearson's $\mathrm{r}$ & $0.39^{* *}$ & $<0.001$ & $0.47^{* *}$ & $<0.001$ & $0.46^{* *}$ & $<0.001$ & 0.02 & 0.85 & 0.04 \\
Spearman's $\rho$ & $0.38^{* *}$ & $<0.001$ & $0.46^{* *}$ & $<0.001$ & $0.53^{* *}$ & $<0.001$ & 0.04 & 0.64 \\
Kendall's $\tau$ & $0.25^{* *}$ & $<0.001$ & $0.32^{* *}$ & $<0.001$ & $0.37^{* *}$ & $<0.001$ & 0.02 & 0.65 \\
\hline
\end{tabular}

*Significant at $\mathrm{p}<0.05$

**Significant at $\mathrm{P}<0.01$ 


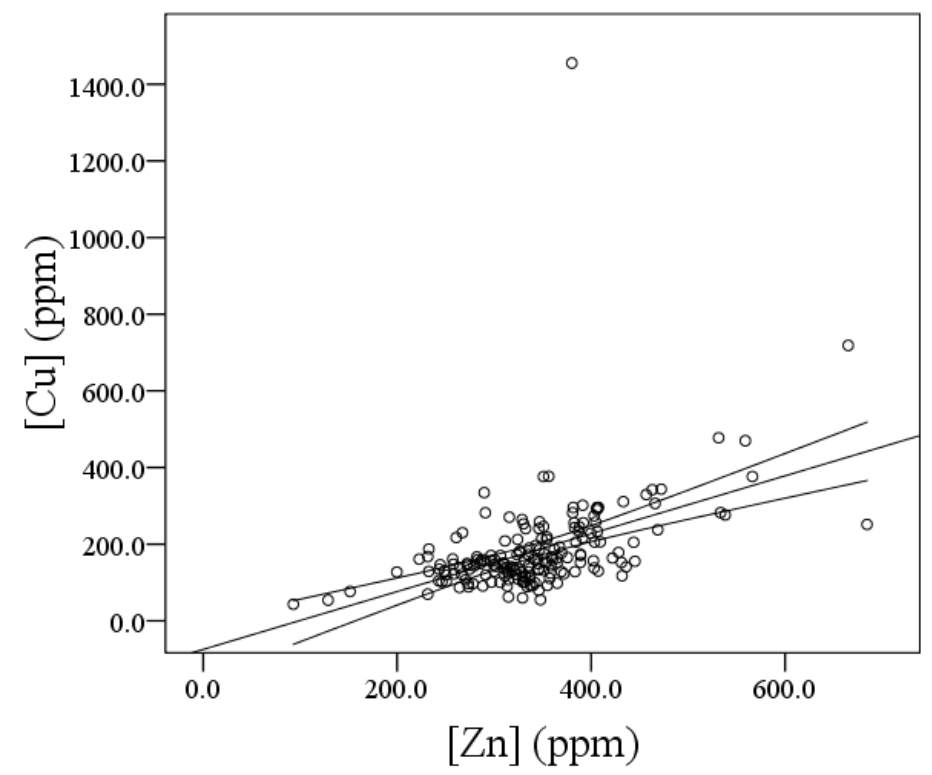

Figure 3.32: A linear regression line showing the relationship between zinc and copper in all teeth. Confidence intervals at the $95 \%$ level are shown above and below the regression line. Associated statistics are shown in Table 3.28. 


\subsection{Copper}

Copper is an essential element that has received comparatively little attention in the literature for its potential toxicity. However, there has been recent work aimed at finding a reliable biomarker for copper exposure of workers at Australian vineyards who are exposed copper-containing fungicides (193).

Copper plays many important roles in physiology. Because copper is needed for the initiation of endothelial cells towards angiogenesis, chelation therapies for the reduction of bioavailability of copper have been a focus of some chemotherapeutic agents against cancer $(194,195)$. A biomarker for cumulative exposure to (or deprivation of) copper may provide a useful tool for improvement of copper chelation agents. The current work examined correlations between copper in surface enamel and other metals, as well as health outcomes that are known to be related to metals exposures.

Descriptive statistics for copper in children's tooth enamel are shown in Table 3.29. The average relative standard deviation between teeth donated from the same child was $31.5 \%$. The concentrations of copper in this work are considerably higher than the range observed in other tooth samples in the literature (159, 160). It must also be noted that the method for quantifying $\mathrm{Cu}$ in enamel reported in these studies used a synchrotron x-ray beamline with cross sections of molars. The scan of the x-ray beam measured the molar enamel between the occlusal surface and the dentine, parallel to the occlusal surface, whereas the values obtained in this work are surface measurements (159).

The range of values in the current work is greater than the range reported by Oprea (165). It should be noted, however, that there are only 4 samples of 178 that were measured that had enamel-[Cu] greater than 400 ppm (shown in Figure 3.34). 
Table 3.29: Descriptive Statistics of $\mathrm{Cu}$ in tooth enamel

\begin{tabular}{ccccc}
\hline $\begin{array}{c}\text { Number of } \\
\text { samples }\end{array}$ & Minimum & Maximum & Mean & Variance \\
\hline 178 & $43 \mathrm{ppm}$ & $1455 \mathrm{ppm}$ & $185 \mathrm{ppm}$ & $16868 \mathrm{ppm}^{2}$ \\
\hline
\end{tabular}

The non-normal distribution of measured concentrations of copper in tooth enamel is shown in figure 3.32 (Shapiro-Wilk test, $\mathrm{p}<0.001$ ).

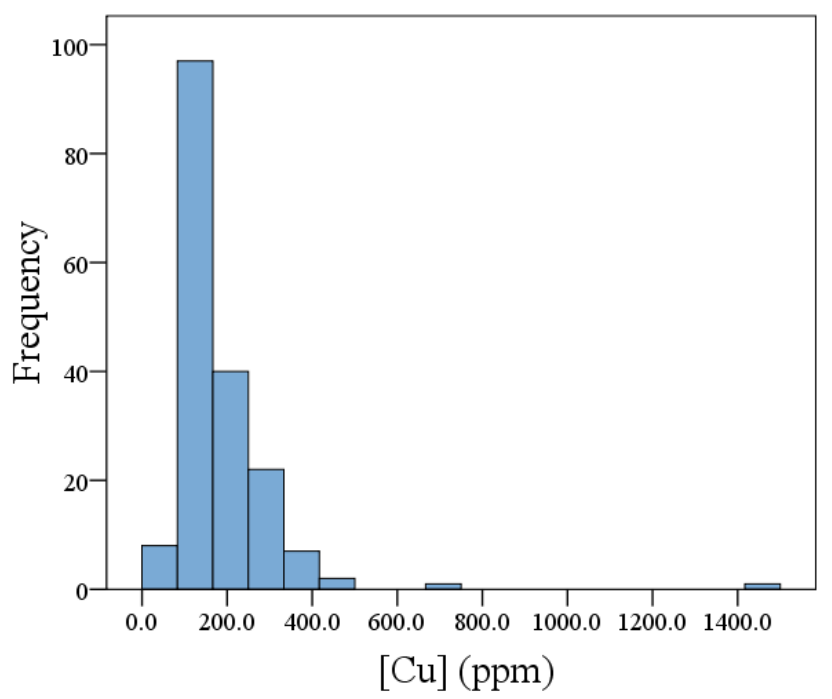

Figure 3.33: Histogram showing the distribution of copper concentrations of all teeth measured in this study. Shapiro-Wilk test $(\mathrm{W}=0.58, \mathrm{p}<0.001)$.

As is the case for all metals in this work except for zinc, incisors have a higher concentration of copper than canines and molars (Kruskall-Wallis test, $\mathrm{p}=0.001$ ). The distributions of the three different tooth types are represented in a boxplot in figure 3.34. 


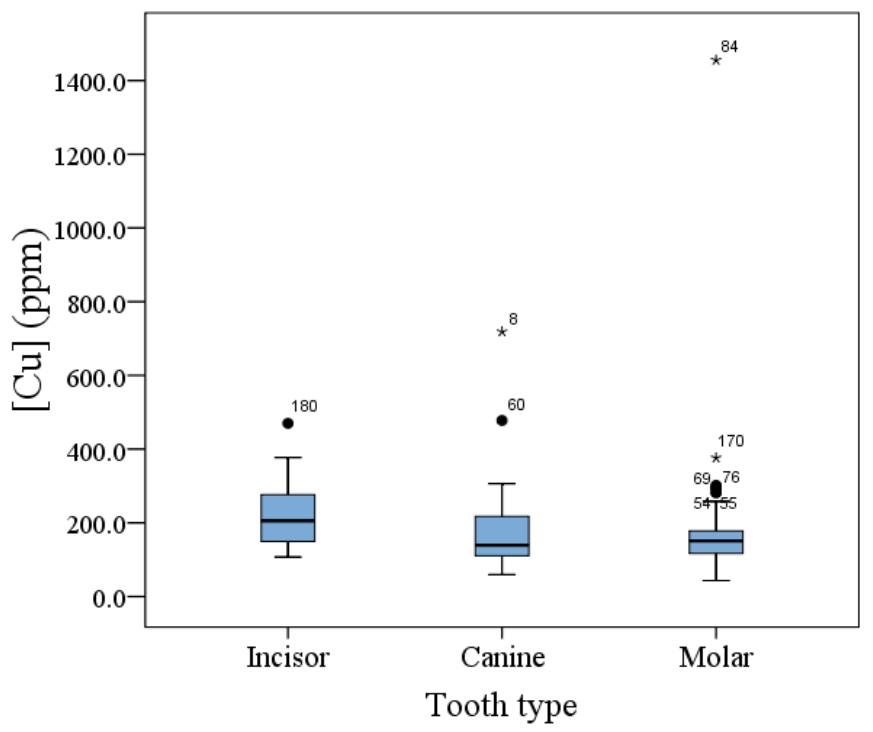

Figure 3.34: Boxplot showing the concentration of copper for incisors, canines and molars. A Kruskal-Wallis test showed that at least one group had a median that was significantly different from the population median $(\mathrm{p}=0.001)$. The median value is depicted as a black line in the center of the box. The second and third quartiles are the boxes on either side and the first and fourth quartiles are depicted by the whiskers below and above the boxes. Outliers are shown as points outside of the whiskers.

\subsubsection{Relationships between copper and children's height}

When age is controlled for as a covariate in a linear correlation model, there is no significant correlation between copper and children's height. For all teeth, the standardized $\beta$ coefficient in the linear regression was reduced from $-0.22(p=0.003)$ to $-0.05(p=0.24)$. For average concentrations of each child the standardized $\beta$ coefficient was reduced from $-0.37(p=0.001)$ to $-0.10(p=0.10)$. It is interesting to note the similarity of the results between iron and copper. Although there is little evidence to suggest a direct mechanism of interaction between copper concentrations within healthy margins and bone development, it is possible that dyshomeostasis of an element such as iron could have an effect on the presence of copper in tissues. 
Table 3.30: Correlations of [Cu] in enamel and children's height

\begin{tabular}{|c|c|c|c|c|c|c|c|c|c|c|}
\hline \multirow[b]{3}{*}{ Correlation } & \multicolumn{10}{|c|}{ Cases } \\
\hline & \multicolumn{2}{|c|}{ Incisor } & \multicolumn{2}{|c|}{ Canine } & \multicolumn{2}{|c|}{ Molar } & \multicolumn{2}{|c|}{ All teeth } & \multicolumn{2}{|c|}{ Average } \\
\hline & Statistic & $\mathrm{p}$ & Statistic & $\mathrm{p}$ & Statistic & $\mathrm{p}$ & Statistic & $\mathrm{p}$ & Statistic & $\mathrm{p}$ \\
\hline Pearson's r & -0.14 & 0.36 & -0.27 & 0.06 & -0.14 & 0.18 & $-0.22 *$ & 0.003 & $-0.37 * *$ & 0.001 \\
\hline Spearman's $\rho$ & -0.22 & 0.15 & $-0.38 *$ & 0.01 & -0.14 & 0.19 & $-0.07 * *$ & $<0.001$ & $-0.46^{* *}$ & $<0.001$ \\
\hline Kendall's $\tau$ & -0.15 & 0.17 & $-0.27 * *$ & 0.01 & -0.10 & 0.17 & $-0.21 * *$ & $<0.001$ & $-0.31 * *$ & $<0.001$ \\
\hline
\end{tabular}

*Significant at $\mathrm{p}<0.05$

**Significant at $\mathrm{P}<0.01$ (Canine $\mathrm{p}$-value was rounded up)

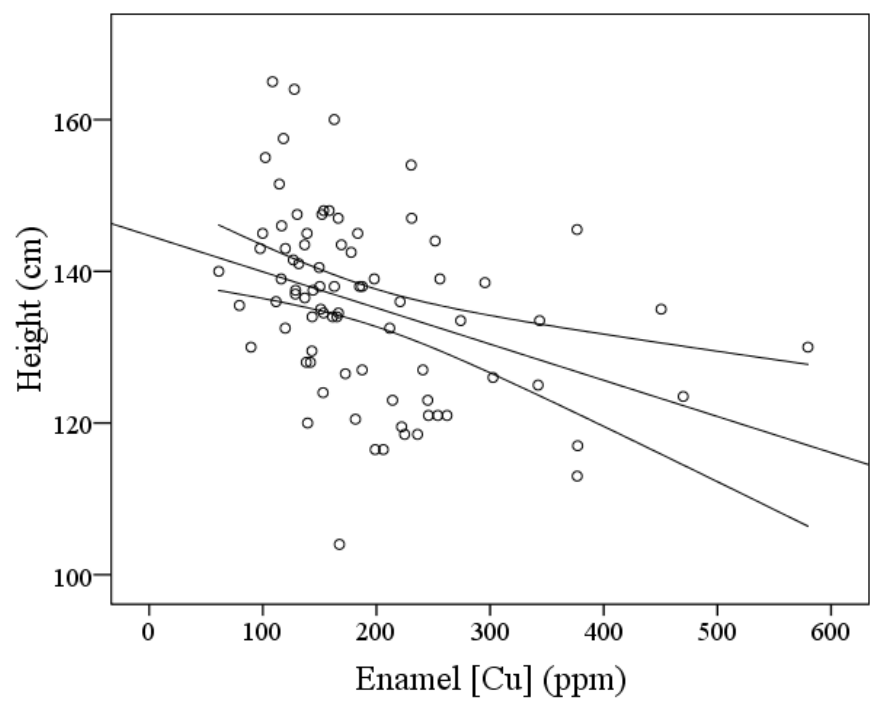

Figure 3.35: A linear regression line showing the relationship between the average copper in all measured tooth enamel of each child and the children's height. Confidence intervals at the 95\% level are shown above and below the regression line. Associated statistics are shown in Table 3.30.

\subsubsection{Relationships between copper in enamel and neurological test scores}

The great majority of the literature pertaining to the potential neurotoxicity of copper relates to neurodegenerative conditions such as Alzheimer's disease and amyotrophic lateral sclerosis (ALS), or to the genetic conditions Wilson's disease and Menkes disease. As a result, this work is somewhat unique for investigating healthy children's teeth as a potential biomarker for copper. 
There were no significant correlations between children's IQ test scores and enamel-[Cu] concentrations (Table 3.31). Similarly, no correlation was found between Santa Ana dexterity test scores of either dominant or non-dominant hands and average concentration of copper in teeth donated by each child as well as all teeth, when controlling for age as a covariate.

Table 3.31: Correlations of [Cu] in enamel and full WASI IQ test scores

\begin{tabular}{|c|c|c|c|c|c|c|c|c|c|c|}
\hline \multirow[b]{3}{*}{ Correlation } & \multicolumn{10}{|c|}{ Cases } \\
\hline & \multicolumn{2}{|c|}{ Incisor } & \multicolumn{2}{|c|}{ Canine } & \multicolumn{2}{|c|}{ Molar } & \multicolumn{2}{|c|}{ All teeth } & \multicolumn{2}{|c|}{ Average } \\
\hline & Statistic & $p$ & Statistic & $p$ & Statistic & $\mathrm{p}$ & Statistic & $\mathrm{p}$ & Statistic & $\mathrm{p}$ \\
\hline Pearson's r & 0.06 & 0.72 & 0.15 & 0.32 & 0.07 & 0.50 & 0.07 & 0.36 & 0.03 & 0.79 \\
\hline Spearman's $\rho$ & 0.03 & 0.86 & 0.22 & 0.15 & -0.13 & 0.22 & -0.04 & 0.61 & -0.07 & 0.57 \\
\hline Kendall's $\tau$ & 0.03 & 0.76 & 0.15 & 0.16 & -0.09 & 0.21 & -0.03 & 0.58 & -0.04 & 0.59 \\
\hline
\end{tabular}

*Significant at $\mathrm{p}<0.05$

$* *$ Significant at $\mathrm{P}<0.01$

Table 3.32: Correlations of [Cu] in enamel and Santa Ana dominant hand scores

\begin{tabular}{|c|c|c|c|c|c|c|c|c|c|c|}
\hline \multirow[b]{3}{*}{ Correlation } & \multicolumn{10}{|c|}{ Cases } \\
\hline & \multicolumn{2}{|c|}{ Incisor } & \multicolumn{2}{|c|}{ Canine } & \multicolumn{2}{|c|}{ Molar } & \multicolumn{2}{|c|}{ All teeth } & \multicolumn{2}{|c|}{ Average } \\
\hline & Statistic & $\mathrm{p}$ & Statistic & $\mathrm{p}$ & Statistic & $\mathrm{p}$ & Statistic & $\mathrm{p}$ & Statistic & $\mathrm{p}$ \\
\hline Pearson's r & -0.28 & 0.06 & -0.07 & 0.63 & 0.03 & 0.23 & -0.09 & 0.23 & $-0.26^{*}$ & 0.02 \\
\hline Spearman's $\rho$ & -0.21 & 0.17 & -0.10 & 0.50 & -0.12 & 0.27 & $-0.23 * *$ & 0.002 & $-0.32 * *$ & 0.004 \\
\hline Kendall's $\tau$ & -0.15 & 0.16 & -0.07 & 0.49 & -0.08 & 0.32 & $-0.16 * *$ & 0.003 & $-0.22 * *$ & 0.005 \\
\hline
\end{tabular}

*Significant at $\mathrm{p}<0.05$

** Significant at $\mathrm{P}<0.01$ 
Table 3.33: Correlations of [Cu] in enamel and Santa Ana non-dominant hand scores

\begin{tabular}{|c|c|c|c|c|c|c|c|c|c|c|}
\hline \multirow[b]{3}{*}{ Correlation } & \multicolumn{10}{|c|}{ Cases } \\
\hline & \multicolumn{2}{|c|}{ Incisor } & \multicolumn{2}{|c|}{ Canine } & \multicolumn{2}{|c|}{ Molar } & \multicolumn{2}{|c|}{ All teeth } & \multicolumn{2}{|c|}{ Average } \\
\hline & Statistic & $\mathrm{p}$ & Statistic & $\mathrm{p}$ & Statistic & $\mathrm{p}$ & Statistic & $\mathrm{p}$ & Statistic & $\mathrm{p}$ \\
\hline Pearson's r & -0.22 & 0.14 & -0.06 & 0.72 & -0.06 & 0.62 & -0.14 & 0.07 & $-0.26^{*}$ & 0.02 \\
\hline Spearman's $\rho$ & -0.23 & 0.12 & -0.12 & 0.41 & -0.06 & 0.58 & $-0.23 * *$ & 0.002 & $-0.36 * *$ & 0.001 \\
\hline Kendall's $\tau$ & -0.16 & 0.13 & -0.09 & 0.37 & -0.04 & 0.62 & $-0.16^{* *}$ & 0.002 & $-0.24 * *$ & 0.002 \\
\hline
\end{tabular}

*Significant at $\mathrm{p}<0.05$

**Significant at $\mathrm{P}<0.01$

\subsubsection{Relationships between copper and other metals in enamel}

Copper was observed to have strong correlations to manganese, iron and zinc in surface enamel. A review of the literature found no information correlating copper to other trace metals in enamel. However, a study that investigated the effect of smoking on trace element concentrations in saliva found that levels of copper and zinc were observed in consistent ratios between different groups despite varying concentrations, suggesting that these elements may be correlated in enamel as well (196).

Table 3.34: Correlations of [Cu] and other metals in enamel

\begin{tabular}{|c|c|c|c|c|c|c|c|c|}
\hline \multirow[b]{3}{*}{ Correlation } & \multicolumn{8}{|c|}{ Elements } \\
\hline & \multicolumn{2}{|c|}{ Manganese } & \multicolumn{2}{|c|}{ Iron } & \multicolumn{2}{|c|}{ Zinc } & \multicolumn{2}{|c|}{ Lead } \\
\hline & Statistic & $\mathrm{p}$ & Statistic & $\mathrm{p}$ & Statistic & $\mathrm{p}$ & Statistic & $\mathrm{p}$ \\
\hline Pearson's r & $0.37 * *$ & $<0.001$ & $0.48 * *$ & $<0.001$ & $0.46 * *$ & $<0.001$ & 0.26 & $<0.001$ \\
\hline Spearman's $\rho$ & $0.64 * *$ & $<0.001$ & $0.81 * *$ & $<0.001$ & $0.53 * *$ & $<0.001$ & $0.19 *$ & 0.01 \\
\hline Kendall's $\tau$ & $0.47 * *$ & $<0.001$ & $0.67 * *$ & $<0.001$ & $0.37 * *$ & $<0.001$ & $0.13 *$ & 0.01 \\
\hline
\end{tabular}

*Significant at $\mathrm{p}<0.05$

**Significant at $\mathrm{P}<0.01$ 


\section{Chapter 4}

\section{Conclusions}

This work developed a method for non-destructive quantification of $\mathrm{Mn}, \mathrm{Fe}, \mathrm{Cu}, \mathrm{Zn}$ and $\mathrm{Pb}$ in deciduous tooth enamel of 178 tooth samples collected from 80 children the province of Quebec, Canada using

EDXRF. Figures of merit of the measurement method and relevant quantification statistics are summarized in Table 4.1.

Table 4.1: Figures of merit and quantification statistics for the EDXRF measurement of divalent metals in tooth enamel

\begin{tabular}{lcccc}
\hline Element & $\begin{array}{c}\text { Range of } \\
\text { concentrations } \\
(\mathbf{p p m})\end{array}$ & $\begin{array}{c}\text { Mean } \\
\text { concentration } \\
(\mathbf{m e a n} \pm \boldsymbol{\sigma})\end{array}$ & $\begin{array}{c}\text { Limit of } \\
\text { detection } \\
(\mathbf{p p m})\end{array}$ & $\begin{array}{c}\text { Analytical } \\
\text { sensitivity } \\
\left(\mathbf{p p m}^{-\mathbf{1}} \mathbf{s}^{-\mathbf{1}}\right)\end{array}$ \\
\hline Manganese & $8-109$ & $29 \pm 15$ & 1.6 & 7.9 \\
Iron & $34-356$ & $147 \pm 57$ & 6.5 & 6.7 \\
Copper & $43-1455$ & $185 \pm 130$ & 1.8 & 2.3 \\
Zinc & $93-685$ & $343 \pm 79$ & 1.7 & 2.6 \\
Lead & $<$ MDL-30 & $8.4 \pm 6.2$ & 0.6 & 9.4 \\
\hline
\end{tabular}

The method presented in this work has the advantage of being a non-destructive, non-invasive, multielemental quantification method for trace metals that are related to human health in tooth enamel. 
Deciduous teeth are shed naturally and can be easily stored and transported. Enamel is highly conservative, so the tissue imposes no time constraints on the analysis.

The detection limits of the current system are sufficiently low for all elements investigated other than lead that the minimum analyte concentrations observed are above the detection limit of the system. Multielemental analysis has the additional advantage of allowing for comparisons between metals, providing researchers with insights about interactions between metals in the oral environment.

The disadvantage of multi-elemental analysis is that trade-offs are required in the optimization of the system that detrimentally affect the quantification of lead. Specifically, the selection of an aluminum filter for the $40 \mathrm{kV}$ Pd-anode $\mathrm{x}$-ray tube led to high background, and therefore high detector noise at the $\mathrm{Pb} \mathrm{L} \beta$ line $(12.5 \mathrm{keV})$. The geometry of the source, sample and tube appear to create Bragg diffraction peaks in the spectrum also. These problems could be minimized by measuring lead separately; ideally, with a ${ }^{109} \mathrm{Cd}$ source and hyper-pure germanium detector to measure the $\mathrm{Pb}-\mathrm{K} \alpha$ line $\left(\mathrm{Pb}-\mathrm{K} \alpha_{1}=74.97 \mathrm{keV} ;{ }^{109} \mathrm{Cd}-\gamma=\right.$ $88.04 \mathrm{keV}$ ). It must be noted, however, that the incident and take-off angles would have to be much smaller than $45^{\circ}$ with a $\mathrm{Pb}-\mathrm{K} \alpha$ system, if the critical penetration depth of measurement were to be maintained within the depth of enamel.

Another disadvantage of the current work is that it is observational in nature. Because of this, it is limited in its capacity to attribute trace element concentrations to specific routes of exposure. Controlled experiments would provide more accurate information about ion exchange and adsorption at the enamel surface. However, observational data are still very useful as a starting point for investigations of a novel biomarker.

In this work, weak positive correlations were shown between concentrations of manganese in tooth enamel and dietary intakes of $\mathrm{Mn}(\mathrm{p}<0.01)$, but not for tap water intake of Mn. Controlling for age as a covariate, there was no observed correlation between manganese and full WASI IQ test scores or Santa 
Ana dexterity test scores. Manganese concentrations in surface enamel were strongly correlated to iron levels $(\mathrm{p}<0.001)$.

Iron concentrations in tooth enamel were found to have no correlation to estimated dietary and tap water intakes of iron. There was a weak negative correlation between concentrations of iron in molars and IQ test scores $(p=0.02)$. Iron concentrations were found to strongly correlate with manganese and copper, suggesting that these elements share similar metabolic pathways to surface enamel.

Deciduous incisors were found to have higher concentrations of lead than canines and molars. Controlling for age, there were no significant correlations between lead and height, IQ, or Santa Ana test scores. There were no significant correlations between lead levels in surface enamel and neurological test scores, suggesting that there was no significant source of environmental lead that might have been expected to cause neurotoxicity among a subset of children.

Zinc was unique in its distribution among various tooth types in that there was no significant difference between median values among incisors, canines and molars. Zinc concentrations were generally higher than those of other trace metals quantified in this study. There was no correlation observed between $\mathrm{Zn}$ and height, IQ or Santa Ana test scores.

Copper is a trace element that has gained some attention for its role in angiogenesis, particularly during rapid tumor growth. Copper levels in surface enamel in this work were highest in incisors. There were no significant correlations between copper concentrations and height, IQ or Santa Ana test scores. Considering the observational nature of this work, however, more controlled experiments would be necessary to provide conclusive evidence for the usefulness of tooth enamel as a biomarker for copper exposure. 



\section{Chapter 5}

\section{Future work}

An emergent technology that may have an impact in work of this nature is portable, hand-held XRF (HHXRF) systems. HHXRF may enable researchers to travel to sights of occupational or environmental exposures to trace metals and to take many in situ measurements that would be of significant interest including dust, soil and potentially in vivo measurements also. Method development for each of dust, soil and in vivo applications would likely have a tremendous impact in the environmental health community because of the drastic improvement in cost-effectiveness of the measurements relative to conventional techniques.

Radiation exposure and time of measurement currently present considerable challenges to these measurements in vivo. However, improvements in SDD detector thoughtput may benefit the feasibility of in vivo HHXRF measurements in the future, providing researchers with an inexpensive, non-destructive tool to measure sources and pathways of trace metals exposures in situ. 
There are several other possibilities for future work following this method development and observational study. Deciduous tooth enamel has not yet been validated as a biomarker for manganese, iron, copper or zinc. There is some uncertainty in the effect that de- and re-mineralization might have on the outer layer of tooth enamel. It will be of considerable interest to quantify the adsorption of trace elements onto enamel of teeth in a simulated oral environment.

It would be ideal to perform a set of experiments with unerupted teeth that had been carefully removed to avoid any potential contamination. The use of unerupted teeth would provide a biomarker for the presence of trace metals in blood and extracellular fluid during enamel development since there is no other pathways for metals to enter the enamel. The use of unerupted teeth would then enable the simplest interpretation of results, since any changes that were observed would be attributed directly to the experimental setup without confounding effects such as differences in wear or erosion after eruption. However, any teeth that are well-characterized for surface hardness and trace element concentrations would still be appropriate.

The effect of $\mathrm{pH}$ and varying plaque fluid and saliva trace element concentrations could be tested in a controlled environment by paired comparisons. For example, maxillary central incisors from the same child could be measured for trace element concentrations using the method developed in this work and then immersed in artificial saliva with identical trace element concentrations but at differing physiological pH. Other experiments might keep the $\mathrm{pH}$ contant but vary the trace element concentration of the artificial saliva or plaque fluid over time. The method developed in the current work offers the benefit of being non-destructive, so measurements could be made weekly or bi-weekly to measure changes over time without damaging or altering the sample. These experiments would be very simple, inexpensive and useful, although it seems likely that they would need to be maintained over a prolonged period of at least a year before any significant change is likely to be measured. 
Other experiments could be performed using the above-mentioned setup to test the effect of periodic drops in $\mathrm{pH}$ on the trace element profile of teeth, simulating consumption of acidic food and drinks. There has been some interest in this in the literature, although the experimental methods have failed to take into account the buffering of $\mathrm{pH}$ and increased fluid flow that is provided by saliva in vivo. It would be very useful to measure the effect of periodic de-minerization and re-mineralization under physiological conditions. To the author's knowledge, this work would be novel in its investigation on the effects of most trace metal concentrations in enamel. To date, similar experiments have been performed to test the efficacy of fluoride treatments in improving surface enamel resistivity to acid erosion and cariogenesis, but have ignored other trace elements in saliva and surface enamel.

Knowledge of physiological processes that contribute to surface enamel concentrations may validate the use of enamel as a biomarker for pre-eruptive concentrations of trace metals in blood, cumulative concentrations of trace metals in saliva and plaque fluid, or a mixture of both. Having quantitative data regarding these processes in conjunction with a non-destructive measurement method would provide researchers with a simple tool to gain insights into a fascinating aspect of long-term exposures to neurotoxins and long term trace metals physiology. 



\section{References}

1. Hillson S. Teeth. 2nd ed. ed. New York: Cambridge University Press; 2005.

2. Austin C, Smith TM, Bradman A, Hinde K, Joannes-Boyau R, Bishop D, et al. Barium distributions in teeth reveal early-life dietary transitions in primates. Nature. 2013;498(7453):216-9.

3. Smith CE. Cellular and chemical events during enamel maturation. Critical Reviews in Oral Biology \& Medicine. 1998;9(2):128-61.

4. Ash MM, Nelson S. Wheeler's dental anatomy, physiology and occlusion, 2nd edition. New York: Saunders; 2004.

5. Aoba T. Recent observations on enamel crystal formation during mammalian amelogenesis. Anat Rec. 1996;245(2):208-1.

6. Kawamoto T, Shimizu M. Pathway and speed of calcium movement from blood to mineralizing enamel. Journal of Histochemistry and Cytochemistry. 1997;45(2):213-30.

7. Johnsson MS-, Nancollas GH. The role of brushite and octacalcium phosphate in apatite formation. Critical Reviews in Oral Biology and Medicine. 1992;3(1-2):61-82.

8. Matsunaga K. Theoretical defect energetics in calcium phosphate bioceramics. J Am Ceram Soc. 2010;93(1):1-14.

9. Dawes C. What is the critical $\mathrm{pH}$ and why does a tooth dissolve in acid? J Can Dent Assoc. 2003;69(11):722-4.

10. Modern nutrition in health and disease. 11th ed. ed. Ross AC, editor. Philadelphia: Wolters Kluwer Health/Lippincott Williams \& Wilkins; 2013.

11. Modern nutrition in health and disease. 9th ed. ed. Shils ME, editor. Baltimore: Williams \& Wilkins; 1999.

12. Finley JW, Johnson PE, Johnson LK. Sex affects manganese absorption and retention by humans from a diet adequate in manganese. Am J Clin Nutr. 1994;60(6):949-55.

13. Aisen P, Aasa R, Redfield AG. The chromium, manganese, and cobalt complexes of transferrin. J Biol Chem. 1969;244(17):4628-33.

14. Gunter TE, Gerstner B, Gunter KK, Malecki J, Gelein R, Valentine WM, et al. Manganese transport via the transferrin mechanism. Neurotoxicology. 2013;34(1):118-27.

15. Gunshin H, Mackenzie B, Berger UV, Gunshin Y, Romero MF, Boron WF, et al. Cloning and characterization of a mammalian proton-coupled metal-ion transporter. Nature. 1997;388(6641):482-8. 
16. Crossgrove JS, Yokel RA. Manganese distribution across the blood-brain barrier: IV. evidence for brain influx through store-operated calcium channels. Neurotoxicology. 2005;26(3):297-30.

17. He L, Girijashanker K, Dalton TP, Reed J, Li H, Soleimani M, et al. ZIP8, member of the solutecarrier-39 (SLC39) metal-transporter family: Characterization of transporter properties. Mol Pharmacol. 2006;70(1):171-80.

18. Girijashanker K, He L, Soleimani M, Reed JM, Li H, Liu Z, et al. Slc39a14 gene encodes ZIP14, a metal/bicarbonate symporter: Similarities to the ZIP8 transporter. Mol Pharmacol. 2008;73(5):1413-2.

19. Zheng W, Fu SX, Dydak U, Cowan DM. Biomarkers of manganese intoxication. Neurotoxicology. 2011;32(1):1-8.

20. Arnold ML, McNeill FE, Stronach IM, Pejovic-Milic A, Chettle DR, Waker A. An accelerator based system for in vivo neutron activation analysis measurements of manganese in human hand bones. Med Phys. 2002;29(11):2718-24.

21. Pejovic-Milic A, Aslam, Chettle DR, Oudyk J, Pysklywec MW, Haines T. Bone manganese as a biomarker of manganese exposure: A feasibility study. Am J Ind Med. 2009;52(10):742-50.

22. Ballatori N, Miles E, Clarkson TW. Homeostatic control of manganese excretion in the neonatal rat. American Journal of Physiology - Regulatory Integrative and Comparative Physiology. 1987;252(5).

23. Smith D, Gwiazda R, Bowler R, Roels H, Park R, Taicher C, et al. Biomarkers of mn exposure in humans. Am J Ind Med. 2007;50(11):801-1.

24. Stauber JL, Florence TM. Manganese in scalp hair: Problems of exogenous manganese and implications for manganese monitoring in groote eylandt aborigines. Sci Total Environ. 1989;83(1-2):8598.

25. Ericson JE, Crinella FM, Clarke-Stewart KA, Allhusen VD, Chan T, Robertson RT. Prenatal manganese levels linked to childhood behavioral disinhibition. Neurotoxicol Teratol. 2007;29(2):181-7.

26. Arora M, Hare D, Austin C, Smith DR, Doble P. Spatial distribution of manganese in enamel and coronal dentine of human primary teeth. Sci Total Environ. 2011;409(7):1315-9.

27. Arora M, Austin C. Teeth as a biomarker of past chemical exposure. Curr Opin Pediatr. 2013;25(2):261-7.

28. Couper J. On the effects of black oxide of manganese when inhaled into the lungs. Br Ann Med Pharmacol. 1837;1:41-2.

29. Barron TF, Devenyi AG, Mamourian AC. Symptomatic manganese neurotoxicity in a patient with chronic liver disease: Correlation of clinical symptoms with MRI findings. Pediatr Neurol. 1994;10(2):145-8.

30. Fabiani G, Rogacheski E, Wiederkehr JC, Khouri J, Cianfarano A. Liver transplantion in a patient with rapid onset parkinsonism-dementia complex induced by manganism secondary to liver failure. Arq Neuropsiquiatr. 2007;65(3 A):685-8. 
31. Bertinet DB, Tinivella M, Balzola FA, De Francesco A, Davini O, Rizzo L, et al. Brain manganese deposition and blood levels in patients undergoing home parenteral nutrition. J Parenter Enteral Nutr. 2000;24(4):223-7.

32. Yamada M, Ohno S, Okayasu I, Okeda R, Hatakeyama S, Watanabe H, et al. Chronic manganese poisoning: A neuropathological study with determination of manganese distribution in the brain. Acta Neuropathol. 1986;70(3-4):273-8.

33. Bowman AB, Kwakye GF, Herrero Hernández E, Aschner M. Role of manganese in neurodegenerative diseases. Journal of Trace Elements in Medicine and Biology. 2011;25(4):191-203.

34. Sidoryk-Wegrzynowicz M, Lee E, Mingwei N, Aschner M. Disruption of astrocytic glutamine turnover by manganese is mediated by the protein kinase C pathway. Glia. 2011;59(11):1732-43.

35. Chen C-, Liao S-. Oxidative stress involves in astrocytic alterations induced by manganese. Exp Neurol. 2002;175(1):216-25.

36. Sidoryk-Wegrzynowicz M, Wegrzynowicz M, Lee E, Bowman AB, Aschner M. Role of astrocytes in brain function and disease. Toxicol Pathol. 2011;39(1):115-23.

37. Sofroniew MV, Vinters HV. Astrocytes: Biology and pathology. Acta Neuropathol. 2010;119(1):735 .

38. Montes S, Alcaraz-Zubeldia M, Muriel P, Ríos C. Striatal manganese accumulation induces changes in dopamine metabolism in the cirrhotic rat. Brain Res. 2001;891(1-2):123-9.

39. Racette BA, Aschner M, Guilarte TR, Dydak U, Criswell SR, Zheng W. Pathophysiology of manganese-associated neurotoxicity. Neurotoxicology. 2012;33(4):881-6.

40. Aschner M, Guilarte TR, Schneider JS, Zheng W. Manganese: Recent advances in understanding its transport and neurotoxicity. Toxicol Appl Pharmacol. 2007;221(2):131-47.

41. Aschner M, Erikson KM, Dorman DC. Manganese dosimetry: Species differences and implications for neurotoxicity. Crit Rev Toxicol. 2005;35(1):1-32.

42. Mergler D. Neurotoxic effects of low level exposure to manganese in human populations. Environ Res. 1999;80(2 I):99-102.

43. Lucchini R, Selis L, Folli D, Apostoli P, Mutti A, Vanoni O, et al. Neurobehavioral effects of manganese in workers from a ferroalloy plant after temporary cessation of exposure. Scandinavian Journal of Work, Environment and Health. 1995;21(2):143-9.

44. Roels H, Lauwerys R, Buchet J-, Genet P, Sarhan MJ, Hanotiau I, et al. Epidemiological survey among workers exposed to manganese: Effects on lung, central nervous system, and some biological indices. Am J Ind Med. 1987;11(3):307-2.

45. Erikson KM, Thompson K, Aschner J, Aschner M. Manganese neurotoxicity: A focus on the neonate. Pharmacology and Therapeutics. 2007;113(2):369-77. 
46. Bouchard M, Laforest F, Vandelac L, Bellinger D, Mergler D. Hair manganese and hyperactive behaviors: Pilot study of school-age children exposed through tap water. Environ Health Perspect. 2007;115(1):122-7.

47. Bouchard MF, Sauve S, Barbeau B, Legrand M, Brodeur M, Bouffard T, et al. Intellectual impairment in school-age children exposed to manganese from drinking water.(children's health)(report). Environ Health Perspect. 2011 01/01;119(1):138(6).

48. Khan K, Wasserman GA, Liu X, Ahmed E, Parvez F, Slavkovich V, et al. Manganese exposure from drinking water and children's academic achievement. Neurotoxicology. 2012;33(1):91-7.

49. Mergler D. Neurotoxic exposures and effects: Gender and sex matter! hänninen lecture 2011. Neurotoxicology. 2012;33(4):644-51.

50. Betharia S, Maher TJ. Neurobehavioral effects of lead and manganese individually and in combination in developmentally exposed rats. Neurotoxicology. 2012;33(5):1117-2.

51. Madison JL, Wegrzynowicz M, Aschner M, Bowman AB. Gender and manganese exposure interactions on mouse striatal neuron morphology. Neurotoxicology. 2011;32(6):896-90.

52. Riojas-Rodríguez H, Solís-Vivanco R, Schilmann A, Montes S, Rodríguez S, Ríos C, et al. Intellectual function in mexican children living in a mining area and environmentally exposed to manganese. Environ Health Perspect. 2010;118(10):1465-70.

53. Fitsanakis VA, Zhang N, Garcia S, Aschner M. Manganese (mn) and iron (fe): Interdependency of transport and regulation. Neurotoxicity research. 2010;18(2):124-31.

54. Cowan DM, Zheng W, Zou Y, Shi X, Chen J, Rosenthal FS, et al. Manganese exposure among smelting workers: Relationship between blood manganese-iron ratio and early onset neurobehavioral alterations. Neurotoxicology. 2009;30(6):1214-22.

55. Cowan DM, Fan Q, Zou Y, Shi X, Chen J, Aschner M, et al. Manganese exposure among smelting workers: Blood manganeseiron ratio as a novel tool for manganese exposure assessment. Biomarkers. 2009;14(1):3-16.

56. Zheng W, Zhao Q. Iron overload following manganese exposure in cultured neuronal, but not neuroglial cells. Brain Res. 2001;897(1-2):175-9.

57. Molina RM, Phattanarudee S, Kim J, Thompson K, Wessling-Resnick M, Maher TJ, et al. Ingestion of $\mathrm{mn}$ and $\mathrm{pb}$ by rats during and after pregnancy alters iron metabolism and behavior in offspring. Neurotoxicology. 2011;32(4):413-22.

58. Claus Henn B, Kim J, Wessling-Resnick M, Téllez-Rojo M, Jayawardene I, Ettinger AS, et al. Associations of iron metabolism genes with blood manganese levels: A population-based study with validation data from animal models. Environmental Health: A Global Access Science Source. 2011;10(1).

59. Smith EA, Newland P, Bestwick KG, Ahmed N. Increased whole blood manganese concentrations observed in children with iron deficiency anaemia. Journal of Trace Elements in Medicine and Biology. 2013;27(1):65-9. 
60. Brna P, Gordon K, Dooley JM, Price V. Manganese toxicity in a child with iron deficiency and polycythemia. J Child Neurol. 2011;26(7):891-4.

61. Lucchini RG, Zoni S, Guazzetti S, Bontempi E, Micheletti S, Broberg K, et al. Inverse association of intellectual function with very low blood lead but not with manganese exposure in italian adolescents. Environ Res. 2012;118:65-71.

62. McLean E, Cogswell M, Egli I, Wojdyla D, De Benoist B. Worldwide prevalence of anaemia, WHO vitamin and mineral nutrition information system, 1993-2005. Public Health Nutr. 2009;12(4):444-5.

63. Iron physiology and pathophysiology in humans. Anderson GJ and McLaren GD, editors. Totowa, NJ: Humana Press; 2012.

64. Heme. Available from: https://en.wikipedia.org/wiki/Heme. Accessed: Aug. 13, 2013.

65. Gunshin H, Starr CN, DiRenzo C, Fleming MD, Jin J, Greer EL, et al. Cybrd1 (duodenal cytochrome b) is not necessary for dietary iron absorption in mice. Blood. 2005;106(8):2879-83.

66. Park CH, Valore EV, Waring AJ, Ganz T. Hepcidin, a urinary antimicrobial peptide synthesized in the liver. J Biol Chem. 2001;276(11):7806-10.

67. Nemeth E, Tuttle MS, Powelson J, Vaughn MD, Donovan A, Ward DM, et al. Hepcidin regulates cellular iron efflux by binding to ferroportin and inducing its internalization. Science.

2004;306(5704):2090-3.

68. Nicolas G, Viatte L, Bennoun M, Beaumont C, Kahn A, Vaulont S. Hepcidin, a new iron regulatory peptide. Blood Cells Mol Dis. 2002;29(3):327-35.

69. Al-Delaimy WK, Jansen EHJM, Peeters PHM, van der Laan JD, van Noord PAH, Boshuizen HC, et al. Reliability of biomarkers of iron status, blood lipids, oxidative stress, vitamin D, C-reactive protein and fructosamine in two dutch cohorts. Biomarkers. 2006;11(4):370-82.

70. Hambidge M. Biomarkers of trace mineral intake and status. J Nutr. 2003;133(3 SUPPL.):948S-55.

71. Webb E, Amarasiriwardena D, Tauch S, Green EF, Jones J, Goodman AH. Inductively coupled plasma-mass (ICP-MS) and atomic emission spectrometry (ICP-AES): Versatile analytical techniques to identify the archived elemental information in human teeth. Microchemical Journal. 2005;81(2):201-8.

72. Cooper M, Greene-Finestone L, Lowell H, Levesque J, Robinson S. Iron sufficiency of canadians. Health reports / Statistics Canada, Canadian Centre for Health Information = Rapports sur la santé $/$ Statistique Canada, Centre canadien d'information sur la santé. 2012;23(4):41-8.

73. Nyaradi A, Li J, Hickling S, Foster J, Oddy WH. The role of nutrition in children's neurocognitive development, from pregnancy through childhood. Frontiers in Human Neuroscience. 2013(MAR).

74. Tamura T, Goldenberg RL, Hou J, Johnston KE, Cliver SP, Ramey SL, et al. Cord serum ferritin concentrations and mental and psychomotor development of children at five years of age. J Pediatr. 2002;140(2):165-70. 
75. Chaparro CM, Neufeld LM, Tena Alavez G, Eguia-Líz Cedillo R, Dewey KG. Effect of timing of umbilical cord clamping on iron status in mexican infants: A randomised controlled trial. Lancet. 2006;367(9527):1997-2004.

76. Zhou SJ, Gibson RA, Crowther CA, Baghurst P, Makrides M. Effect of iron supplementation during pregnancy on the intelligence quotient and behavior of children at $4 \mathrm{y}$ of age: Long-term follow-up of a randomized controlled trial. Am J Clin Nutr. 2006;83(5):1112-7.

77. Rioux FM, Bélanger-Plourde J, Leblanc CP, Vigneau F. Relationship between maternal DHA and iron status: And infants' cognitive performance. Canadian Journal of Dietetic Practice and Research. 2011;72(2):e140-6.

78. Mushak P. Lead and public health: Science, risk, and regulation. Boston: Elsevier; 2011.

79. Statistics Canada. Canada health survey (1978-79). 1982.

80. Wong SL, Lye EJ. Lead, mercury and cadmium levels in canadians. Health reports / Statistics Canada, Canadian Centre for Health Information = Rapports sur la santé $/$ Statistique Canada, Centre canadien d'information sur la santé. 2008;19(4):31-6.

81. Rasmussen PE, Beauchemin S, Chénier M, Levesque C, MacLean LCW, Marro L, et al. Canadian house dust study: Lead bioaccessibility and speciation. Environmental Science and Technology.

2011;45(11):4959-65.

82. Bell T, Campbell S, Liverman DGE, Allison D, Sylvester P. Environmental and potential human health legacies of non-industrial sources of lead in a canadian urban landscape - the case study of st john's, newfoundland. Int Geol Rev. 2010;52(7-8):771-800.

83. He K, Wang S, Zhang J. Blood lead levels of children and its trend in china. Sci Total Environ. 2009;407(13):3986-93.

84. Dooyema CA, Neri A, Lo Y-, Durant J, Dargan PI, Swarthout T, et al. Outbreak of fatal childhood lead poisoning related to artisanal gold mining in northwestern nigeria, 2010. Environ Health Perspect. 2012;120(4):601-7.

85. Spiegel SJ, Marcello V. Global impacts of mercury supply and demand on small-scale mining. Global Mercury Project; 2007.

86. Rabinowitz MB, Wetherill GW, Kopple JD. Kinetic analysis of lead metabolism in healthy humans. J Clin Invest. 1976;58(2):260-7.

87. Keller CA, Doherty RA. Distribution and excretion of lead in young and adult female mice. Environ Res. 1980;21(1):217-28.

88. Leggett RW. Research advances: An age-specific kinetic model of lead metabolism in humans. Environ Health Perspect. 1993;101(7):598-616. 
89. Age-dependent doses to members of the public from intake of radionuclides: Part 2. ingestion dose coefficients. A report of a task group of committee 2 of the international commission on radiological protection. Ann ICRP. 1993;23(3-4):1-167.

90. Canfield RL, Henderson Jr. CR, Cory-Slechta DA, Cox C, Jusko TA, Lanphear BP. Intellectual impairment in children with blood lead concentrations below $10 \mu \mathrm{g}$ per deciliter. N Engl J Med. 2003;348(16):1517-26.

91. O'Flaherty EJ. Physiologically based models for bone-seeking elements: I. rat skeletal and bone growth. Toxicol Appl Pharmacol. 1991;111(2):299-312.

92. O'Flaherty EJ. Physiologically based models for bone-seeking elements: II. kinetics of lead disposition in rats. Toxicol Appl Pharmacol. 1991;111(2):313-31.

93. O'Flaherty EJ. Physiologically based models for bone-seeking elements: III. human skeletal and bone growth. Toxicol Appl Pharmacol. 1991;111(2):332-41.

94. O'Flaherty EJ. Physiologically based models for bone-seeking elements. IV. kinetics of lead disposition in humans. Toxicol Appl Pharmacol. 1993;118(1):16-29.

95. O'Flaherty EJ. Physiologically based models for bone-seeking elements. V. lead absorption and disposition in childhood. Toxicol Appl Pharmacol. 1995;131(2):297-308.

96. Fleming DEB, Chettle DR, Webber CE, O'Flaherty EJ. The O'flaherty model of lead kinetics: An evaluation using data from a lead smelter population. Toxicol Appl Pharmacol. 1999;161(1):100-9.

97. Chettle DR, Scott MC, Somervaille LJ. Lead in bone: Sampling and quantitation using K X-rays excited by 109Cd. Environ Health Perspect. 1991;91:49-55.

98. Tvinnereim HM, Eide R, Riise T, Wesenberg GR, Fosse G, Steinnes E. Lead in primary teeth from norway: Changes in lead levels from the 1970s to the 1990s. Sci Total Environ. 1997;207(2-3):165-77.

99. Uryu T, Hojo S, Kida A, Nishikawa M, Yoshinaga J. Relationship between fetal lead exposure and birth weight--evaluation using deciduous incisor enamel. Nippon eiseigaku zasshi.Japanese journal of hygiene. 2004;59(4):387-94.

100. Gomes VE, De Sousa MDLR, Barbosa Jr. F, Krug FJ, Saraiva MDCP, Cury JA, et al. In vivo studies on lead content of deciduous teeth superficial enamel of preschool children. Sci Total Environ.

2004;320(1):25-3.

101. Budd P, Montgomery J, Evans J, Barreiro B. Human tooth enamel as a record of the comparative lead exposure of prehistoric and modern people. Sci Total Environ. 2000;263(1-3):1-10.

102. de Almeida GRC, de Souza Guerra C, Tanus-Santos JE, Barbosa Jr. F, Gerlach RF. A plateau detected in lead accumulation in subsurface deciduous enamel from individuals exposed to lead may be useful to identify children and regions exposed to higher levels of lead. Environ Res. 2008;107(2):264-70.

103. Bloch P, Shapiro IM, Soule L, Close A, Revich B. Assessment of lead exposure of children from KXRF measurements of shed teeth. Applied Radiation and Isotopes. 1998;49(5-6):703-5. 
104. Arruda-Neto JDT, de Oliveira MCC, Sarkis JES, Bordini P, Manso-Guevara MV, Garcia F, et al. Study of environmental burden of lead in children using teeth as bioindicator. Environ Int. 2009;35(3):614-8.

105. Hunt VR, Radford Jr. EP, Segall AJ. Comparison of concentrations of alpha-emitting elements in teeth and bones. Int J Radiat Biol Relat Stud Phys Chem Med. 1963;7:277-8.

106. Budd P, Montgomery J, Evans J, Trickett M. Human lead exposure in england from approximately 5500 BP to the 16th century AD. Sci Total Environ. 2004;318(1-3):45-58.

107. Ericson JE. Enamel lead biomarker for prenatal exposure assessment. Environ Res. 2001;87(3):13640.

108. Pinchin MJ, Newham J, Thompson RPJ. Lead, copper, and cadmium in teeth of normal and mentally retarded children. Clinica Chimica Acta. 1978;85(1):89-94.

109. Rabinowitz MB, Bellinger D, Leviton A, Wang J-. Lead levels among various deciduous tooth types. Bull Environ Contam Toxicol. 1991;47(4):602-8.

110. Brudevold F, Aasenden R, Srinivasian BN, Bakhos Y. Lead in enamel and saliva, dental caries and the use of enamel biopsies for measuring past exposure to lead. J Dent Res. 1977;56(10):1165-71.

111. Tvinnereim HM, Eide R, Riise T. Heavy metals in human primary teeth: Some factors influencing the metal concentrations. Sci Total Environ. 2000;255(1-3):21-7.

112. Arora M, Kennedy BJ, Elhlou S, Pearson NJ, Walker DM, Bayl P, et al. Spatial distribution of lead in human primary teeth as a biomarker of pre- and neonatal lead exposure. Sci Total Environ.

2006;371(1-3):55-62.

113. Brudevold F, Steadman L. The distribution of lead in human enamel. J Dent Res. 1956;35(3):430-7.

114. Dietary reference intakes for vitamin A, vitamin K, arsenic, boron, chromium, copper, iodine, iron, manganese, mlybdenum, nickel, silicon, vanadium and zinc: A report of the panel on micronutrients ... [et al.], standing committee on the scientific evaluation of dietary reference intakes, food and nutrition board, institute of medicine. Institute of Medicine (U.S.). Panel on Micronutrients., editor. Washington, D.C.: National Academy Press; 2001.

115. Chung CS, Stookey J, Dare D, Welch R, Nguyen TQ, Roehl R, et al. Current dietary zinc intake has a greater effect on fractional zinc absorption than does longer term zinc consumption in healthy adult men. Am J Clin Nutr. 2008;87(5):1224-9.

116. Hambidge KM, Miller LV, Westcott JE, Sheng X, Krebs NF. Zinc bioavailability and homeostasis. Am J Clin Nutr. 2010;91(5):1478S-83.

117. Lönnerdal B. Dietary factors influencing zinc absorption. J Nutr. 2000;130(5 SUPPL.):1378S-83.

118. Sandstrom B, Davidsson L, Cederblad A, Lonnerdal B. Oral iron, dietary ligands and zinc absorption. J Nutr. 1985;115(3):411-4. 
119. Lichten LA, Cousins RJ. Mammalian zinc transporters: Nutritional and physiologic regulation; 2009 [cited 29 June 2013].

120. Cousins RJ. Gastrointestinal factors influencing zinc absorption and homeostasis. International Journal for Vitamin and Nutrition Research. 2010;80(4-5):243-8.

121. Davies NT, Williams RB. The effect of pregnancy and lactation on the absorption of zinc and lysine by the rat duodenum in situ. Br J Nutr. 1977;38(3):417-23.

122. Foster DM, Aamodt RL, Henkin RI, Berman M. Zinc metabolism in humans: A kinetic model. Am J Physiol. 1979;237(5):R340-349.

123. Wastney ME, Aamodt RL, Rumble WF, Henkin RI. Kinetic analysis of zinc metabolism and its regulation in normal humans. American Journal of Physiology - Regulatory Integrative and Comparative Physiology. 1986;251(2).

124. Leggett RW. A biokinetic model for zinc for use in radiation protection. Sci Total Environ. 2012;420:1-12.

125. Suzuki T, Ishihara K, Migaki H, Ishihara K, Nagao M, Yamaguchi-Iwai Y, et al. Two different zinc transport complexes of cation diffusion facilitator proteins localized in the secretory pathway operate to activate alkaline phosphatases in vertebrate cells. J Biol Chem. 2005;280(35):30956-62.

126. Ten Cate AR. Oral histology: Development, structure, and function. Dale AC, editor. St. Louis: Mosby; 1980.

127. Matsunaga T, Ishizaki H, Tanabe S, Hayashi Y. Synchrotron radiation microbeam X-ray fluorescence analysis of zinc concentration in remineralized enamel in situ. Arch Oral Biol. 2009;54(5):420-3.

128. McClain CJ. Zinc metabolism in malabsorption syndromes. J Am Coll Nutr. 1985;4(1):49-64.

129. Högberg L, Danielsson L, Jarleman S, Sundqvist T, Stenhammar L. Serum zinc in small children with coeliac disease. Acta Paediatrica, International Journal of Paediatrics. 2009;98(2):343-5.

130. Andersson KE, Bratt L, Dencker H, Lanner E. Some aspects of the intestinal absorption of zinc in man. Eur J Clin Pharmacol. 1976;9(5-6):423-8.

131. Swanson CA, King JC. Zinc and pregnancy outcome. Am J Clin Nutr. 1987;46(5):763-71.

132. Morris DR, Levenson CW. Ion channels and zinc: Mechanisms of neurotoxicity and neurodegeneration. Journal of Toxicology. 2012;2012.

133. Safty AE, Mahgoub KE, Helal S, Maksoud NA. Zinc toxicity among galvanization workers in the iron and steel industry; 2008 [cited 9 July 2013].

134. Dorner K, Dziadzka S, Hohn A, Sievers E, Oldigs H-, Schulz-Lell G, et al. Longitudinal manganese and copper balances in young infants and preterm infants fed on breast-milk and adapted cow's milk formulas. Br J Nutr. 1989;61(3):559-72. 
135. Collins JF, Prohaska JR, Knutson MD. Metabolic crossroads of iron and copper. Nutr Rev. 2010;68(3):133-47.

136. Brubaker C, Sturgeon P. Copper deficiency in infants; a syndrome characterized by hypocupremia, iron deficiency anemia, and hypoproteinemia. A.M.A.journal of diseases of children. 1956;92(3):254-65.

137. Collins JF, Franck CA, Kowdley KV, Ghishan FK. Identification of differentially expressed genes in response to dietary iron deprivation in rat duodenum. American Journal of Physiology - Gastrointestinal and Liver Physiology. 2005;288(5 51-5):G964-71.

138. Hill CH, Matrone G. Chemical parameters in the study of in vivo and in vitro interactions of transition elements. Fed Proc. 1970;29(4):1474-81.

139. Greenough MA, Camakaris J, Bush AI. Metal dyshomeostasis and oxidative stress in alzheimer's disease. Neurochem Int. 2013;62(5):540-55.

140. Bush AI. The metal theory of alzheimer's disease. J Alzheimer's Dis. 2013;33(SUPPL. 1):S277-81.

141. Lovell MA, Robertson JD, Teesdale WJ, Campbell JL, Markesbery WR. Copper, iron and zinc in alzheimer's disease senile plaques. J Neurol Sci. 1998 6/11;158(1):47-52.

142. Schrag M, Mueller C, Oyoyo U, Smith MA, Kirsch WM. Iron, zinc and copper in the alzheimer's disease brain: A quantitative meta-analysis. some insight on the influence of citation bias on scientific opinion. Prog Neurobiol. 2011;94(3):296-30.

143. Mak CM, Lam C-. Diagnosis of wilson's disease: A comprehensive review. Crit Rev Clin Lab Sci. 2008;45(3):263-90.

144. Ferenci P, Caca K, Loudianos G, Mieli-Vergani G, Tanner S, Sternlieb I, et al. Diagnosis and phenotypic classification of wilson disease. Liver International. 2003;23(3):139-42.

145. Mercer JFB. Menkes syndrome and animal models. Am J Clin Nutr. 1998;67(5 SUPPL.):1022S-8.

146. Hill AB. The environment and disease: Association or causation? Proc R Soc Med. 1965;58:295300.

147. Weschler D. Weschler abbreviated scale of intelligence (WASI). San Antonio, TX: Harcourt Assessment; 1999.

148. Da Silva E, Pejović-Milić A, Heyd DV. The use of teeth as the site for the in vivo or ex vivo quantification of skeletal strontium by energy-dispersive X-ray fluorescence spectrometry: A feasibility study. J Anal At Spectrom. 2008;23(4):527-34.

149. Markowicz A. An overview of quantificationmethods in energy-dispersive X-ray fluorescence analysis. Pramana - Journal of Physics. 2011;76(2):321-9.

150. National institute for standards and technology (NIST) X-ray transition energies database [Internet]. Available from: http://www.nist.gov/pml/data/xraytrans/.Accessed Aug. 12, 2013. 
151. Bates DM, Watts DG. Nonlinear regression and its applications. Hoboken, NJ, USA: John Wiley \& Sons, Inc.; 2008.

152. Seber GAF, Wild CJ. Nonlinear regression. New York: Wiley; 2003.

153. Marquardt D. An algorithm for least-squares estimation of nonlinear parameters. Journal of the Society for Industrial and Applied Mathematics. 1963 06/01; 2013/07;11(2):431-4.

154. Levenberg K. A method for the solution of certain non-linear problems in least squares. Quarterly of Applied Mathamatics. 1944:164-8.

155. Numerical recipes in C++: The art of scientific computing. [Rev.] 2nd ed. ed. Press WH, editor. New York: Cambridge University Press; 2002.

156. Rebohle L, Lehnert U, Zschornack G. K $\beta / \mathrm{k} \alpha$ intensity ratios and chemical effects of some $3 \mathrm{~d}$ elements. X-Ray Spectrom. 1996;25(6):295-300.

157. Da Silva E, Kirkham B, Heyd DV, Pejović-Milić A. Pure hydroxyapatite phantoms for the calibration of in vivoX-ray fluorescence systems of bone lead and strontium quantification. Analytical Chemistry. 2013;Accepted for publication.

158. Van Grieken R, Markowicz A. Handbook of X-ray spectrometry. CRC Press; 2001.

159. Carvalho ML, Casaca C, Pinheiro T, Marques JP, Chevallier P, Cunha AS. Analysis of human teeth and bones from the chalcolithic period by X-ray spectrometry. Nuclear Instruments and Methods in Physics Research, Section B: Beam Interactions with Materials and Atoms. 2000;168(4):559-65.

160. Carvalho ML, Casaca C, Marques JP, Pinheiro T, Cunha AS. Human teeth elemental profiles measured by synchrotron $x$-ray fluorescence: Dietary habits and environmental influence. X-Ray Spectrom. 2001;30(3):190-3.

161. Zaichick V, Ovchjarenko N, Zaichick S. In vivo energy dispersive X-ray fluorescence for measuring the content of essential and toxic trace elements in teeth. Applied Radiation and Isotopes. 1999;50(2):2839 .

162. Zaichick VY, Ovchjarenko NN. In vivo X-ray fluorescent analysis of ca, zn, sr, and pb in frontal tooth enamel. J Trace Microprobe Tech. 1996;14(1):143-52.

163. Ahlberg M, Akselsson R. Proton induced X ray emission in the trace analysis of human tooth enamel and dentine. Int J Appl Radiat Isot. 1976;27(5-6):279-90.

164. Hare D, Austin C, Doble P, Arora M. Elemental bio-imaging of trace elements in teeth using laser ablation-inductively coupled plasma-mass spectrometry. J Dent. 2011;39(5):397-403.

165. Oprea C, Szalanski PJ, Gustova MV, Oprea IA, Buzguta V. Multivariate comparison of elemental concentrations in human teeth. Applied Radiation and Isotopes. 2009 200912;67(12):2142-5. 
166. Medvecký L, Štulajterová R, Parilák L, Trpcevská J, Durišin J, Barinov SM. Influence of manganese on stability and particle growth of hydroxyapatite in simulated body fluid. Colloids Surf Physicochem Eng Aspects. 2006;281(1-3):221-9.

167. Pinheiro T, Carvalho M, Casaca C, Barreiros M, Cunha A, Chevallier P. Microprobe analysis of teeth by synchrotron radiation: Environmental contamination. Nuclear Instruments and Methods in Physics Research Section B: Beam Interactions with Materials and Atoms. 1999;158(1):393-8.

168. Leone FA, Ciancaglini P, Pizauro JM, Rezende AA. Rat osseous plate alkaline phosphatase: Mechanism of action of manganese ions. Biometals. 1995;8(1):86-91.

169. Pabbruwe MB, Standard OC, Sorrell CC, Howlett CR. Bone formation within alumina tubes: Effect of calcium, manganese, and chromium dopants. Biomaterials. 2004;25(20):4901-10.

170. Hernández-Bonilla D, Schilmann A, Montes S, Rodríguez-Agudelo Y, Rodríguez-Dozal S, SolísVivanco R, et al. Environmental exposure to manganese and motor function of children in mexico. Neurotoxicology. 2011;32(5):615-21.

171. Myers JE, Thompson ML, Ramushu S, Young T, Jeebhay MF, London L, et al. The nervous system effects of occupational exposure on workers in a south african manganese smelter. Neurotoxicology. 2003;24(6):885-94.

172. Agency for Toxic Substances and Disease Registry. Summary report hair analysis panel discussion exploring the state of the science.; 2001. Available from:

http://www.atsdr.cdc.gov/HAC/hair_analysis/index.html. Accessed August 10, 2013.

173. Chen H, Copes R. Manganese in drinking water and intellectual impairment in school-age children. Environ Health Perspect. 2011;119(6).

174. Cowan DM, Zheng W, Zou Y, Shi X, Chen J, Rosenthal FS, et al. Manganese exposure among smelting workers: Relationship between blood manganese-iron ratio and early onset neurobehavioral alterations. Neurotoxicology. 2009;30(6):1214-22.

175. Oprea C. Multivariate analysis of environmental data by SPSS. Environment \& Progress. 2005;3:285-90.

176. Almeida GRC, Pereira Saraiva MC, Barbosa Jr. F, Krug FJ, Cury JA, Rosário de Sousa MdL, et al. Lead contents in the surface enamel of deciduous teeth sampled in vivo from children in uncontaminated and in lead-contaminated areas. Environ Res. 2007;104(3):337-45.

177. Nriagu J, Burt B, Linder A, Ismail A, Sohn W. Lead levels in blood and saliva in a low-income population of detroit, michigan. Int J Hyg Environ Health. 2006;209(2):109-21.

178. Costa de Almeida GR, Umbelino de Freitas C, Barbosa Jr. F, Tanus-Santos JE, Gerlach RF. Lead in saliva from lead-exposed and unexposed children. Sci Total Environ. 2009;407(5):1547-50.

179. Cleymaet R, Collys K, Retief DH, Michotte Y, Slop D, Taghon E, et al. Relation between lead in surface tooth enamel, blood, and saliva from children residing in the vicinity of a non-ferrous metal plant in belgium. Br J Ind Med. 1991;48(10):702-9. 
180. Anttila A. Proton-induced x-ray emission analysis of $\mathrm{zn}, \mathrm{sr}$ and $\mathrm{pb}$ in human deciduous tooth enamel and its relationship to dental caries scores. Arch Oral Biol. 1986;31(11):723-6.

181. Yang H, Huo X, Yekeen TA, Zheng Q, Zheng M, Xu X. Effects of lead and cadmium exposure from electronic waste on child physical growth. Environ Sci Pollut Res Int. 20132013 Jul (Epub 2012 Dec 18);20(7):4441-7.

182. Canfield RL, Henderson CR, Cory-Slechta D, Cox C, Jusko TA, Lanphear BP. Intellectual impairment in children with blood lead concentrations below $10 \mu \mathrm{g}$ per deciliter. N Engl J Med. 2003 04/17; 2013/07;348(16):1517-26.

183. Needleman HL, Gunnoe C, Leviton A, Reed R, Peresie H, Maher C, et al. Deficits in psychologic and classroom performance of children with elevated dentine lead levels. N Engl J Med. 1979 03/29; 2013/07;300(13):689-95.

184. Needleman HL, Schell A, Bellinger D, Leviton A, Allred EN. The long-term effects of exposure to low doses of lead in childhood. an 11-year follow-up report. N Engl J Med. 1990;322(2):83-8.

185. Tvinnereim HM, Eide R, Riise T, Fosse G, Wesenberg GR. Zinc in primary teeth from children in norway. Sci Total Environ. 1999;226(2-3):201-12.

186. Lynch RJM. Zinc in the mouth, its interactions with dental enamel and possible effects on caries; A review of the literature. Int Dent J. 2011;61(SUPPL. 3):46-54.

187. Brudevold F, Steadman LT, Spinelli MA, Amdur BH, Grøn P. A study of zinc in human teeth. Arch Oral Biol. 1963;8(2):135-44.

188. Prasad AS. Impact of the discovery of human zinc deficiency on health. J Am Coll Nutr. 2009;28(3):257-65.

189. Khor GL, Misra S. Micronutrient interventions on cognitive performance of children aged 5-15 years in developing countries. Asia Pac J Clin Nutr. 2012;21(4):476-8.

190. Gogia S, Sachdev HS. Zinc supplementation for mental and motor development in children.

Cochrane database of systematic reviews (Online). 2012;12.

191. de Moura JE, de Moura ENO, Alves CX, de Lima Vale SH, Dantas MMG, de Araújo Silva A, et al. Oral zinc supplementation may improve cognitive function in schoolchildren. Biol Trace Elem Res.

2013:1-6.

192. Borella P, Fantuzzi G, Aggazzotti G. Trace elements in saliva and dental caries in young adults. Sci Total Environ. 1994;153(3):219-24.

193. Thompson T, Freestone D, Michalczyk AA, Ackland ML. Copper levels in buccal cells of vineyard workers engaged in various activities. Ann Occup Hyg. 2012;56(3):305-14.

194. Tisato F, Marzano C, Porchia M, Pellei M, Santini C. Copper in diseases and treatments, and copperbased anticancer strategies. Med Res Rev. 2010;30(4):708-49. 
195. Finney L, Mandava S, Ursos L, Zhang W, Rodi D, Vogt S, et al. X-ray flourescence microscopy reveals large-scale relocalization and extracellular translocation of cellular copper during angiogenesis. Proc Natl Acad Sci U S A. 2007;104(7):2247-52.

196. Kim Y-, Kim Y-, Kho H-. Effects of smoking on trace metal levels in saliva. Oral Dis. 2010;16(8):823-30. 